\title{
DISSOLUTION OF A 316L STAINLESS STEEL VESSEL BY A POOL OF MOLTEN ALUMINUM
}

\author{
N.K. Tutu, C.C. Finfrock, J.D. Lara, C.E. Schwarz, and G.A. Greene
}

January 1993

DEPARTMENT OF NUCLEAR ENERGY

BROOKHAVEN NATIONAL LABORATORY

ASSOCIATED UNIVERSITIES, INC.

UPTON, NEW YORK 11973 


\section{DISCLAIMER}

This report was prepared as an account of work sponsored by an agency of the United States Government. Neither the United States Government nor any agency thereof, nor any of their employees, nor any of their contractors, subcontractors, or their employees, makes any warranty, express or implied, or assumes any legal liability or responsibility for the accuracy, completeness, or usefulness of any information, apparatus, product, or process disclosed, or represents that its use would not infringe privately owned rights. Reference herein to any specific commercial product, process, or service by trade name, trademark, manufacturer, or otherwise, does not necessarily constitute or imply its endorsement, recommendation, or favoring by the United States Government or any agency, contractor or subcontractor thereof. The views and opinions of authors expreseed herein do not necessarily state or reflect those of the United States Government or any agency, contractor or subcontractor thereof.

\section{Printed in the United States of America}

Available from

National Technical Information Service

U.S. Department of Commerce

5285 Port Royal Road

Springfield, VA 22161

NTIS price codes:

Printed Copy: A05; Microfiche Copy: A01 


\begin{abstract}
Two experiments to study the dissolution of a torospherical stainless steel vessel by an isothermal pool of molten aluminum have been performed. The test vessels consisted of 24 inch diameter 316L stainless steel "ASME Flanged and Dished Heads." The nominal values of the average melt temperatures for the two tests were: $977^{\circ} \mathrm{C}$ and $1007^{\circ} \mathrm{C}$. The measurements of the dissolution depth as a function of the position along the vessel surface showed the dissolution to be spatially highly non-uniform. Large variations in the dissolution depth with respect to the azimuthal coordinate were also observed. The maximum value of the measured time averaged dissolution rate was found to be $5.05 \mathrm{~mm} / \mathrm{hr}$, and this occurred near the edge of the molten pool. The concentration measurements indicated that the molten pool was highly stratified with respect to the concentration of stainless steel in the melt (molten aluminum-stainless steel solution).
\end{abstract}




\section{EXECUTIVE SUMMARY}

Under postulated severe accident sequences that lead to fuel melting in the New Production Reactor-Heavy Water Reactor (NPR-HWR), a pool of molten material (aluminum-uranium-lithiumstainless steel) is likely to exist in the reactor vessel bottom. Previous experiments have shown that molten aluminum can dissolve stainless steel at temperatures as low as the melting point of aluminum $\left(660.2^{\circ} \mathrm{C}\right)$. Therefore, as suggested by some preliminary and detailed heat transfer calculations, it is quite likely that even if the downfacing boiling heat transfer from the vessel bottom to the water in the reactor cavity were sufficient to remove all the decay heat from the melt, the equilibrium melt temperature may not be low enough to prevent the dissolution of the vessel wall by stainless steel. Consequently, in order to assess the inherent ability of the reactor vessel to retain the molten core material on the vessel bottom, the dissolution of the vessel wall as a function of position and time must be calculated. However, due to the very complex nature of the stainless steel-molten aluminum dissolution process, and the extremely large uncertainties in the relevant thermophysical properties, reliable calculations to predict the dissolution of the reactor vessel cannot be performed. Therefore, to reduce the uncertainties in numerical predictions of dissolution, it is important to perform integral molten pool dissolution experiments.

In connection with the NPR-HWR program, an experimental facility to perform $1 / 10^{\text {th }}$ (of full scale NPR-HWR) scale molten pool dissolution experiments was fabricated. The apparatus consisted of four major components: (a) an aluminum melting furnace, (b) an oven iu serve as an isothermal enclosure for the test vessel during the test, (c) the control panels for the oven and the furnace, and (d) the data acquisition system. Two experiments to study the dissolution of a stainless steel vessel by a pool of molten aluminum were performed. In these molten aluminum pool dissolution experiments, 24 inch diameter 316L stainless steel "ASME Flanged and Dished Heads" were used as the test vessels. During the experiment the test vessel was held in the oven, and molten aluminum was poured into the test vessel. After a specified time interval, the test vessel was removed from the enclosure, and the melt was drained from the test vessel. The difference between the pre-test and post-test values of the vessel wall thickness yielded the data for the dissolution depth as a function of position along the vessel surface. For these experiments, no forced convective motion was established in the molten aluminum pool. The nominal value of the average melt temperature for the first test was $977^{\circ} \mathrm{C}$, and for the second test it was $1007^{\circ} \mathrm{C}$. In addition, while the inside surface of the test vessel for the first experiment was virtually un-oxidized, it was heavily oxidized for the second test.

For the first experiment, the post-test visual inspection and the measurements of the dissolution depth at various locations on the test vessel show the dissolution process to be highly nonuniform spatially. Large variations in the dissolution depth with respect to the azimuthal coordinate were also observed. However, qualitatively, the azimuthally-averaged dissolution depth was found to increase as one traversed from the vessel center towards the edge of the molten pool. The maximum local value of the measured time-averaged dissolution rate for this test was found to be $5.05 \mathrm{~mm} / \mathrm{hr}$, and this occurred near the edge of the molten pool. The concentration measurements show the molten pool to be highly stratified with respect to the concentration of stainless steel in the melt (molten aluminum-stainless steel so'ution). 
For the second experiment, wherein the inside surface of the test vessel was heavily oxidized prior to injection of molten aluminum, a large reduction in the dissolution rate was observed. The maximum value of the measured dissolution rate for this test was $1.18 \mathrm{~mm} / \mathrm{hr}$, which is much smaller than the peak dissolution rate of $5.05 \mathrm{~mm} / \mathrm{hr}$ for the first test. Thus this experiment shows that, at least up to a temperature of $1007^{\circ} \mathrm{C}$, a pre-existing oxide layer on the surface of stainless steel is protective in nature. However, it is noted that at higher temperatures, this may not be the case due to the expected thermite reaction between the iron oxide and molten aluminum.

An analysis showing the relationship between the linear dissolution rate and the mass transfer coefficient which is not restricted to vanishingly small values of the concentration (of solute in the solution), was developed. Since the diffusivity of iron in molten aluminum is a key property that must be known in order to predict the dissolution of stainless steel by molten aluminum, uncertainties in its value were also documented. 
TABLE OF CONTENTS

Page

ABSTRACT $\ldots \ldots \ldots \ldots \ldots \ldots \ldots \ldots \ldots \ldots \ldots \ldots \ldots \ldots$ iii

EXECUTIVE SUMMARY $\ldots \ldots \ldots \ldots \ldots \ldots \ldots \ldots \ldots \ldots \ldots$ v

LIST OF FIGURES $\ldots \ldots \ldots \ldots \ldots \ldots \ldots \ldots \ldots \ldots \ldots \ldots \ldots \ldots \ldots \ldots$ ix

LIST OF TABLES $\ldots \ldots \ldots \ldots \ldots \ldots \ldots \ldots \ldots \ldots \ldots \ldots \ldots \ldots \ldots$ xii

NOMENCLATURE $\ldots \ldots \ldots \ldots \ldots \ldots \ldots \ldots \ldots \ldots \ldots \ldots \ldots \ldots$ xiii

ACKNOWLEDGMENTS $\ldots \ldots \ldots \ldots \ldots \ldots \ldots \ldots \ldots \ldots \ldots \ldots \ldots$ xv

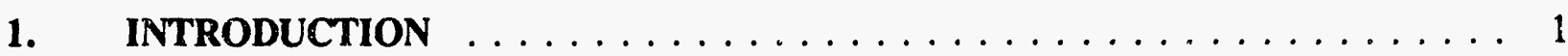

1.1 Background $\ldots \ldots \ldots \ldots \ldots \ldots \ldots \ldots \ldots \ldots \ldots$

1.2 Previous Studies on Molten Aluminum/Stainless Steel Dissolution . . . . . . 1

1.3 Objectives for the Integral Molten Aluminum Pool/Stainless Steel Dissolution Experiments . . . . . . . . . . . . . . . . . . 2

1.4 The Experimental Strategy $\ldots \ldots \ldots \ldots \ldots \ldots \ldots \ldots \ldots$

2. ANALYTICAL CONSIDERATIONS $\ldots \ldots \ldots \ldots \ldots \ldots \ldots$

2.1 Some Definitions and Assumptions . . . . . . . . . . . . 5

2.2 A Model For The Saturation Concentration of Stainless Steel

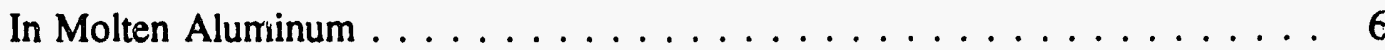

2.3 An Idealized Relationship Between the Linear Dissolution Rate and the Mass Transfer Coefficient $\ldots \ldots \ldots \ldots \ldots \ldots \ldots$

2.4 The Differential Equation for the Solute Concentration in the Solvent . . . . . . . . . . . . . . . . . . 13

2.5 The Uncertainties in the Prediction of the Dissolution Rate of Stainless Steel by Molten Aluminum $\ldots \ldots \ldots \ldots \ldots \ldots$

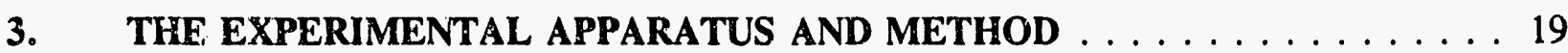

3.1 The Test Vessel . . . . . . . . . . . . . . . . . . . . 19

3.2 The Experimental Apparatus $\ldots \ldots \ldots \ldots \ldots \ldots \ldots \ldots \ldots \ldots$

3.3 Test Procedure . . . . . . . . . . . . . . . . . . . . . . . 19

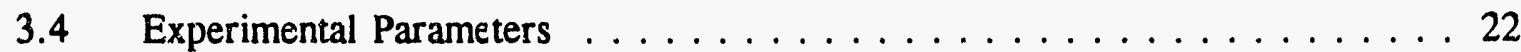

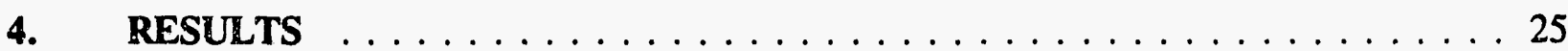

4.1 Results From the First Molten Pool Dissolution Experiment,

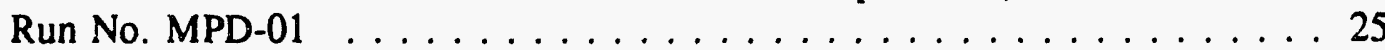

4.1.1 The Melt and Test Vessel Temperature History . . . . . . . . 25

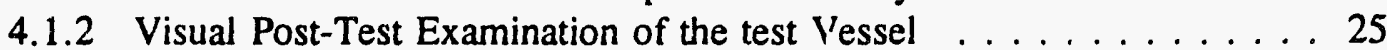

4.1.3 The Linear Dissolution Depth Measurements . . . . . . . . . . 29 


\section{TABLE OF CONTENTS (Cont'd)}

Page

4.1.4 Concentration Measurements . . . . . . . . . . . . 36

4.1.5 The Scanning Electron Microscopy (SEM) Measurements . . . . . 37

4.2 Results From the Second Molten Pool Dissolution Experiment,

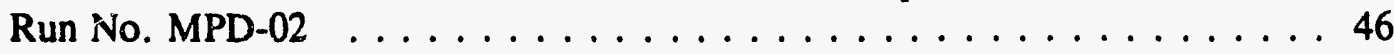

4.2.1 The Melt and Test Vessel Temperature History . . . . . . . . . 46

4.2.2 Visual Post-Test Examination of the test Vessel . . . . . . . . 46

4.2.3 The Linear Dissolution Depth Measurements . . . . . . . . . 52

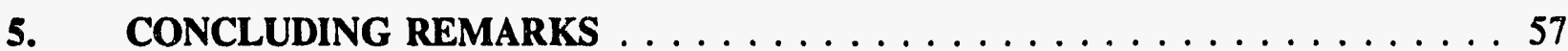

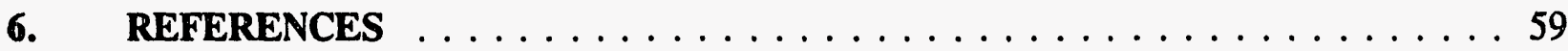




\section{LIST OF FIGURES}

Figure

Page

1 A schematic of a method of producing convective motion

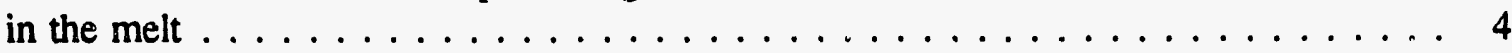

2 The saturation concentration of iron in molten aluminum $\ldots \ldots \ldots \ldots$

3 A schematic of the idealized dissolution process $\ldots \ldots \ldots \ldots \ldots$

4 The dependence of the linear dissolution rate of stainless steel on the concentration of stainless steel in the molten aluminum-stainless

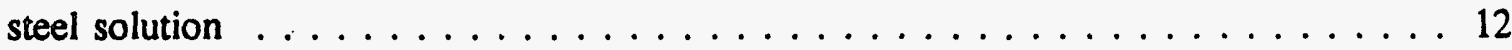

5 The diffusivity of iron in molten aluminum $\ldots \ldots \ldots \ldots$

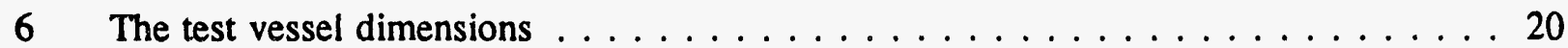

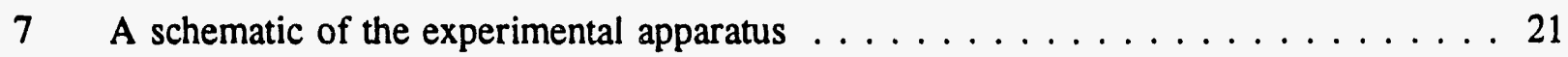

8 A schematic of the locations of the intrinsic thermocouples on the test vessel wall and the thermocouples within the molten pool $\ldots \ldots \ldots \ldots \ldots$

9 Melt and test vessel wall temperatures during Run No. MPD-01.

See Figure 8 for thermocouple locations $\ldots \ldots \ldots \ldots$

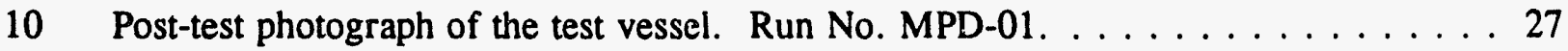

11 Post-test photograph of the test vessel. A close-up of zone A from

Figure 10. Run No. MPD-01 . . . . . . . . . . . . . . . . . 28

12 The definition sketch for the linear dissolution depth, d. . . . . . . . . . . . . 29

13 The pre-test vessel wall thickness measurements for Run

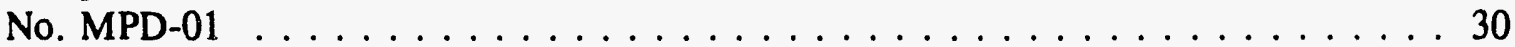

14 The dissolution depth and time-averaged dissolution rate measurements

for Run No. MPD-01. . . . . . . . . . . . . . . . . . . . . 32

15 Selected dissolution depth measurements with $\theta$ as a parameter.

Run No. MPD $01 \ldots \ldots \ldots$. . . . . . . . . . . . . . . . . . . . 34

16 The dissolution depth map for Run No. MPD-01.

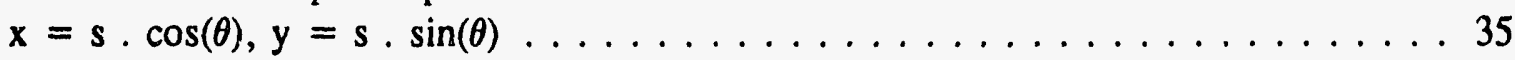




\section{LIST OF FIGURES (Cont'd)}

Figure

Page

17 The SEM image of the cross-section of the test vessel in the neighborhood of $s=11^{n}$ and $\theta=67.5^{\circ}$. Magnification $=10 \ldots \ldots 39$

18 The SEM image of the cross-section of the test vessel and some EDS measurements in the neighborhood of $s=11^{\prime \prime}$ and $\theta=67.5^{\circ}$. A magnified view of the location $X$ in Figure 17. No macroscopic decrease in the thickness of the vessel wall was measured at this point

19 The SEM image of the cross-section of the test vessel and some EDS measurements in the neighborhood of $s=11^{\prime \prime}$ and $\theta=67.5^{\circ}$. An enlargement of the view in Figure 18 .

20 EDS measurements at locations 9 and 10 in Figure $19 \ldots \ldots \ldots 2$

21 The SEM image of the cross-section of the test vessel and some EDS measurements in the neighborhood of $s=11^{\prime \prime}$ and $\theta=67.5^{\circ}$.

A magnified view of the location $Y$ in Figure 17. The dissolution depth at this point was measured to be equal to $0.044^{n}$

22 The SEM image of the cross-section of the test vessel and some EDS measurements at the center of the test vessel $\ldots \ldots \ldots \ldots \ldots \ldots$

23 The SEM image of the cross-section of the test vessel and some EDS measurements in the neighborhood of $s=11 "$ and $\theta=85^{\circ}$. The dissolution depth at this location was large and equal to $0.120^{\prime \prime} \ldots \ldots \ldots \ldots$

24 The melt and test vessel wall temperatures during Run No. MPD-02. See Figure 8 for thermocouple locations . . . . . . . . . . . . . 47

25 A post-test photograph of the test vessel prior to cleaning of the test vessel. Run No. MPD-02

26 Post-test photograph of the test vessel following the $\mathrm{NaOH}$ treatment.

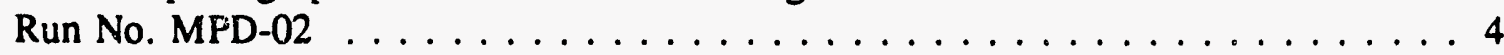

27 Post-test photograph of the test vessel for Run No. MPD-02. A close-up of the Region 2 in Figure $26 \ldots \ldots \ldots \ldots \ldots$

28 Post-test photograph of the test vessel for Run No. MPD-02. A close-up of the Region 3 in Figure 26 


\section{LIST OF FIGURES (Cont'd)}

Figure

Page

29 The pre-test vessel wall thickness measurements for Run

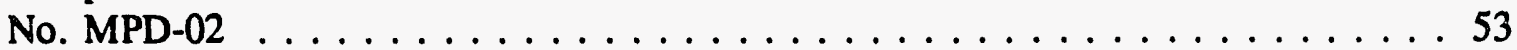

30 The dissolution depth and time-averaged dissolution rate measurements

for Run No. MPD-02 . . . . . . . . . . . . . . . . . . . . . . . . . 54

31 The dissolution depth map for Run No. MPD-02.

$x=s \cdot \cos (\theta), y=s \cdot \sin (\theta) \ldots \ldots \ldots \ldots \ldots \ldots$ 


\section{LIST OF TABLES}

Table

Page

1 The experimental data for the saturation concentration of iron

in molten aluminum $\ldots \ldots \ldots \ldots \ldots \ldots \ldots \ldots \ldots \ldots$

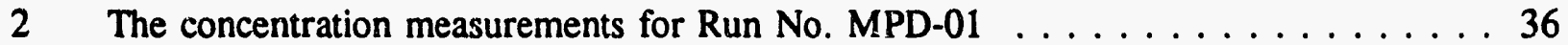




\section{NOMENCLATURE}

c concentration, mass of dissolved solute per unit volume of the solution

$c_{s}$ concentration when the solution is saturated with solute

$c^{*} \quad$ mass fraction of solute in the solution (see Equation (3))

$c_{8}^{*} \quad$ dimensionless saturation concentration (see Equation (3))

d dissolution depth, local decrease in the wall thickness due to dissolution

D Diffusivity of solute in solution

g acceleration due to gravity

h mass transfer coefficient (see Equation (8)), except in Figure 8, where it is used to denote the location of melt thermocouples

$\mathrm{H}_{0} \quad$ volumetric heat generation rate within the melt

$k$ thermal conductivity of the melt

$\mathrm{K} \quad$ linear dissolution rate, erosion depth per unit time on the sample surface

L melt height or length scale

$\mathrm{m}_{\mathbf{s}} \quad$ mass of dissolved solute in the solution

r radial coordinate in the horizontal plane (see Figure 8)

R Reynolds number

$\mathrm{Ra} \quad$ Rayleigh number

$\Re \quad$ atomic radii

s curvilinear coordinate measured from the test vessel center along the bottom surface of the test vessel

S interfacial contact area between the solid (solute) and the melt

Sc Schmidt number

Sh Sherwood number

t pre-test wall thickness of test vessel; in Chapter 2: instantaneous value of time

T temperature 


\section{NOMENCLATURE (Cont'd)}

U Velocity scale for convective motion in the melt

$\mathrm{x}=\mathrm{s} \cdot \cos (\hat{\boldsymbol{\theta}})$

$y=s \cdot \sin (\theta)$

\section{Greek Symbols}

$\alpha \quad$ thermal diffusivity of melt

$\beta \quad$ isobaric coefficient of thermal expansion of the melt

$\theta$ azimuthal coordinate in the horizontal plane (see Figure 8)

$\kappa \quad$ Boltzmann constant

$\mu_{\mathrm{Al}} \quad$ absolute viscosity of molten aluminum

$\nu \quad$ kinematic viscosity of the melt

p density

$\tau$ time duration during which the melt stays within the test vessel

$v \quad$ total volume of solution

$v_{8} \quad$ volume occupied by dissolved solute

\section{Subscripts}
Al aluminum
m melt
s solute
$\mathrm{m}, \mathrm{s} \quad$ melt at saturation 


\section{ACKNOWLEDGMENTS}

This work was performed under contract to Sandia National Laboratories in support of the NPR-HWR program of the DOE's Office of New Production Reactors. The authors gratefully acknowledge the support of Dr. Kenneth D. Bergeron (Sandia National Laboratory) during the course of this investigation. The authors also thank Mark Fuhrmann for performing the Inductively Coupled Plasma Atomic Emission Spectrometry analysis. 


\section{INTRODUCTION}

\subsection{Background}

Let us consider postulated severe accident sequences that lead to fuel melting in the New Production Reactor-Heavy Water Reactor (NPR-HWR). In these sequences it is likely that the fuel and structural material (aluminum) within the core would eventually be relocated to the vessel bottom. The ability of the reactor vessel to indefinitely retain the molten core material within it not only depends upon various factors, such as the mass of molten core material, the decay heat level, the downward facing boiling heat transfer from the vessel bottom to the water surrounding the NPRHWR pressure vessel, but is critically dependent upon the chemical compatibility between the molten core material and the vessel wall at the prevailing conditions. These conditions are the melt temperature, the melt-vessel wall interface temperature, the convective velocity induced within the melt due to natural convection, and the local chemical composition of the melt adjacent to the vessel wall. It is therefore possible that even if the downward facing boiling heat transfer from the vessel wall to the water in the reactor cavity is sufficient to remove all the decay heat from melt, the equilibrium melt temperature may not be low enough to prevent the dissolution of the stainless steel from the wall into the molten pool. It is well known that Type 316L stainless steel and other ferrous alloys are dissolved by molten aluminum [1-6]. In fact, the experimental evidence [3] suggests that the melt temperature threshold for the dissolution of stainless steel by molten aluminum may be the melting point of aluminum. Therefore, unless it can be shown that the core debris (aluminum/uranium/lithium) adjacent to the vessel bottom remains in the frozen state during the postulated severe accident, the dissolution of the vessel wall by the molten core debris must be calculated in order to assess the "in-vessel retention" of the molten core debris.

\subsection{Previous Studies on Molten Aluminum/Stainless Steel Dissolution}

Webb [1] studied the dissolution of 316 stainless steel samples in molten aluminum in the temperature range of $705^{\circ} \mathrm{C}$ to $927^{\circ} \mathrm{C}$. In these experiments, there was no relative motion between the stainless steel samples and the molten aluminum. He observed the growth of hemispherical pits in the stainless steel samples, indicating that the dissolution did not occur uniformly over the surface of the samples. His experiments indicate that at $927^{\circ} \mathrm{C}$, the linear dissolution rate on the sample surface was about $1 \mathrm{~mm} / \mathrm{hr}$. This linear dissolution rate is simply defined as the average erosion depth per unit time on the sample surface. Dybkov's [2] experiments showed that the dissolution of stainless in molten aluminum was "non-selective," i.e., all the elements of the stainless steel passed on to the solution uniformly. His experiments also showed that the dissolution rate was controlled by diffusion in the solution (melt). Furthermore, he observed the formation of intermetallic layers adjacent to the steel surface.

Greene [3] studied the dissolution of 316L stainless steel samples in molten aluminum in the temperature range of $680^{\circ} \mathrm{C}$ to $950^{\circ} \mathrm{C}$. In addition to performing a few static ${ }^{1}$ tests, he performed experiments in which the small flat plate stainless steel samples were moved parallel to their surfaces

\footnotetext{
${ }^{1}$ No relative velocity between the melt and the stainless steel sample.
} 
at velocities of approximately 13,26 , and $40 \mathrm{~cm} / \mathrm{s}$ within the molten aluminum pool. As expected, he found the dissolution rate to increase, both with increasing melt temperature and with increasing sample velocity. In addition, he observed that, when the surface of the stainless steel sample was heavily pre-oxidized, the sample showed no erosion in molten aluminum. The empirical correlation of his data indicates that at $1000^{\circ} \mathrm{C}$, a $316 \mathrm{~L}$ stainless steel sample, at rest in molten aluminum at the same temperature, would experience a linear dissolution rate of $1.6 \mathrm{~mm} / \mathrm{hr}$. Under similar conditions, the dissolution rate for a stainless steel sample moving at $2 \mathrm{~cm} / \mathrm{s}$ would be $6.7 \mathrm{~mm} / \mathrm{hr}$. However, these are surface averaged erosion rates; he further observed that local peak erosion rates could be a factor of four times larger. This phenomenon of local attack on the stainless steel surface by molten aluminum is consistent with the observations of Marra [4,5] and Webb [1]. Marra [4,5], who studied the dissolution of $316 \mathrm{~L}$ stainless steel samples in molten aluminum and molten aluminum alloys in the temperature range of $700^{\circ} \mathrm{C}$ to $1100^{\circ} \mathrm{C}$, also investigated the effect of sample surface condition (as received, \#600 grit ground surface, air annealed, ana passivated) on the dissolution rate. He found the dissolution rate to be strongly dependent upon the surface condition of the sample. Furthermore, as expected, he also found the dissolution rate to decrease with an increase in the concentration of stainless steel in the melt.

To summarize, the following parameters among others, have a large effect on the dissolution rate of stainless steel in molten aluminum: temperature, concentration of stainless steel in the melt, melt agitation or convective velocity, and the surface condition of the stainless steel surface. In addition, molten aluminum is observed to attack the stainless steel surface preferentially at local spots. This phenomenon of "localized attack", and the fact that there are large uncertainties in (a) the viscosity of molten aluminum and aluminum-stainless steel solutions, and (b) the diffusivity of stainless steel in molten aluminum-stainless steel solutions, make it very difficult to develop reliable dimensionless correlations ${ }^{2}$ for predicting the dissolution rate. Clearly, more experimental work is needed to resolve these problems. The rationale for the present experiments is discussed in Section 1.3.

\subsection{Objectives for the Integral Molten Aluminum Pool/Stainless Steel Dissolution Experiments}

Previous studies have shown that the dissolution of stainless steel by molten aluminum is a complex phenomenon that is difficult to predict quantitatively. One of the major difficulties associated with making predictions for the dissolution rate is the fact that there are very large uncertainties in the most important properties of molten aluminum and molten aluminum-stainless steel solutions. These are the diffusivity of stainless steel in molten aluminum-stainless steel solutions, and the viscosity of molten aluminum-stainless steel solutions. In fact, no experimental data for the: viscosity of aluminum-stainless steel solutions as a function of temperature and concentration of stainless steel are available. In this connection, it is important to note that Marra [5] has qualitatively observed an extremely large increase in the viscosity of the aluminum-stainless steel melt as the concentration of stainless steel approaches saturation conditions. Because of these reasons, therefore, it is important to perform integral molten pool dissolution experiments directly,

\footnotetext{
${ }^{2}$ Correlations for Sherwood number as a function of Reynolds number and Schimidt number.
} 
wherein the dissolution of a small scale ${ }^{3}$ torospherical stainless steel vessel by a pool of molten aluminum can be studied. This not only would provide direct experimental data for the dissolution rate for a reasonably sized experiment, but also provides an experimental data base which can then be used for model validation. Furthermore, in the actual reactor case, the concentration of stainless steel within the molten U-Al pool would increase with time as more and more stainless steel from the vessel wall is dissolved into the melt. It has been postulated that since stainless steel is heavier than aluminum, the U-Al-Stainless steel solution would be stratified, such that the concentration of stainless steel is highest near the vessel bottom. It has therefore been argued that the melt in contact with the vessel wall would quickly get saturated with the stainless steel, and would thus prevent further erosion of the vessel wall. This argument pre-supposes that diffusion and natural circulation within the molten pool are insufficient to prevent the argued "chemical stratification" within the molten pool. Since the dissolution rates of stainless steel in pure aluminum are quite high, whether or not chemical stratification occurs is very important for establishment of in-vessel retention. Therefore, experiments to demonstrate the presence or absence of chemical stratification are needed.

\subsection{The Experimental Strategy}

For the full scale NPR-HWR case, the following situation would exist at the vessel bottom. There is a heat generating pool of liquid (molten U-Al-Li-Stainless Steel) at the vessel bottom, and the vessel bottom is being cooled from the outside via downfacing boiling. Because the vessel bottom is curved, natural convection would be established in the melt as a result of temperature gradients within the melt. Ideally, one would want to simulate this natural convective motion within the melt in the small scale dissolution experiment by using a heat generating pool of molten aluminum and cooling the vessel bottom from the outside. However, this is not a trivial matter. Let us now discuss the difficulties in performing a phenomenologically scaled small scale combined natural convection/dissolution experiment. One of the important dimensionless scaling parameters that governs the natural convection, and hence induced convective velocities in the melt, within a heat generating molten layer is the internal Rayleigh number, Ra, defined as,

$$
R a=\frac{g \beta H_{0} L^{5}}{2 \alpha \nu k}
$$

where $g$ is the acceleration due to gravity, $\beta$ is the isobaric coefficient of thermal expansion of the melt, $\mathrm{H}_{0}$ is volumetric heat generation rate within the melt, $\mathrm{L}$ is the melt height and thus corresponds to the physical scale of the experiment, $\alpha$ is the thermal diffusivity of the melt, $\nu$ is the kinematic viscosity of the melt, and $k$ is the thermal conductivity of the melt. Since we wish to study the dissolution of stainless steel in the melt, it is therefore necessary that we use the prototypic melt. Hence the thermophysical properties of the melt used in the experiments would be the same as for the prototypic reactor case. Due to practical considerations, we can not perform a full scale experiment. This implies that for a correctly scaled experiment the following condition must be satisfied:

\footnotetext{
${ }^{3}$ Small compared to the full scale NPR-HWR, but much larger than typical bench top experiments. Present experiment uses a vessel that is $1 / 10^{\text {th }}$ the size of the full scale NPR-HWR.
} 


$$
\left|H_{0} L^{5}\right|_{\text {model }}=\left|H_{0} L^{5}\right|_{\text {full scale }}
$$

Since the largest experiment that can be performed economically is about $1 / 10^{\text {th }}$ scale, this implies that the above equality can only be satisfied if the volumetric heat generation rate in the experiment is $10^{5}$ times greater than the volumetric heat generation rate in the reactor. This is clearly not possible to achieve. In fact, being able to provide a non-nuclear volumetric heat generation rate equal to the reactor case in a molten pool of aluminum would itself be a significant experimental challenge. Therefore, it is clear from the above discussion that the Rayleigh number for the $1 / 10^{\text {th }}$ scale experiment is going to be smaller than the full scale Rayleigh number by a factor of $10^{5}$. Hence, the convective velocities induced in the melt during the experiment would be much smaller than those for the full scale case and any conclusions about chemical stratification and dissolution rates based upon the experimental data would be difficult to extrapolate to the full scale reactor case. In order to circumvent this problem, we have elected to perform experiments in which a prescribed forced convective flow is mechanically established in an isothermal poo! of molten aluminum, and the characteristic forced convective melt velocity is used as an experimental parameter. As shown in Figure 1, the convective flow is to be induced in the molten aluminum pool by means of a small rotating ceramic propeller. Significant effort was devoted to the development of methods for

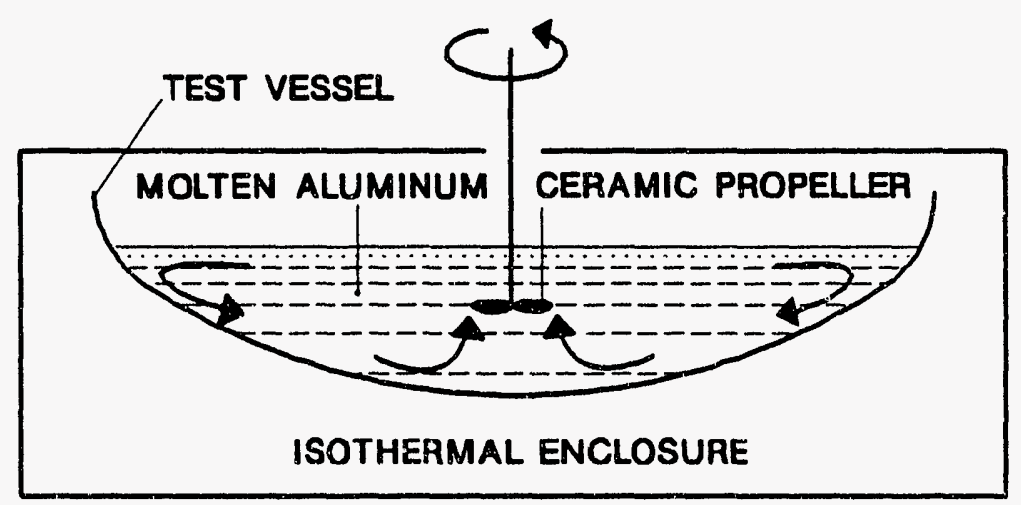

Figure 1. A schematic of a method of producing convective motion in the melt.

producing convective motion in a pool of molten aluminum. The details and the results of these experimental studies are not discussed here because no dissolution experiments with mechanically induced convective motion in the molten aluminum pool have been performed to date. These planned experiments with convective motion were not performed because of the deferral of the NPR program by DOE in the fall of 1992.

This report presents the results of the two "static" experiments that have been performed. Some analytical considerations of the dissolution process are discussed in Chapter 2, and a description of the experimental apparatus and the values of the test parameters for these experiments are provided in Chapter 3. The results of these tests are discussed in Chapter 4, and some concluding remarks are presented in Chapter 5. 


\section{ANALYTICAL CONSIDERATIONS}

\subsection{Some Definitions and Assumptions}

Since we are considering the dissolution of stainless steel by molten aluminum, stainless steel is the "solute" and molten aluminum is the "solvent" for our problem. The "melt," then, consists of a solution of stainless steel and aluminum. The concentration, $c$, of the dissolved solute in the solution, is defined as the mass of solute per unit volume of the solution. We shall denote the concentration under saturation conditions by $c_{s}$. Here, the concentrations $c$ and $c_{s}$ are defined in units of $\mathrm{kg} / \mathrm{m}^{3}$. It is, however, more convenient to define concentration in terms of a dimensionless mass fraction, that is, the mass of dissolved solute per unit mass of total melt. Let $c^{*}$ and $c_{s}^{*}$ be the concentration and the saturation concentration, respectively, of the solute in the melt expressed as mass fractions. Then, these are simply related to $c$ and $c_{\mathrm{s}}$ by the following equations:

$$
c^{*}=\frac{c}{\rho_{m}}, \quad c_{s}^{*}=\frac{c_{s}}{\rho_{m, s}}
$$

where $\rho_{\mathrm{m}}$ is the density of the melt. Since the melt consists of the solute and the solvent (stainless steel and aluminum in our case), the melt density, $\rho_{m}$, is a function of the concentration $c^{*}$. When the melt is saturated with the solute, which occurs when the concentration of the solute equals $c_{s}$, the melt density will be denoted by $\rho_{\mathrm{m}, \mathrm{s}}$. Note that since the saturation concentration is a function of temperature, $\rho_{\mathrm{m}, \mathrm{s}}$ is a function of temperature.

No experimental data for the density of molten aluminum-stainless steel solutions as a function of temperature and concentration of stainless steel in the melt are available. Therefore, in the absence of such data, we make the following assumption: As stainless steel dissolves in molten aluminum, the incremental change in the volume of the solution is equal to the volume of the solid stainiess steel dissolved. We shall use this assumption to derive an expression for the melt density, $\rho_{\mathrm{m}}$, as a function of the concentration of stainless steel in the meit.

Let $\mathrm{m}_{\mathrm{s}}$ be the mass of the dissolved solute in a solution of total volume $v$. Then, if $\rho_{\mathrm{g}}$ is the density of the solute (stainless steel in our case) and $v_{8}$ is the volume occupied by the dissolved solute, we have:

$$
\begin{gathered}
\qquad c=\frac{m_{s}}{v} \\
\text { Volume occupied by dissolved solute }=\frac{m_{s}}{\rho_{s}}=v_{s} \\
\text { Mass of solvent }=\rho_{A l}\left(v-v_{s}\right) \\
\text { Melt Density }=\rho_{m}=\frac{\left[m_{s}+\rho_{A l}\left(v-v_{s}\right)\right]}{v}
\end{gathered}
$$

where $\rho_{\mathrm{Al}}$ is the density of molten aluminum (solvent). Equations (3) and (4) lead to the following relationships for $\rho_{\mathrm{m}}$ and $\rho_{\mathrm{m}, \mathrm{s}}$ : 


$$
\begin{gathered}
\rho_{m}=\frac{\rho_{A l}}{\left[1-c^{*}+c^{*}\left(\rho_{A l} / \rho_{s}\right)\right]} \\
\rho_{m, s}=\frac{\rho_{A l}}{\left[1-c_{s}^{*}+c_{s}^{*}\left(\rho_{A l} / \rho_{s}\right)\right]}
\end{gathered}
$$

Note that when $c^{*}=0$, Equation (5) gives $\rho_{\mathrm{m}}=\rho_{\mathrm{Al}}$, and when $\mathrm{c}^{*}=1, \rho_{\mathrm{m}}$ reduces to $\rho_{\mathrm{s}}$, as should be the case.

\subsection{A Model For The Saturation Concentration of Stainless Steel In Molten Aluminum}

As discussed in Section 1.2, Dybkov [2] found the dissolution of stainless steel in molten aluminum to be non-selective. Furthermore, he found the solubility of stainless steel in molten aluminum to be approximately the same as the solubility of iron in molten aluminum. Since experimental data for the solubility of iron in molten aluminum at high temperatures is available, we shall assume that the saturation concentration of stainless steel in molten aluminum is the saree as the saturation concentration of iron in molten aluminum. Figure 2 shows a plot of data (from References $[2,7$, and 8]) for the saturation concentration of iron in molten aluminum as a function of the melt temperature. For computational convenience a mathematical expression was used to fit this data. This least squares fit through the data is shown as the solid line in this figure, and is given by:

$$
c_{s}^{*}=0.916 \exp \left[-\left(\frac{T-1550}{446.16}\right)^{2}\right], \quad 650^{\circ} \mathrm{C} \leq T \leq 1550^{\circ} \mathrm{C}
$$

where $\mathrm{T}$ is the melt temperature in ${ }^{\circ} \mathrm{C}$. It should be noted that the saturation concentration is bounded between zero and unity. Therefore, even though the saturation concentration increases sharply with temperature around $1100{ }^{\circ} \mathrm{C}$, it can not indefinitely continue to increase at this rate. The experimental data for the saturation concentration of iron in molten aluminum is tabulated in Table 1. 


\section{SATURATION CONCENTRATION OF IRON IN MOLTEN ALUMINUM}

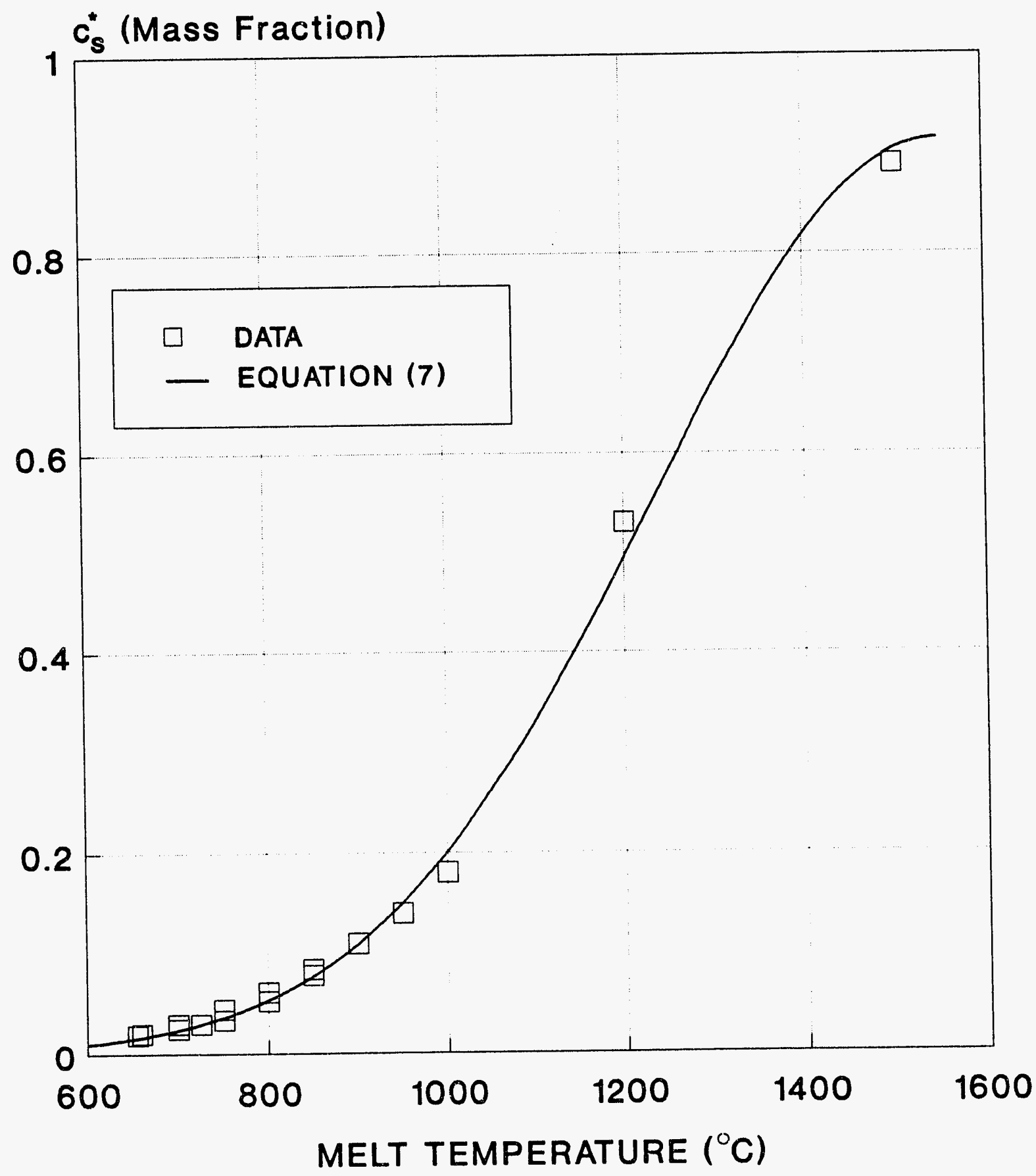

Figure 2. The saturation concentration of iron in molten aluminum. 
Table 1. The Experimental Data for the Saturation Concentration of Iron in Molten Aluminum

\begin{tabular}{|c|c|c|}
\hline $\begin{array}{l}\text { Melt Temperature } \\
{ }^{\circ} \mathbf{C}\end{array}$ & $c_{s}^{*}$ & Reference \\
\hline 700 & 0.025 & [2] \\
\hline 725 & 0.03 & [2] \\
\hline 750 & 0.034 & [2] \\
\hline 800 & 0.053 & [2] \\
\hline 850 & 0.079 & [2] \\
\hline 655 & 0.0187 & [7] \\
\hline 660 & 0.02 & {$[8]$} \\
\hline 700 & 0.03 & [8] \\
\hline 750 & 0.045 & [8] \\
\hline 800 & 0.062 & [8] \\
\hline 850 & 0.085 & [8] \\
\hline 900 & 0.11 & [8] \\
\hline 950 & 0.14 & [8] \\
\hline 1000 & 0.18 & [8] \\
\hline 1200 & 0.53 & [8] \\
\hline 1500 & 0.89 & [8] \\
\hline
\end{tabular}

\subsection{An Idealized Relationship Between the Linear Dissolution Rate and the Mass Transfer Coefficient}

A.s discussed in Section 1.2, previous experimental work $[2,3,5]$ has shown that the dissolution of stainless steel in molten aluminum is controlled by the diffusion of stainless steel within the solution (melt), and not by diffusion through solid intermetallic layers formed on the stainless steel specimens. This is inferred from the experimental observations, which show that the dissolution rate increases sharply with the increase in the relative velocity between the melt and the stainless steel sample. If the dissolution rate were controlled by the diffusion through the solid intermetallic layers, there would be no or little increase in the dissolution rate with an increase in the melt agitation. Therefore, it is reasonable to conclude that, once the dissolution process is initiated, the dissolution rate of stainless steel by molten aluminum is controlled by the mass transfer coefficient at the stainless steel-melt interface. Similar conclusions, on the dissolution of pure iron and some ferrous alloys by molten aluminum, were drawn by Niinomi et al. $[6,9]$. 
A schematic of the idealized dissolution process at a given location on the stainless steel surface is shown in Figure 3. Since, as discussed above, for situations of practical interest (i.e., finite melt agitation or melt convective velocity) the dissolution rate is only limited by the mass transfer coefficient, $h$, at the solid-melt interface, it follows that the concentration of the stainless steel at the melt-solid interface ( $x=0$ in Figure 3.) is always equal to the saturation concentration $c_{s}$. This is because the diffusion process through the solid intermetallic layers is relatively very fast, and therefore sufficiently large to maintain the concentration at the solid-liquid interface to be always equal to the maximum allowable concentration, $c_{8}$. If $S$ is the surface area of the solid in contact with the melt, then, it follows that:

$$
\text { Rate at which the solid is dissolved into the melt }=h S\left(c_{s}-c\right), \quad(k g / s)
$$

where $c$ is the concentration in the bulk of the melt far away from the solid-melt interface. Let $\mathbf{K}$ be the local value of the linear dissolution rate on the stainless steel surface. It is simply defined as the local erosion depth per unit time on the sample surface, and therefore, is the quantity of practical interest. Thus, as shown in Figure 3, in the time interval dt, the thickness of the solid specimen would be reduced by $\mathrm{Kdt}$. Therefore, it follows that:

$$
\text { Rate at which the solid is dissolved into the melt }=K S \rho_{s}, \quad(k g / s)
$$

From Equations (3), (8), and (9), it is easy to show that:

$$
K=h \frac{\rho_{m, s}}{\rho_{s}}\left[c_{s}^{*}-c^{*} \frac{\rho_{m}}{\rho_{m, s}}\right]
$$

Substituting the values of $\rho_{\mathrm{m}}$ and $\rho_{\mathrm{m}, \mathrm{s}}$ from Equations (5) and (6) into the above equation, we get:

$$
K=h \frac{\rho_{A l}}{\rho_{s}} \frac{\left(c_{s}^{*}-c^{*}\right)}{\left[1-c_{s}^{*}+c_{s}^{*} \frac{\rho_{A l}}{\rho_{s}}\right]\left[1-c^{*}+c^{*} \frac{\rho_{A l}}{\rho_{s}}\right]}, \quad 0 \leq c^{*} \leq c_{s}^{*}
$$

It should be noted that the dimensionless concentration, $\mathrm{c}^{*}$, is always bounded between zero and the saturation concentration, $c_{s}^{*}$. The above equation gives us a relationship between the local value of the mass transfer coefficient, $h$, and the local value of the linear dissolution rate, $K$. Therefore, if the former can be calculated, for example, from a relevant engineering correlation, then the value of the latter for any concentration, $c^{*}$, can be deduced. Equation (11) shows that the dissolution rate is a function of the concentration, $c^{*}$, and the saturation concentration, $c_{s}^{*}$. For the special case when the concentration of stainless steel in the bulk of the melt ${ }^{4}$ is zero, Equation (11) reduces to:

\footnotetext{
${ }^{4}$ Everywhere, except the concentration boundary layer adjacent to the dissolving stainless steel sample.
} 


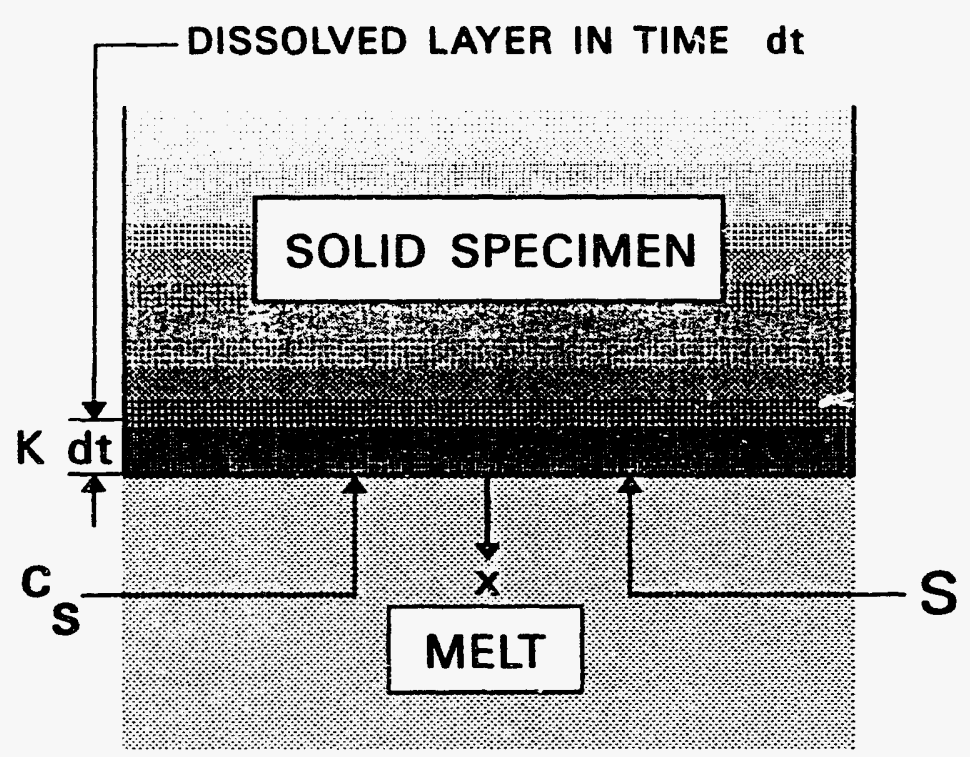

Figure 3. A schematic of the idealized dissolution process. 


$$
K=h \frac{\rho_{A l}}{\rho_{s}} \frac{c_{s}^{*}}{\left.1-c_{s}^{*}+c_{s}^{*} \frac{\rho_{A l}}{\rho_{s}}\right]} \text { valid only when } c^{*}=0
$$

Since the density of aluminum is smaller than the density of stainless steel, Equations (11) and (12) show that the $\mathrm{K}$ increases with increasing $c_{\mathrm{s}}^{*}$. As discussed in Section 2.2, the saturation concentration of stainless steel in molten aluminum increases with increasing temperature of the melt. Therefore, it can be expected that the dissolution rate of stainless steel in molten aluminum will rise as the temperature of molten aluminum is increased. Furthermore, as expected, Equation (11) shows that the dissolution rate decreases as the concentration of stainless steel in the melt increases, and vanishes when $c^{*}=c_{s}^{*}$.

For a given melt temperature, $T$, and a mass transfer coefficient, $h$, the ratio of $K$ at any concentration $c^{*}$ to the value of $\mathrm{K}$ at $c^{*}=0$, is obtained simply by dividing Equation (11) by Equation (12). This gives:

$$
\frac{K\left(c^{*}, T\right)}{K(0, T)}=\frac{K\left(c^{*}\right)}{K(0)}=\frac{\left(1-c^{*} / c_{s}^{*}\right)}{\left[1-\frac{c^{*}}{c_{s}^{*}}\left(1-\frac{\rho_{A l}}{\rho_{s}}\right) c_{s}^{*}\right]}
$$

This ratio, which is valid only for a fixed value of the mass transfer coefficient, can then be used to judge the effective reduction in the dissolution rate as the concentration of solute in the melt increases. It is important to note that, in addition to being a function of the "relative saturation," $c^{*} / c_{s}^{*}$, this ratio is explicitly dependent upon the saturation concentration, $c_{s}^{*}$. A plot of $K\left(c^{*}\right) / K(0)$ for the dissolution of stainless steel in molten aluminum at three different temperatures, and hence for three different values of $c_{s}^{*}$, is shown in Figure 4. For these calculations, as discussed in Section 2.2 , it has been assumed that the saturation concentration of stainless steel in molten aluminum is identical to the saturation concentration of iron in molten aluminum. Therefore, Equation (7) was used to compute $c_{\mathrm{g}}^{*}$. The following correlations for the densities of stainless steel [10] and molten aluminum [11] as a function of temperature were used in these calculations:

$$
\begin{gathered}
\rho_{s}\left(\mathrm{~kg} / \mathrm{m}^{3}\right)=8084-0.4209 \begin{array}{c}
(T+273.15)-3.894 \times 10^{-5}(T+273.15)^{2} \\
\left(T \text { in }{ }^{\circ} \mathrm{C}\right)
\end{array} \\
\rho_{A l}\left(\mathrm{~kg} / \mathrm{m}^{3}\right)=2380-0.35(T-660.2), \quad\left(T \text { in }{ }^{\circ} \mathrm{C}\right)
\end{gathered}
$$

At a melt temperature of $800^{\circ} \mathrm{C}$, when the saturation concentration is very small, as expected, the change in $\mathrm{K}$ with increasing concentration is almost linear. However, at a melt temperature of $1400^{\circ} \mathrm{C}$, when the saturation concentration is large (and equal to 0.818 ), the reduction in $\mathrm{K}$ as concentration increases from zero to higher values is significantly smaller. 


\section{DEPENDENCE OF DISSOLUTION RATE ON CONCENTRATION}

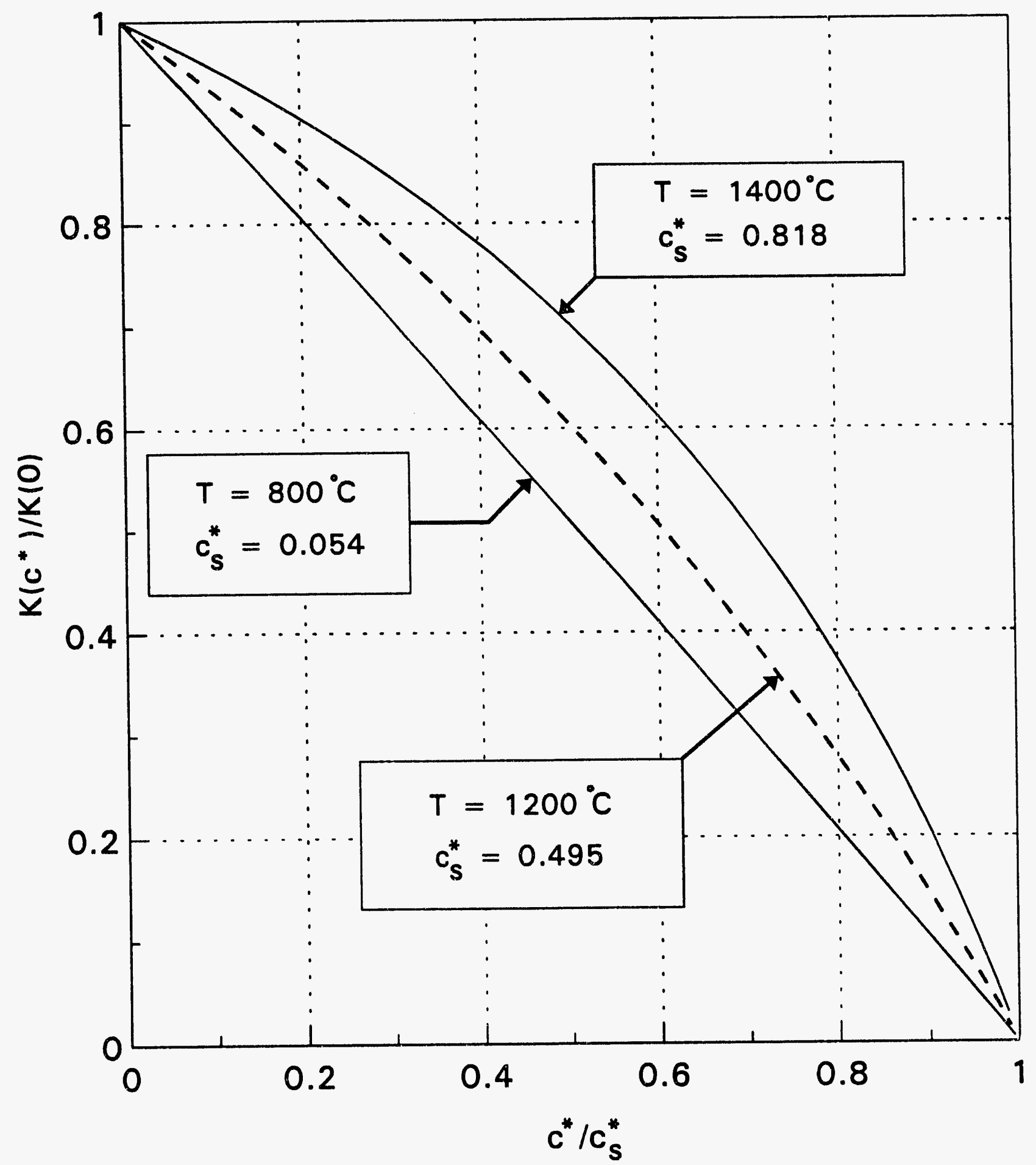

Figure 4. The dependence of the linear dissolution rate of stainless steel on the concentration of stainless steel in the molten aluminum-stainless steel solution. 


\subsection{The Differential Equation for the Solute Concentration in the Solvent}

Consider a solid silute specimen in contact with a solution (dissolved solute and solvent) of finite volume, $v$, such that the interfacial contact area beiween the solid and the solution is $S$. Then the differential equation for the average concentration, $c$, of the solute dissolved in the entire volume of solvent, $v$, has c ften been given in the literature $[2,12]$ as:

$$
\frac{d c}{d t}=h \frac{S}{v}\left(c_{s}-c\right)
$$

where $t$ is the time. However, this equation is valid only for the limit $c \rightarrow 0$. In order to derive an equation with greater applicability, it is necessary to know the density of the solution as a function of concentration. Since this data for the molten aluminum-stainless steel solutions is not available, we shall use the sisumption enumerated in Section 2.1, namely: the incremental change in the volume of the melt, $d v$, due to the dissolution of an incremental mass, $d m_{s}$, in the solution is equal to the volume of the solid dissolved. Therefore,

$$
d v=\frac{d m_{s}}{\rho_{s}}
$$

Differentiating the definition of the concentration, $c$, in Equation (4), we get:

$$
\frac{d c}{d t}=\frac{1}{v}\left(\frac{d m_{s}}{d t}-c \frac{d v}{d t}\right)
$$

Substituting Equations (8) and (16) in the above equation, we get:

$$
\frac{d c}{d t}=h \frac{S}{v}\left(1-\frac{c}{\rho_{s}}\right)\left(c_{s}-c\right)
$$

The above equation, which differs from Equation (15) by the factor $\left(1-c / \rho_{\mathrm{g}}\right)$, provides a better model for the time rate of change of concentration in the solution.

\subsection{The Uncertainties in the Prediction of the Dissolution Rate of Stainless Steel by Molten Aluminum}

The linear dissolution rate on the surface of a stainless steel specimen in contact with a molten aluminum-stainless steel solution is given by Equation (11). Therefore, if the mass transfer coefficient, $h$, which appears iri this eciuation is known or predictable, the linear dissolution rat 0 can be calculated. Thus the orediction of the linear dissolution rate reduces to the prediction of the mass transfer coefficient. The engineering correlations for the mass transfer coefficient are usually given 
in terms of the dimensionless correlations of the following type:

$$
S h=\frac{h L}{D}=\phi(R) \psi(S c) ; \quad R=\frac{U L}{\nu}, \quad S c=\frac{\nu}{D}
$$

where, $\mathrm{Sh}$ is the Sherwood number, $\mathrm{R}$ is the Reynolds number, $\mathrm{Sc}$ is the Schmidt number, $\nu$ is the kinematic viscosity of the solution, $D$ is the diffusivity of the solute in the solution, $L$ is the length scale, and $U$ is the relevant velocity scale for the convective motion. If no direct mass transfer experiments for the problem of interest are available, then, for some cases the use of the analogy between the mass, momentum, and the heat transfer via the Chilton-Colburn $j$ factors $[13,14]$ can be used to determine the mass transfer coefficient. For example, for laminar flow past a flat plate of length L, which corresponds to the experiments of Greene [3] and Marra [5], the Colburn analogy yields:

$$
S h=0.664 R^{0.5} S c^{1 / 3}, \quad R<5 \times 10^{5}
$$

Equations (19) and (20) show that the mass transfer coefficient is dependent upon the properties $\nu$ and $\mathrm{D}$. Therefore, any large uncertainty in the values of the diffusivity of stainless steel in molten aluminum-stainless steel solution, and the viscosity of molten aluminum-stainless steel solution would cause a correspondingly large uncertainty in the calculated value of the mass transfer coefficient, and hence in the predicted value of the dissolution rate. Let us now briefly review the uncertainties in the available experimental data for the diffusivity of stainless steel in molten aluminum-stainless steel solutiuns and the viscosity of molten aluminum-stainless steel solutions.

No experimental data for the diffusivity of stainless steel ${ }^{5}$ in molten aluminum are available. However, we note several points. As discussed in Section 1.2, Dybkov's [2] experiments have shown that upon dissolution, all the elements of stainless steel pass on to the solution (molten aluminum-stainless steel) uniformly. Furthermore, the atomic radii of the major components of stainless steel $(\mathrm{Fe}, \mathrm{Cr}$, and $\mathrm{Ni}$ ), which are the diffusing elements, are about the same. From reference [15], the atomic radii, $\Re$, are: $\Re_{\mathrm{Fe}}=1.17 \AA, \Re_{\mathrm{Cr}}=1.18 \AA$, and $\Re_{\mathrm{Ni}}=1.15 \AA$. Based upon these observations, and the fact that iron is the major component of stainless steel, it seems reasonable to assume that the diffusivity of "stainless steel" could be approximated by the diffusivity of iron in molten aluminum.

The atomic radius of aluminum [15] is equal to $1.25 \AA$, which is very close to the value for iron. Since in our case the radius of the diffusing (iron) particle is of the same order as the radius of the solvent (aluminum) particle, the hydrodynamic theory of diffusion $[11,16]$ gives the following relation for the diffusivity of iron in molten aluminum:

$$
D_{F e, A l}=\frac{\kappa T}{4 \pi \mu_{A l} \Re_{F e}} \quad \text { (Sutherland-Einstein Formula) }
$$

\footnotetext{
${ }^{5}$ Since stainless steel consists of many elements, strictly speaking, the diffusion of these elements must be considered separately. Here, for the purpose of modeling, we look upon stainiess steel as a single component with certain properties.
} 
where $\mathrm{D}_{\mathrm{Fe}, \mathrm{Al}}$ is the diffusivity of iron in molten aluminum, $\mu_{\mathrm{Al}}$ is the viscosity of molten aluminum, $\kappa$ is the Boltzmann constant, and $\mathbf{T}$ is the temperature in Kelvin. This equation is known as the Sutherland-Einstein Formula. Note that the diffusivity is dependent upon the viscosity of the solution. Thus any uncertainty in the value of viscosity would lead to a corresponding uncertainty in the computed diffusivity. Roy and Chhabra [17] have also developed a theoretical model for the diffusion coefficient of solute in liquid metals. The predictions from this model and the SutherlandEinstein model are presented below. Equation (22), given below, was used to compute the viscosity of molten aluminum for the Sutherland-Einstein model.

The experimental data for the diffusivity of iron in molten aluminum is extremely limited and ambiguous. Uemura [18] measured the diffusivity of iron in molten aluminum at temperatures of $700,800,900$, and $1000^{\circ} \mathrm{C}$. He used the method of "Finite-cylinder, semi-infinite-rod technique" [19] for his experiments. A $10 \mathrm{~mm}$ long (and $20 \mathrm{~mm}$ diameter) aluminum disc was brought into contact with a $50 \mathrm{~mm}$ long rod of the same diameter consisting of $15.8 \%$ iron and $84.2 \%$ aluminum, and heated in an oven to the desired temperature. In his experiments, therefore, the initial concentration of iron in the rod was 0.158. Kato and Minowa [20] have also made measurements of the diffusivity of iron in molten aluminum at temperatures of 700,800 , and $900^{\circ} \mathrm{C}$. They performed their experiments for two different values of the initial concentration of iron (presumably at one end of the pure aluminum sample): 0.01415 , and 0.04135 . These measurements, and the predictions from Roy and Chhabra [17] and the Sutherland-Einstein equation are presented in Figure 5. As can be seen, the agreement among the various experimental values of the diffusivity of iron in molten aluminum is extremely poor. However, one trend is noteworthy; the larger the initial concentration of iron in the experiment (at one end of the solvent), the smaller is the measured value of the diffusivity of iron in molten aluminum. In this sense, the experimental results are consistent. This suggests two things: (a) that the diffusivity of iron in a solution of molten aluminum and iron is a very strong function of the concentration of iron in the melt, and (b) that the design of these experiments is flawed in the sense that it is hard to interpret the experimental results. Does the measured value of $\mathrm{D}_{\mathrm{Fe}-\mathrm{Al}}$ represent the diffusivity of iron in pure aluminum, the diffusivity of iron in a melt with the concentration equal to the initial concentration of iron, $c_{i}^{*}$, or the diffusivity of iron in a molten aluminum-iron solution of some intermediate concentration between 0 and $c_{i}^{*}$ ? From these considerations, it appears that the experimental results of Kato and Minowa [20] for the initial iron concentration of 0.01415 (dark triangles in Figure 5.) may be closest to the value of the diffusivity of iron in pure molten aluminum. However, this experimental value is about seven times larger than the prediction from the Sutherland-Einstein equation, and about five times greater than the prediction from Roy and Chhabra [17].

From the experimental data and the theoretical predictions for the diffusivity of iron in molten aluminum, presented in Figure 5, two conclusions can be drawn. First, there is a large uncertainty in the value of the diffusivity, and secondly, since the diffusivity appears to be a strong function of the concentration of iron in the meit, the diffusivity may have to be treated as a variable within the concentration boundary layer.

Iida and Guthrie [11], among others, have documented the experimental measurements of the viscosity of molten aluminum, and have shown that there is a large variation, by as much as a factor of 3.5 , in the measured viscosity of molten aluminum. As pointed out by reference [7], this may be due to the reason that the viscosity of molten aluminum is quite sensitive to small amounts of impurities, for example, aluminum oxide or traces of other soluble impurities. Iida and Guthrie [11] 
DIFFUSIVITY OF IRON IN MOLTEN ALUMINUM

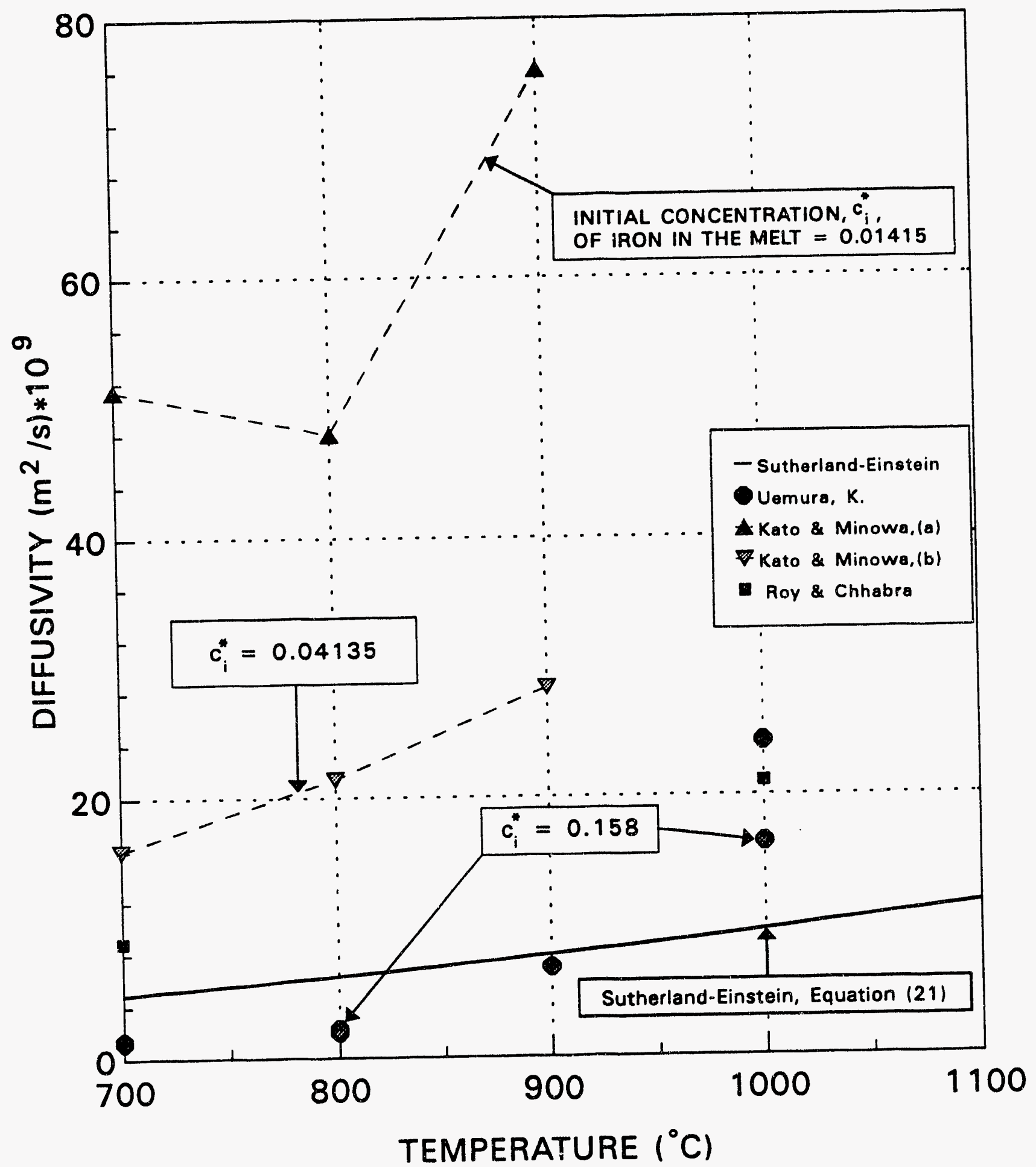

Figure 5. The diffusivity of iron in molten aluminum. 
recommend the use of a predictive model which gives calculated values for the viscosity of molten aluminum (as a function of temperature) that lie between the experimental data. A least square's fit of the tabulated values from this model (dotted line in Figure 6.26 of [11]) gives the following correlation for the absolute viscosity of molten aluminum:

$$
\mu_{A l}=\frac{65.143}{T^{1.5207}} \quad(P a . s) ; \quad 933.35 K \leq T \leq 1320 K
$$

The above equation was used for the computation of the diffusivity of iron in molten aluminum as predicted by the Sutherland-Einstein model in Figure 5. 


\section{THE EXPERIMENTAL APPARATUS AND METHOD}

\subsection{The Test Vessel}

A drawing of the 24 inch diameter 316L stainless steel test vessel used for the experiments is shown in Figure 6. The nominal wall thickness of this commercially available ${ }^{6}$ "ASME Flanged and Dished Head" was 3/16 inches for the first experiment, and 1/4 inch for the second experiment. To prepare the vessel for the test, the following procedure was followed. The inside surface of the vessel was first polished using a deburring wheel with Carborundum coated nylon bristles. Next, the vessel was cleaned with a detergent and thoroughly rinsed with distilled water. After the vessel was dry, its wall thickness was measured at various locations to a precision of 0.0005 inch. Finally, the inside surface of the test vessel was soaked in a $20 \%$ (by weight) solution of $\mathrm{NaOH}$ for one hour, and then rinsed with distilled water. Previous experiments with polished samples of 316L stainless steel have shown that there were no changes in the dimensions or mass of these samples following the $\mathrm{NaOH}$ treatment.

\subsection{The Experimental Apparatus}

A schematic of the experimental apparatus is shown in Figure 7. The apparatus consists of four major components: (a) an aluminum melting furnace, (b) an oven to serve as an isothermal enclosure for the test vessel during the test, (c) the control panels for the oven and the furnace, and (d) the data acquisition system. The control panels and the data acquisition system are not shown in Figure 7. A carbon-bonded silicon carbide crucible, with a capacity to hold $30 \mathrm{~kg}$ of molten aluminum, is placed in the aluminum melting furnace. The oven consists of two parts: the bottom part holds the test vessel, and the top cover contains the penetrations for the melt sampling ports, thermocouples, argon gas supply, and a funnel for pouring molten aluminum into the test vessel. In order to provide an inert atmosphere for the test vessel, argon gas is also injected from the bottom of the oven. To reduce thermal gradients within the oven, electric heating elements are installed in both parts of the oven. Since the melt must quickly be drained from the test vessel at the end of the experiment, a mechanism to lift and move the top cover of the oven along a track was also constructed as shown in Figure 7. This figure shows the top cover in the "open" position. To prevent any interaction between the molten aluminum that might accidently be spilled and the floor, the experimental floor was covered with a non-skid galvanized "grid-work" or grating. The top surface of the grid-work is about 1.5 inches from the ground, and the grid-work is filled with sand to a height of about one inch.

\subsection{Test Procedure}

As discussed in Section 3.1, prior to the experiment the initial thickness of the test vessel wall is measured at various positions. To start the experiment, the carbon-bonded silicon carbide crucible is placed in the aluminum melting furnace and the argon purge gas supply to the furnace is turned

\footnotetext{
${ }^{6}$ Obtained from: American Alloys Inc., Secaucus, New Jersey.
} 


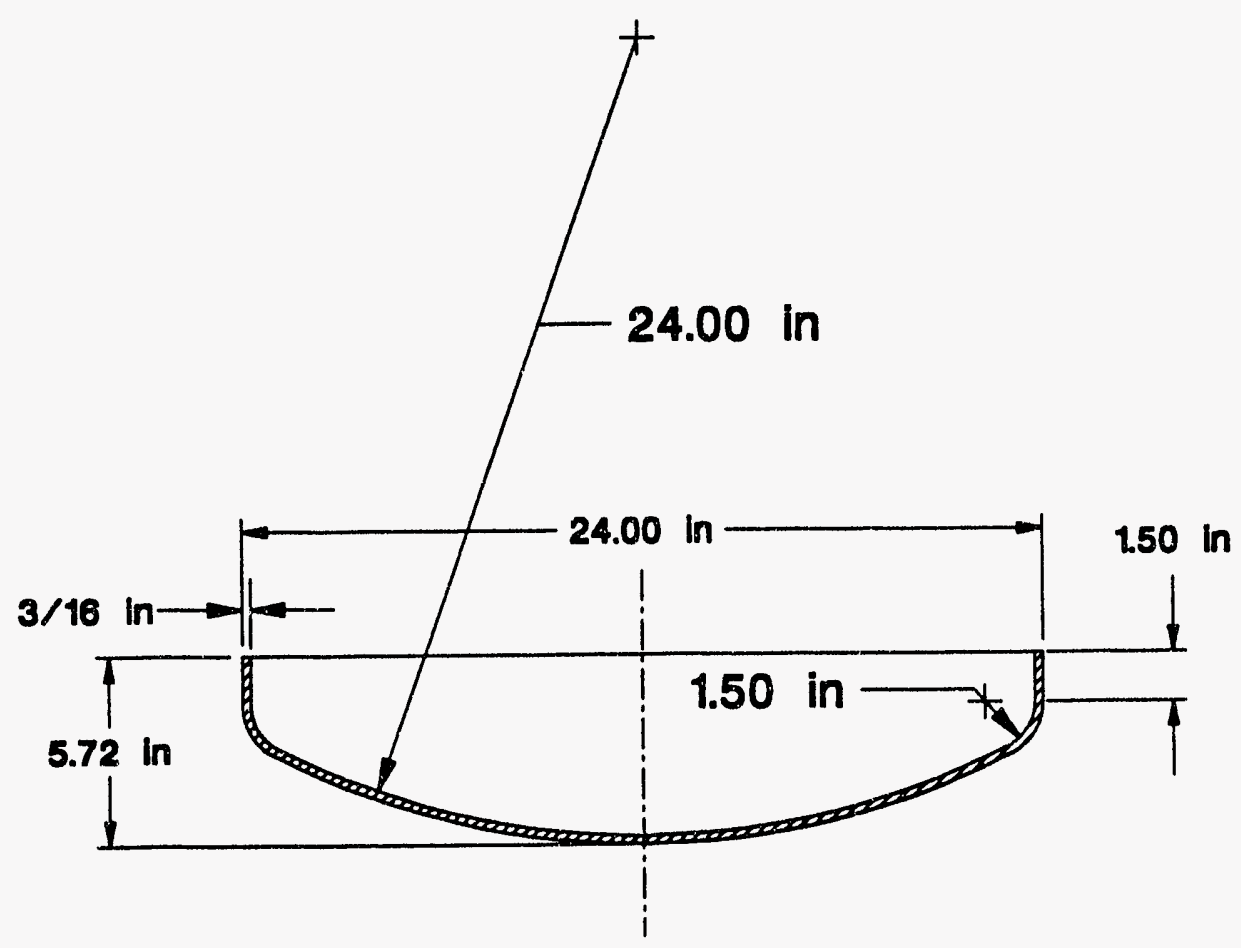

316L STAINLESS STEEL TEST VESSEL

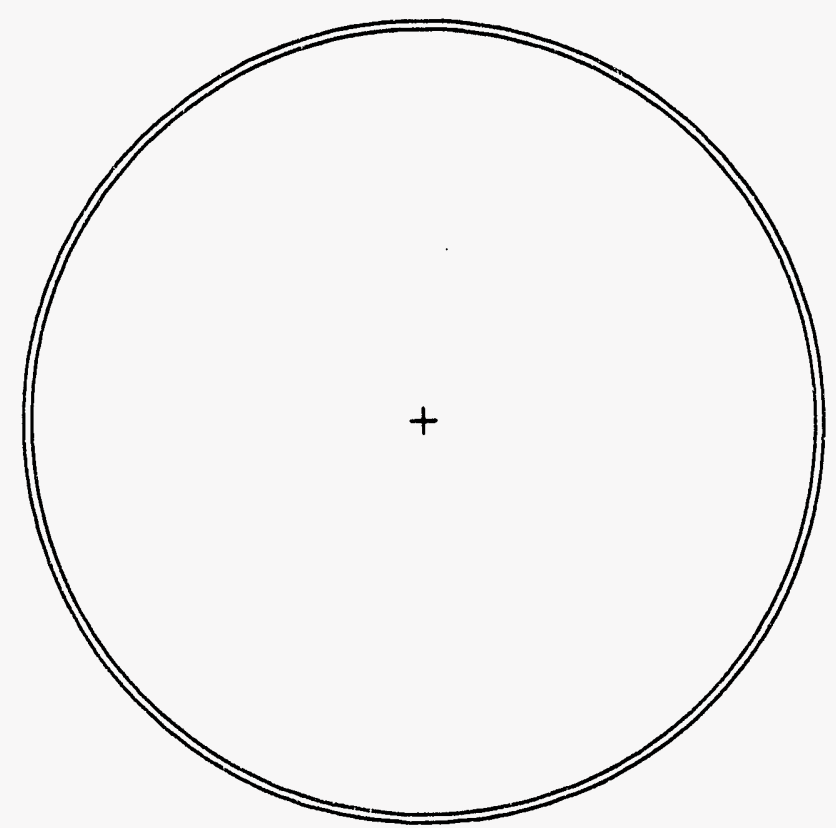

Figure 6. The test vessel dimensions. 


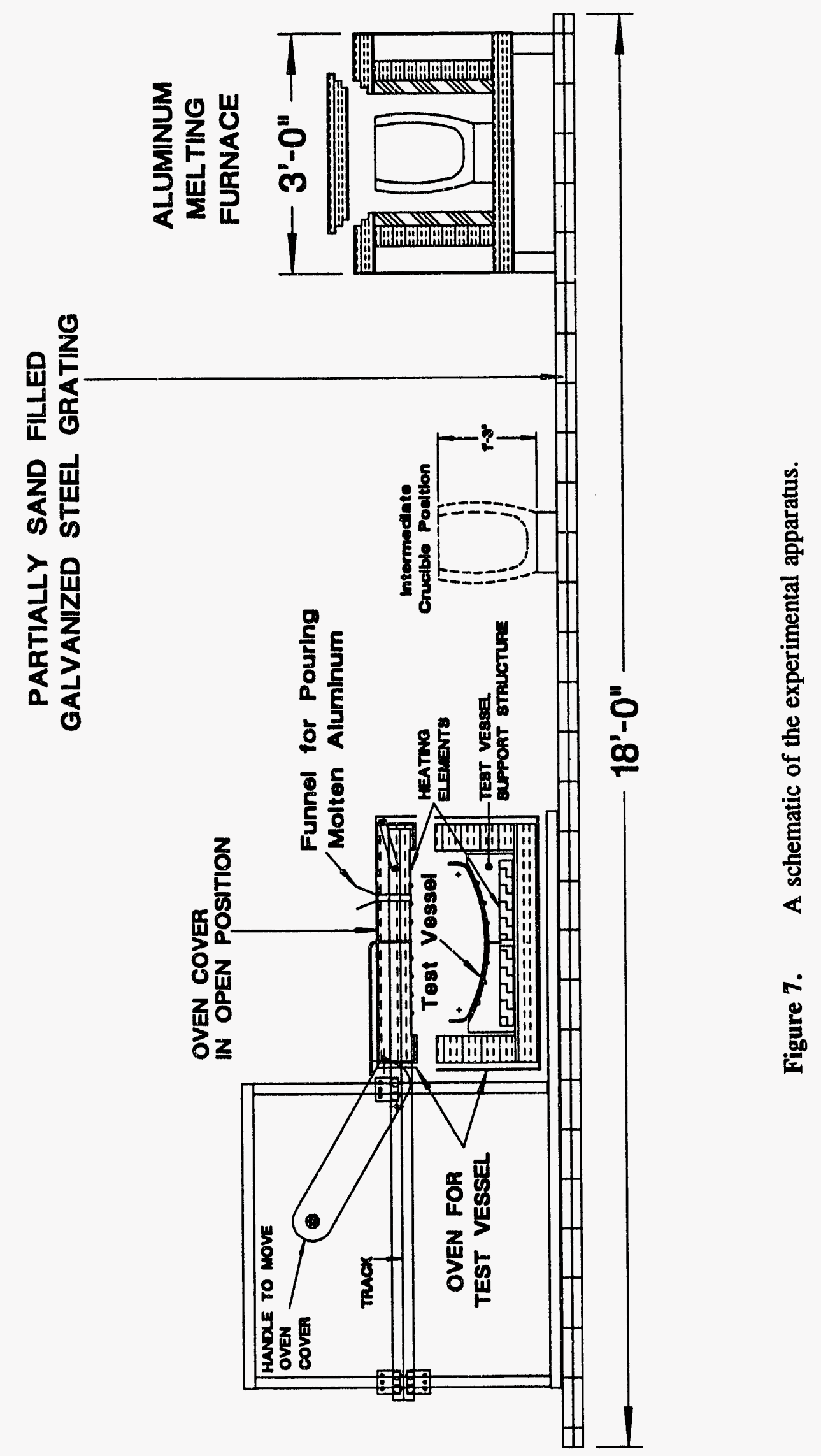


on. Then, $25 \mathrm{~kg}$ of solid aluminum pellets ${ }^{7}$ are poured in the crucible and the aluminum melting furnace is turned on. After a suitable time interval, the argon gas supply and the electric power to the "test vessel oven" are turned on. When the melt (molten aluminum) in the crucible and the test vessel reach the desired test temperature, the crucible is removed from the furnace and the melt is poured into the test vessel via the funnel in the top cover of the oven (see Figure 7). The data acquisition program, which records the vessel wall temperature and the melt temperature in the molten pool during the experiment, is started just prior to the instant that the melt is poured into the test vessel. The locations of these thermocouples are shown in Figure 8. After a predetermined amount of time, samples of melt from various locations in the molten pool are withdrawn and the experiment is terminated. The termination of the experiment involves lifting the test vessel from the oven and draining the melt from it. Following the experiment, the test vessel is cleaned of all the adhering melt by means of the $\mathrm{NaOH}$ treatment, and the vessel wall thickness is again measured at various locations.

\subsection{Experimental Parameters}

As mentioned in Section 1.4, only two "molten pool dissolution experiments" have been performed to date 8 . For these initial experiments, no forced convective motion was set up in the molten aluminum pool. Therefore, in these tests, after the initial motion due to pouring the melt in the test vessel subsided, any convective motion set up in the molten pool would only have been due to the density gradients induced as a result of any concentration ${ }^{9}$ gradients within the molten pool.

The nominal value of the average melt temperature for the first test was $977^{\circ} \mathrm{C}$. The duration of the experiment, which is the time during which the molten aluminum is held in the test vessel, was 2100 seconds for this experiment. For the second experiment, the average melt temperature during the test was $1007^{\circ} \mathrm{C}$, and the duration of the experiment was 2479 seconds. In addition, for the second test the initial (the instant the melt is poured into the test vessel) surface condition of the test vessel was different from that of the first test. It was heavily oxidized due to air infiltration into the test vessel oven during the heat-up phase. Thus a comparison of the results from the two tests shows the effect of the oxide film on the dissolution process at these temperatures.

\footnotetext{
${ }^{7}$ ALCOA, $99.9 \%$ Aluminum

${ }^{8}$ Since the experimental program was terminated long before its planned conclusion, no further experiments are scheduled to be performed.

${ }^{9}$ Concentration of stainless steel in the melt. As the stainless steel from the vessel wall gets dissolved in the molten aluminum, the density of the meit (aluminum-stainless steel solution) increases.
} 

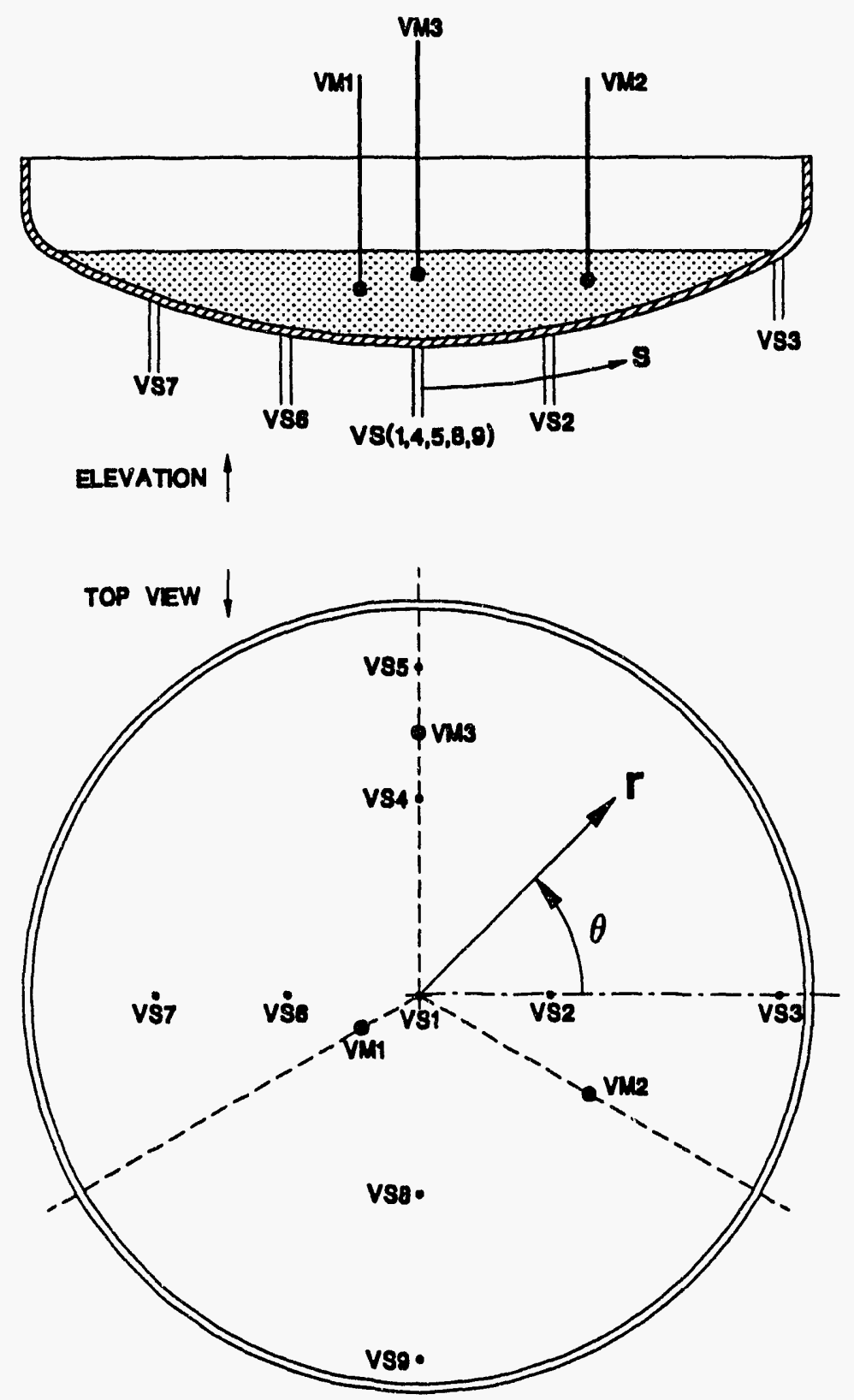

Intrinsic Vessel Wall Thermocouple Locations

\begin{tabular}{|c|c|c|}
\hline TC & $\mathbf{r}$ (in) & $\theta$ (deg) \\
\hline VS1 & 0 & - \\
\hline VS2 & 4 & 0 \\
\hline VS3 & 11 & 0 \\
\hline VS4 & 6 & 90 \\
\hline VS5 & 10 & 90 \\
\hline VS6 & 4 & 180 \\
\hline VS7 & 8 & 180 \\
\hline VS8 & 6 & 270 \\
\hline VS9 & 11 & 270 \\
\hline
\end{tabular}

Melt Thermocouple Locations

\begin{tabular}{|c|c|c|c|}
\hline TC & $\mathbf{r}$ (in) & $\theta$ (deg) & $\mathbf{h}$ (in) \\
\hline VM1 & 2 & 210 & 1.4 \\
\hline VM2 & 6 & 330 & 1.0 \\
\hline VM3 & 8 & 90 & 0.6 \\
\hline
\end{tabular}

$h$ is the distance from the TC to the vessel bottom at the given $r$ and $\theta$ (local elevation of TC from the melt-vessel wall interface).

Figure 8. A Schematic of the Locations of the Intrinsic Thermocouples on the Test Vessel Wall and the Thermocouples Within the Molten Pool. 


\section{RESULTS}

\subsection{Results From the First Molten Pool Dissolution Experiment, Run No. MPD-01}

\subsubsection{The Melt and Test Vessel Temperature History}

As shown in Figure 7, in order to pour the molten aluminum in the test vessel, the crucible containing the melt must be removed from the furnace and transported to the location of the test vessel. During this brief time interval, the crucible, and hence the molten aluminum in the crucible, loses heat to surroundings. Therefore, in order to compensate for this heat loss, the melt must be heated in the furnace to a higher temperature than the target test temperature. However, for this test the actual observed heat loss from the crucible was found to be significantly smaller than the calculated heat loss. As a result, the temperature of the melt delivered to the test vessel was higher than the initial vessel temperature. A plot of the temperature traces from two melt thermocouples (VM1, VM3) and two vessel wall thermocouples (VS1, VS8) is shown in Figure 9. The locations of these thermocouples are shown in Figure 8. The average melt temperature for this test was $977^{\circ} \mathrm{C}$, and the melt remained in the test vessel for 35 minutes. Since it took 26 seconds to deliver the melt into the vessel, and it required 23 seconds to drain the meit from the vessel at the end of the experiment, the uncertainty in the time interval of the test was \pm 25 seconds.

\subsubsection{Visual Post-Test Examination of the test Vessel}

Following the experiment, the adhering frozen "melt ${ }^{10 n}$ on the inside surface of the test vessel was removed in two stages. First, most of the frozen melt was removed by locally heating a small portion of the frozen material under the cover of argon gas, and simultaneously using mechanical means to scrape off the melt. Next, the adhering aluminum was dissolved by treating the vessel with an aqueous solution of $\mathrm{NaOH}$ (20\% by weight).

A post-test photograph of the test vessel following the $\mathrm{NaOH}$ treatment is shown in Figure 10. At the top of this figure, please note that a small wedge shaped section of the test vessel has been sliced off from the vessel. This was done prior to cleaning the vessel so as to preserve samples of frozen material adhering to the test vessel. As can be seen, the dissolution appears to be severely non-uniform. Visual inspection of the test vessel shows negligible dissolution in the bottom central portion of the vessel. This seems to be due to the fact that the concentration of stainless steel in the melt in this region was very high. On the other hand, as can be seen from the top right hand corners of Figure 10 and Figure 11, the dissolution is observed ${ }^{11}$ to be very high in the outer regions of the vessel (near the molten pool edge). However, it is noted that even in these outer regions, there are zones which show very little dissolution, for example, zone B in Figure 10. In addition, it is observed that in regions of large dissolution the test vessel surface is wavy, thus indicating locally

\footnotetext{
${ }^{10}$ The term melt is used here to denote the aluminum-stainless steel solution that remained inside the test vessel at the end of the experiment and solidified on the inside surface of the test vessel.

11 Because of optical illusion, the depressions in the photographs may sometimes appear to be elevated regions and the picture may appear to be confusing. If this happens, it may be necessary to change the orientation of paper and view the picture several times to see the depressions correctly.
} 


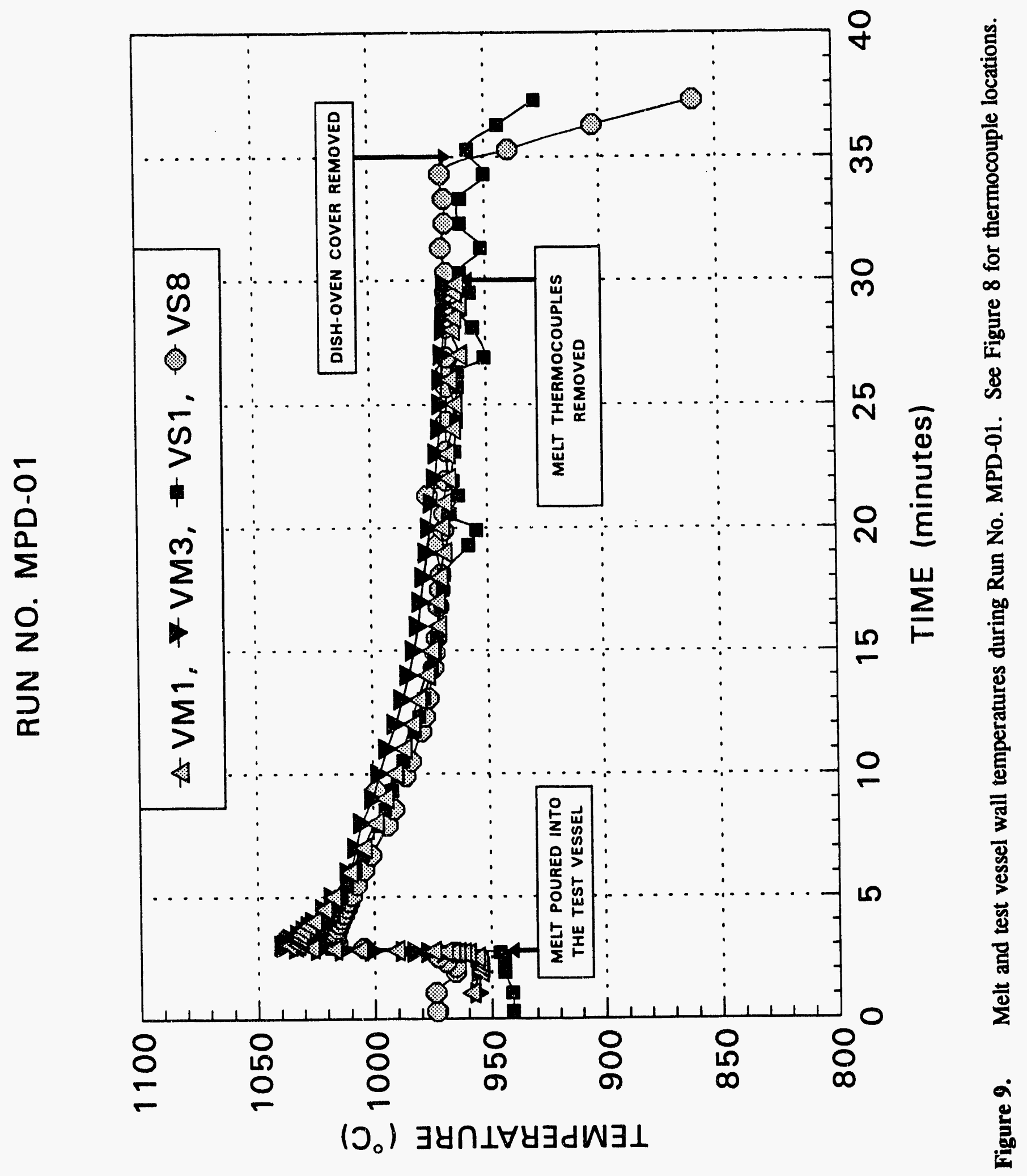




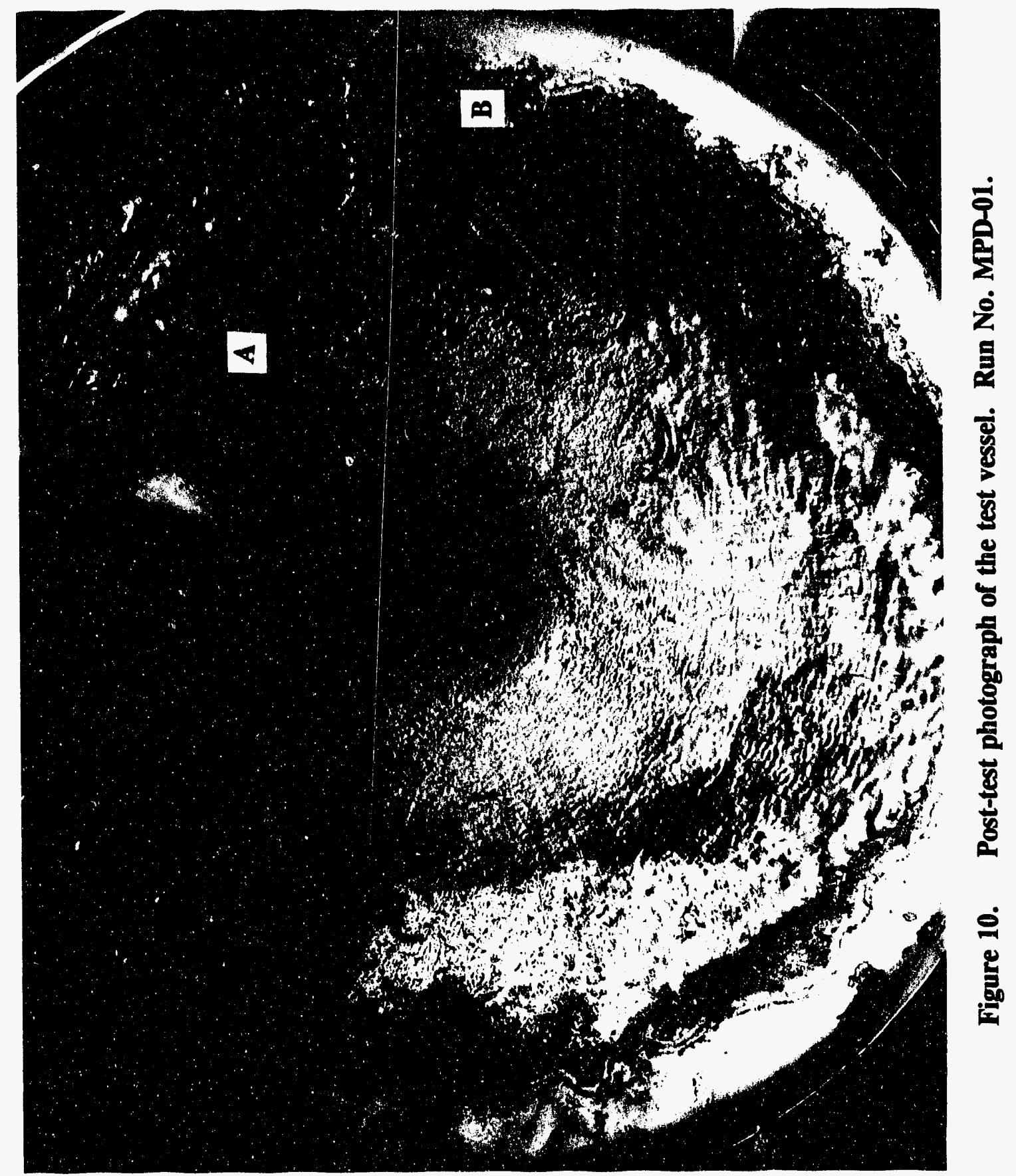




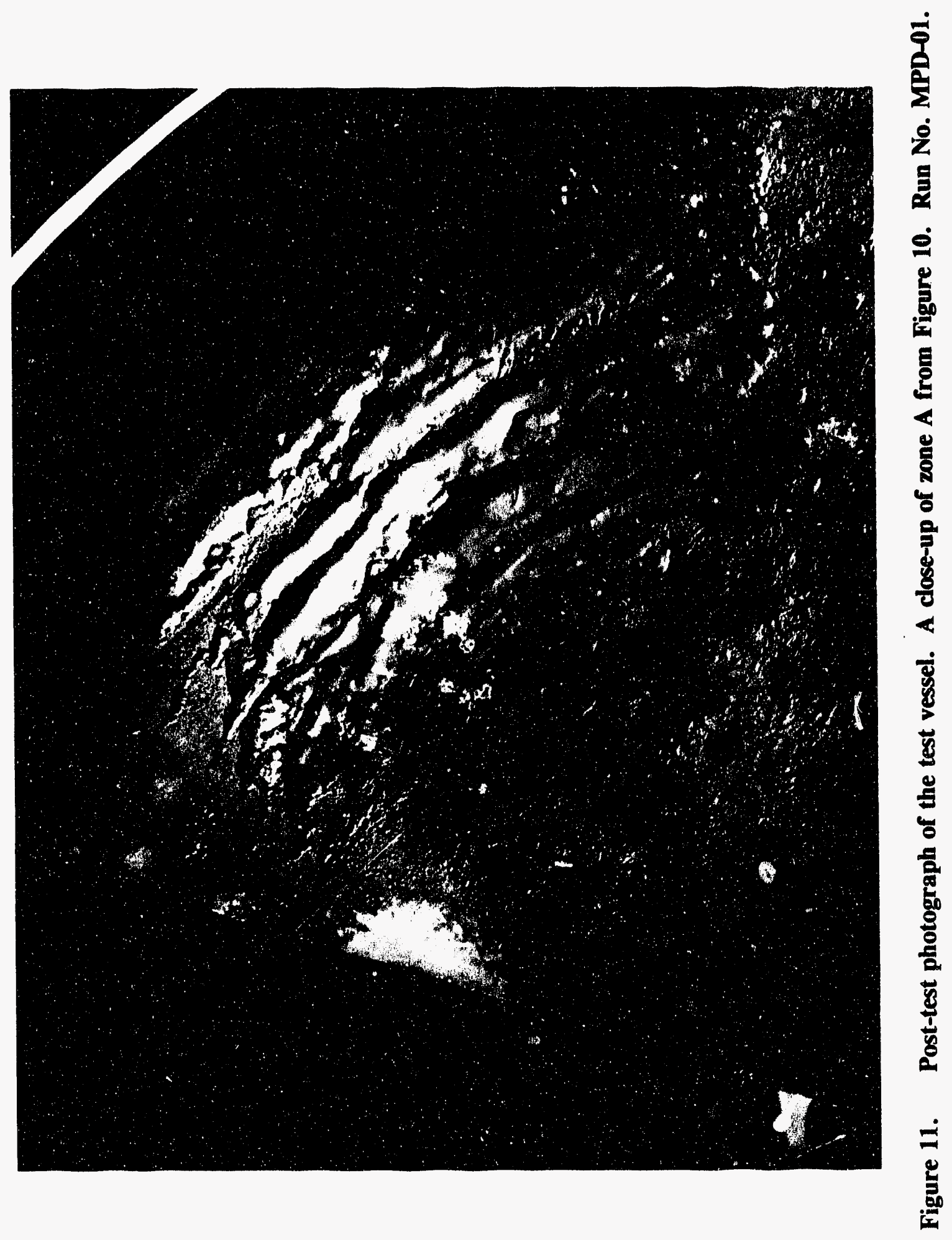


non-uniform dissolution, and suggesting a possible hydrodynamic origin for this phenomenon. This can be seen from Figure 11, which is a close-up of zone A in Figure 10. As indicated in Section 3.4, since stainless steel is heavier than aluminum, the dissolution of stainless steel in the melt can lead to "dissolution induced natural convective motion" in the melt. An important point that should be noted is that even in regions of negligible dissolution, for example the zone B in Figure 10, evidence of attack by molten aluminum on the stainless steel surface is observed. The vessel surface in these regions appears to have microscopic pits. This is discussed further in Section 4.1.5, which presents the results of the Scanning Electron Microscopy.

\subsubsection{The Linear Dissolution Depth Measurements}

As shown in Figure 8, let $s$ be the longitudinal coordinate from the test vessel center as measured along the bottom surface of the test vessel, and $\theta$ be the cylindrical coordinate as measured in the horizontal plaic. Then, $s$ and $\theta$ are sufficient to locate every pcint on the outside surface of the test vessel. If $t$ is the initial (pre-test) thickness of the test vessei at any point, then, as indicated in Figure 12, the difference between the initial and final (post-test) thickness is defined as the linear dissolution depth, $\mathrm{d}$, at that point.

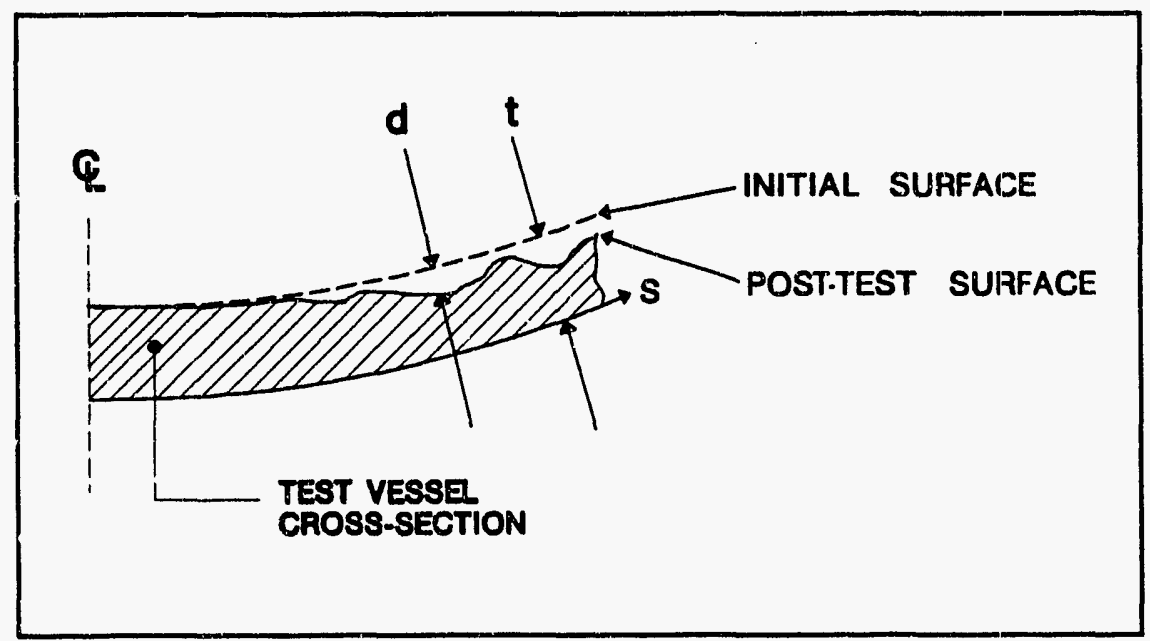

Figure 12. The definition sketch for the linear dissolution depth, $d$.

Prior to perf Jrming the experiment, the initial wall thickness of the test vessel was measured at 94 locations. These measurements are presented in Figure 13. Multiple data points corresponding to a single value of $s$ correspond to different $\theta$ locations on the test vessel surface. The measured wall thickness was in the range $0.175^{\prime \prime} \leq t \leq 0.1825^{\prime \prime}$, with an average value of 0.1789 inches and a standard deviation of 0.00215 inches. After the experiment, the test vessel wall thickness was measured again at these and 101 other locations. For the latter 101 locations, the initial vessel wall thickness was estimated by interpolating from the data of Figure 13. For this purpose, the data in Figure 13 was re-plotted as a function of $s$ with $\theta$ as a parameter.

The measurements for the local dissolution depth, $\mathrm{d}$, as a function of the coordinate $\mathrm{s}$ are 


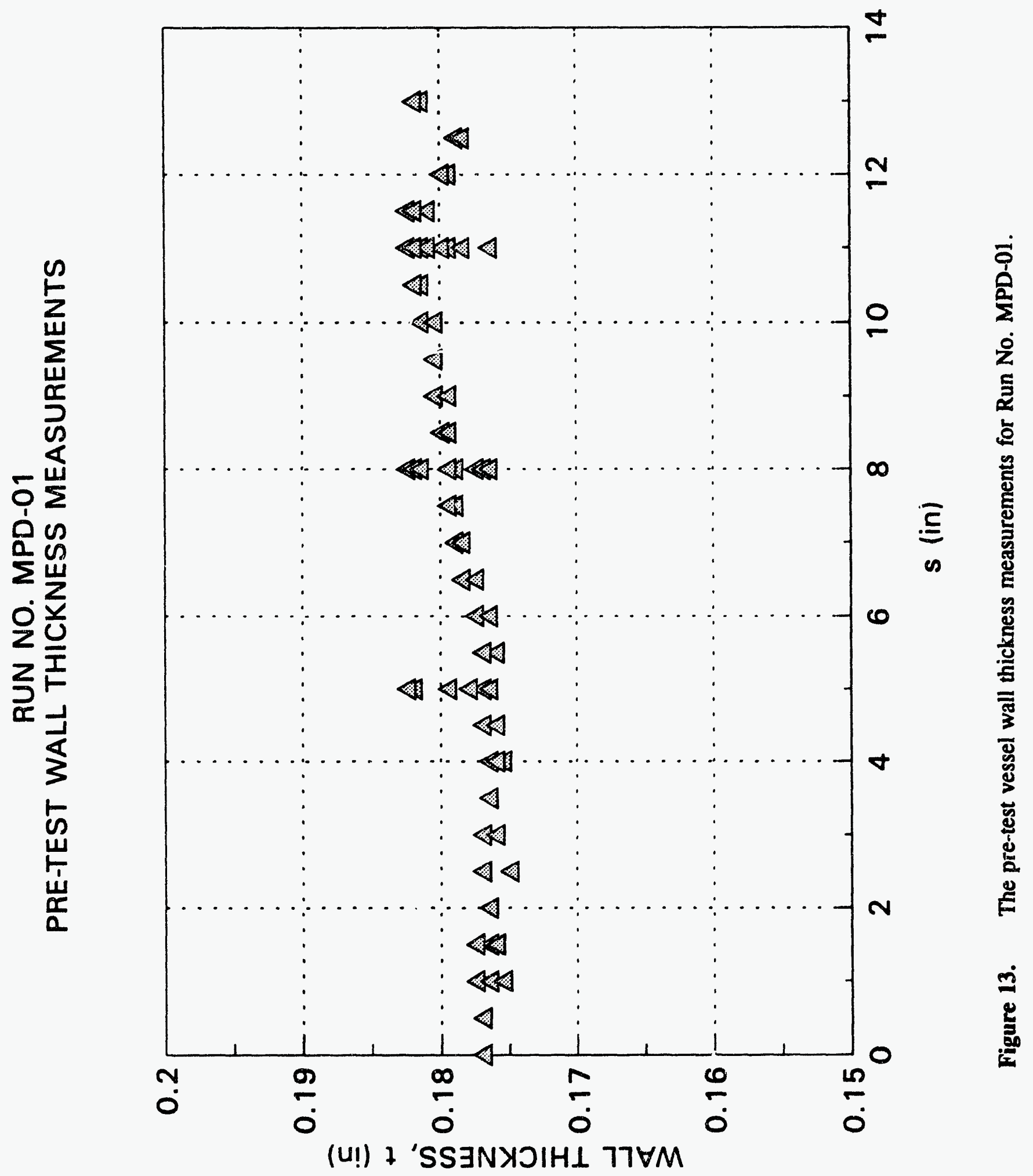


presented in Figure 14. Different data points for a single value of $s$ correspond to different values of $\theta$, and hence represent separate points on the test vessel surface. The left ordinate shows the data for $d$ in inches. Since the present experiment is by design an integral transient ${ }^{12}$ experiment, the local linear dissolution rate is a function of time. Although the instantaneous local dissolution rate could not be measured during this experiment, the time averaged local linear dissolution could easily be calculated. As indicated in Section 1.2, the linear dissolution rate is simply defined as the average dissolution depth per unit time on the sample surface, and thus equals $d / \tau$, where $\tau$ is the duration of the experiment. The right ordinate in Figure 14 shows the experimental data in units of the linear dissolution rate. As can be seen, the maximum measured value of the dissolution rate for this test was $5.05 \mathrm{~mm} / \mathrm{hr}$. On the other hand, Greene's [3] correlation for a static stainless steel sample held vertical in molten aluminum at $977^{\circ} \mathrm{C}$ yields an average dissolution rate of $1.42 \mathrm{~mm} / \mathrm{hr}$, which is about 3.5 times lower than the measured peak value. However, he has reported local erosion rates exceeding the average erosion by as much as a factor of four in his experiments.

Several observations can be made from the data in Figure 14. The dissolution in the bottom central portion ( $s \leq 6$ inches ) of the test vessel is small. In addition, the dissolution depth increases with increasing $s$ as one travels from the bottom center of the test vessel $(s=0)$ to the edge of the molten pool. Furthermore, the maximum local dissolution is observed near the edge of the molten pool. There are two reasons for this. First, as the stainless steel from the test vessel surface is dissolved in the molten aluminum, the local density of the melt increases, and this dense solution travels downwards along the inside surface of the vessel. While this concentration gradient induced natural convective motion causes the concentration of stainless steel to increase at the vessel bottom, it also causes the melt near the pool edge to be replaced by the melt from outside the concentration boundary layer. Thus the concentration of stainless steel in the melt near the pool edge is always lower than the concentration at the vessel bottom. Secondly, since the induced convective velocity is expected to be highest near the pool edge ${ }^{13}$, the mass transfer coefficient would be the highest near the pool edge. Therefore, the expected dissolution rate is the greatest near the pool edge. However, it should be noted that the local dissolution rate is highly non-uniform, and even near the pool edge there are regions of insignificant dissolution. In fact, for $10^{\prime \prime} \leq s \leq 11.75^{\prime \prime}$, Figure 14 shows the dissolution to be either negligible or very large.

As shown in Figure 14, we measured small negative values of dissolution depth at some locations. In other words, the post-test thickness at these points was measured to be greater than the pre-test thickness. We also note that this measured deviation was much larger than the measurement precision. Fo. those regions of the test vessel that were not exposed to molten aluminum, the largest measured negative value of the dissolution depth was measured at $s=13^{\prime \prime}$, and $\theta=225^{\circ}$. At this location $\mathrm{d}=-0.0015^{n}$. This is thought to be due to the thin layer of oxide film formed on both sides of the vessel when the hot vessel was taken out of the inerted atmosphere and exposed to air at the end of the experiment. On the other hand, for regions exposed to molten aluminum, the

\footnotetext{
${ }^{12}$ Transient with respect to concentration of steel in the molten pool, which is initially zero and thereafter a function of time and space.

${ }^{13}$ The inclination of the vessel surface to the vertical is the smallest at the pool edge. If the dissolution rate is the highest near the pool edge due to the low free stream concentration of steel in the melt, then, the driving force for natural convection would also be highest near the pool edge. Furthermore, the center of the vessel bottom is a stagnation point.
} 


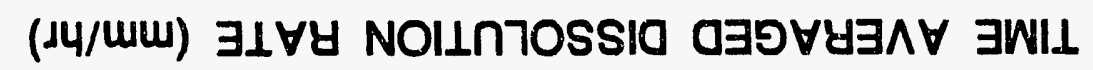

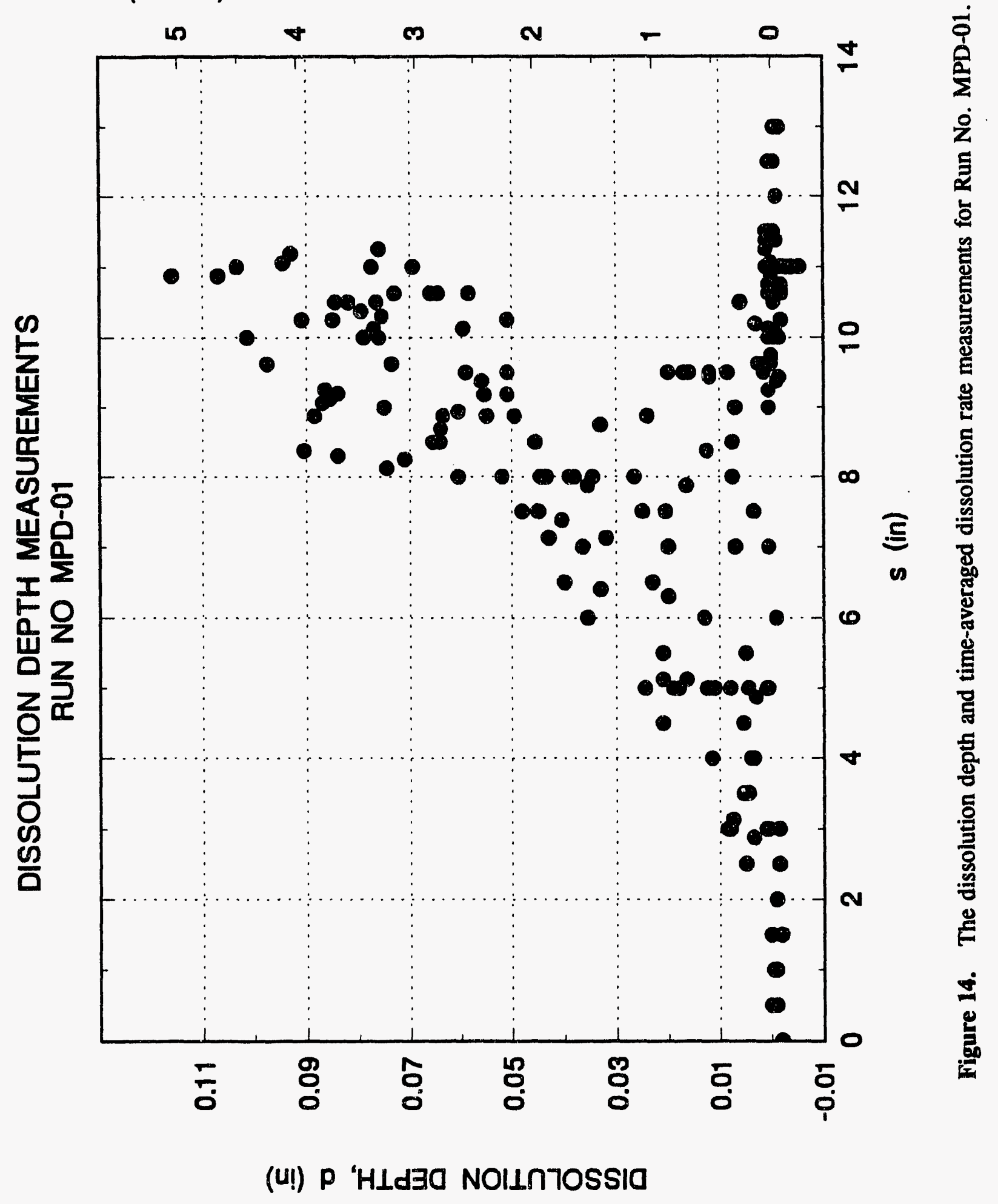


largest measured negative value of the dissolution depth was measured at $s=11^{\prime \prime}$, and $\theta=67.5^{\circ}$. At this location $d=-0.0055^{\prime \prime}$. Since only the outside surface of the test vessel was available for oxidation in this case, this rather large negative value cannot be explained on the basis of the oxidation of the test vessel. Furthermore, at this location the vessel surface shows indications of attack by molten aluminum. It should be noted that for this location the pre-test vessel wall thickness measurements were available and did not have to be interpolated.

To further illustrate the severe local non-uniformity of the dissolution process, some of the data for the dissolution depth is re-plotted in Figure 15 with $\theta$ as a parameter. The data points are joined with a straight line in this figure only for ease of identification; it is not implied that the intermediate data points would lie on the straight line segments. Finally, a dissolution depth map is presented in Figure 16. In this figure, $x=s \cdot \cos (\theta)$ and $y=s \cdot \sin (\theta)$. Thus, the $x-y$ plane in this figure represents a disc that would be formed if the test vessel were flattened (and simultaneously stretched in the circumfrential direction) into a disc of diameter equal to $2 \mathrm{~s}_{\max }$, where $s_{\max }$ is the maximum value of the $s$ coordinate. For this figure the data points were divided into three domains depending upon the value of the dissolution depth: a region of negligible dissolution ( $d<0.01^{\prime \prime}$ ), a region of moderate dissolution $\left(0.01^{\prime \prime}<d<0.05^{\prime \prime}\right.$ ), and a region of high dissolution $\left(d>0.05^{\prime \prime}\right)$. The data points in different domains are represented by separate symbols. The highly non-uniform nature of the dissolution process, and the fact that the dissolution is very small in the central region of the test vessel is clear from this figure. 
DISSOLUTION DEPTH MEASUREMENTS

RUN NO MPD-01

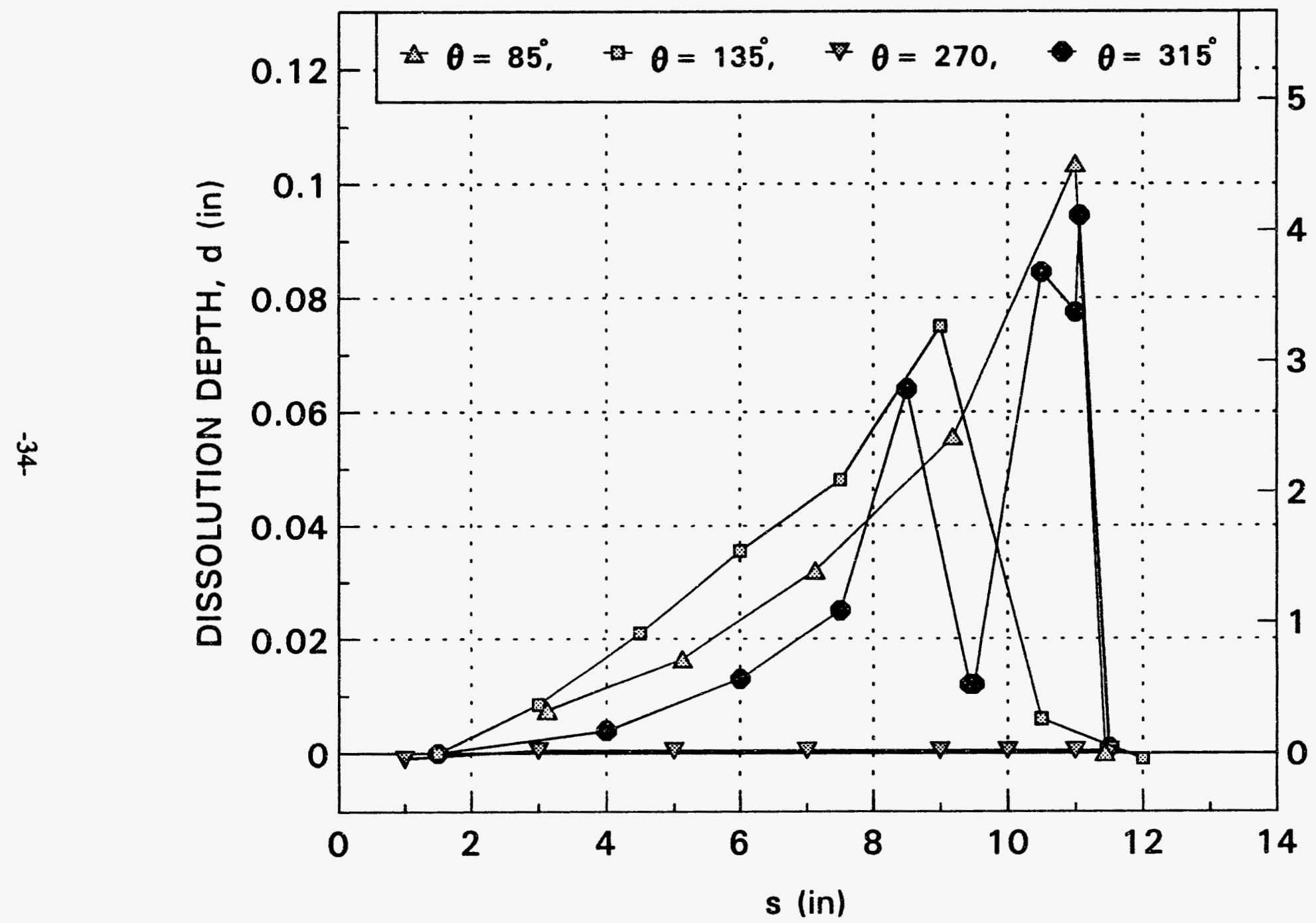

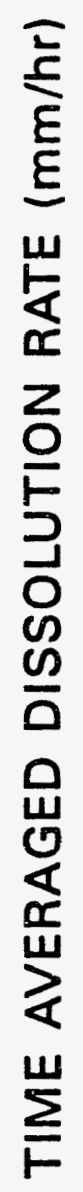

Figure 15. Selected dissolution depth measurements with $\theta$ as a parameter. Run No. MPD-01. 
DISSOLUTION DEPTH MAP FOR RUN NO. MPD-01

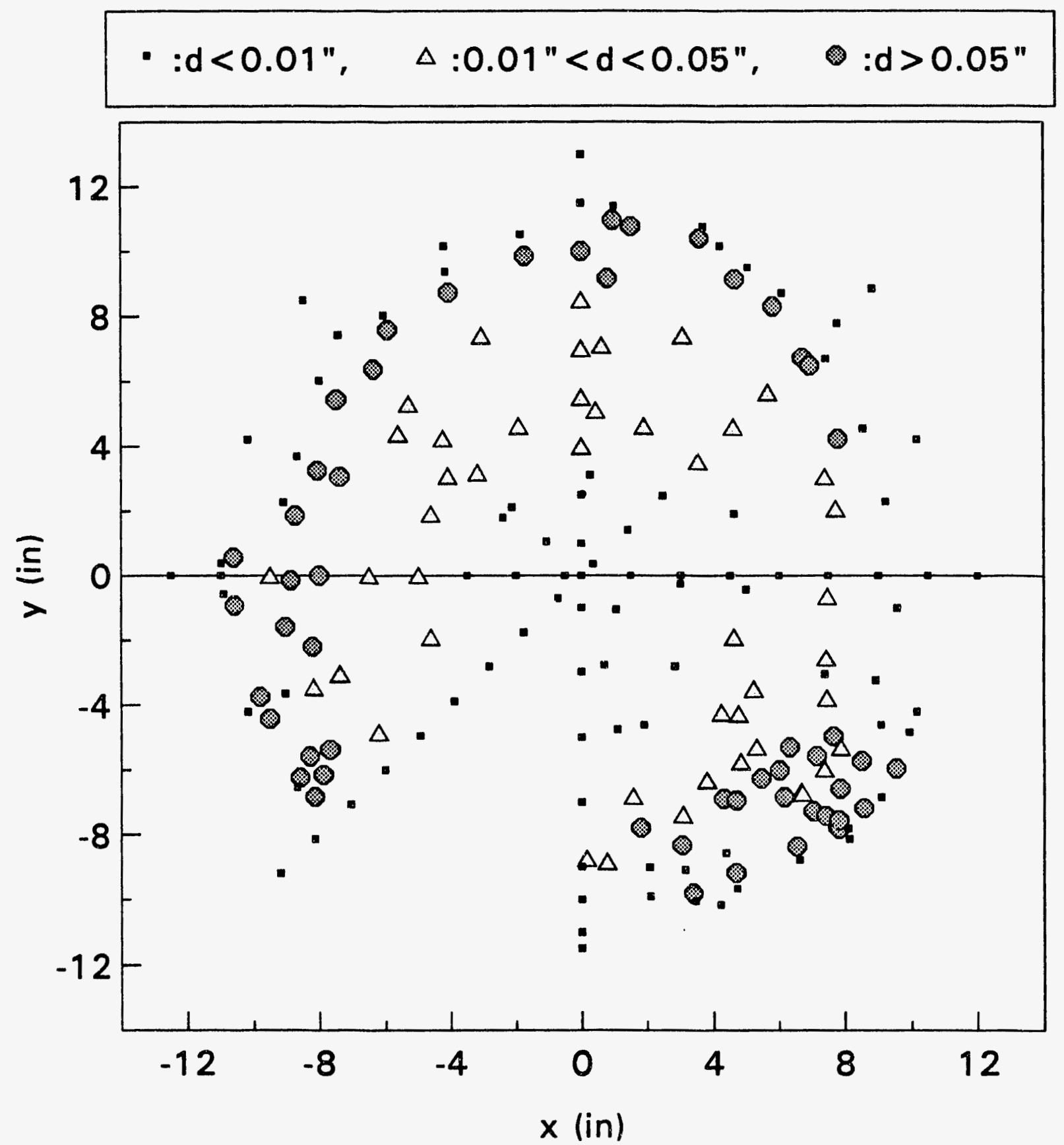

Figure 16. The dissolution depth map for Run No. MPD-01. $x=s \cdot \cos (\theta), y=s . \sin (\theta)$ 


\subsubsection{Concentration Measurements}

Although the experimental procedure called for withdrawing ten melt samples from different locations within the molten pool, only one melt sample (Sample 5) was collected during the experiment due to operational difficulties during this first experiment. Other samples available for concentration measurements were: the "well-mixed" sample from the melt drained from the test vessel at the end of the experiment, and the frozen post-test material removed from the bottom of the test vessel. These samples, and a pure aluminum sample from the aluminum pellets used for the experiment, were analyzed using the Inductively Coupled Plasma Atomic Emission Spectrometry (ICP-AES) ${ }^{14}$. In preparation for this analysis, known masses of these samples were digested in $\mathrm{HNO}_{3}$, and diluted with distilled water. The results of the analysis are presented in Table 2 . The

Table 2. The Concentration Measurements for Run No. MPD-01.

\begin{tabular}{|c|c|c|c|c|c|c|}
\hline \multirow{2}{*}{\multicolumn{2}{|c|}{ Sample Description }} & \multirow{2}{*}{$\begin{array}{c}\text { Mass of } \\
\text { Sample } \\
\text { (g) }\end{array}$} & \multicolumn{4}{|c|}{ Measured Mass Fraction, $c_{j}^{*}$} \\
\hline & & & Al & Fe & $\mathbf{C r}$ & $\mathbf{N i}$ \\
\hline A: & "Pure" Aluminum & 1.71982 & 0.999 & 0.00041 & 0.00034 & 0.00023 \\
\hline B: & $\begin{array}{l}\text { Well-mixed sample from melt } \\
\text { drained from the test vessel }\end{array}$ & 1.50302 & 0.9639 & 0.02706 & 0.00656 & 0.0025 \\
\hline C: & $\begin{array}{l}\text { Frozen post-test material from } \\
\text { the test vessel center }\end{array}$ & 2.89744 & 0.8121 & 0.1488 & 0.02495 & 0.0141 \\
\hline D: & Sample 5 from molten pool & 0.18232 & 0.9975 & 0.00166 & 0.0005 & 0.0004 \\
\hline
\end{tabular}

$\mathrm{j}=\mathrm{Al}$, or $\mathrm{Fe}$, or $\mathrm{Cr}$, or $\mathrm{Ni}$.

mass fraction of each component in Table 2 is simply the ratio of the mass of that component detected to the total observed mass of aluminum, iron, chromium, and nickel.

At the end of the experiment, as a part of the experimental procedure, the melt from the test vessel was drained into a crucible. This melt was well mixed and cast into ingots. The sample designated as B in Table 2, is a small sample form one of these ingots. Therefore, the concentration of iron in this sample gives a measure of the average concentration in the molten pool at the end of the experiment. However, since not all of the melt was drained from the test vessel (a small fraction of the melt remained within the vessel), and because the concentration of iron in the melt that remained adhered to the test vessel (sample $C$ in Table 2) was found to be much higher, the measured concentration of iron in sample $B$ represents a lower bound on the average melt concentration. We also note that this measured average concentration of $2.7 \%$ iron is much smaller than the saturation concentration of iron in molten aluminum at the $977^{\circ} \mathrm{C}$ (the average temperature during the experiment), which is calculated to be $17.6 \%$ from Equation (7). On the other hand, the concentration of iron in the frozen melt sample at the test vessel center (sarrple $C$ in Table 2) was

14"Liberty Model 100", manufactured by Varian (Australia), was used for the analysis. 
found to $14.9 \%$, which is very close to the saturation concentration of iron in molten aluminum. The last sample in Table 2 (designated, $D$ ) was removed from the molten pool (via suction through a small quartz tube) at the following location: radius, $\mathrm{r}=10$ inches from test vessel center, and $1 / 4$ inch above the test vessel surface at that location. This location was approximately 1.5 inches from the edge of the molten pool and roughly $1 / 2$ inch below the free surface of the molten pool. As can be seen, the concentration of iron at this location is very low, and equal to $0.166 \%$. This, and the concentration measurements from samples $\mathbf{B}$ and $\mathbf{C}$ clearly show that molten pool was highly stratified, with most of the dissolved stainless steel settling to the bottom of the vessel. Furthermore, the concentration of iron in the melt near the test vessel center is very close to the saturation concentration. This explains the observed small dissolution rates experienced by the bottom central portion of the test vessel.

\subsubsection{The Scanning Electron Microscopy (SEM) Measurements}

Following the completion of the post-test vessel wall thickness measurements, small samples of the test vessel were cut, mounted in holders, and polished along the vessel cross-section to a finish of 0.3 microns. It should be noted that since the vessel had been treated with $\mathrm{NaOH}$ to remove any adhering aluminum on the inside surface of the vessel, there were no macroscopically visible films of aluminum on these samples. Figure 17 shows a scanning electron microscope (SEM) image ${ }^{15}$ of one of these samples. Two photographs have been butted together to yield a spatially continuous field of view. In this figure, the distance between the top and bottom edge at any position is the thickness of the vessel wall at that location. The two circular rings on the right hand side of this picture are a part of the sample holder and should be disregarded. The interpretation of the three numbers along the left edge of this photograph is as follows: The first three digit number is the magnification, with the last digit being the exponent. Thus 100 in this figure corresponds to a magnification of $10 \times 10^{\circ}=10$. The second number is a counter for the photograph number, and the third and the last number indicates the length of the white line just below this number in microns. In this figure, therefore, $1000.0 \mathrm{u}$ indicates that the white line below this number is 1000 microns long. At location $\mathrm{X}$ in this figure, the post-test wall thickness is measured to be 0.0055 inches larger than the initial thickness at this point. Therefore, the macroscopically measured dissolution depth at this location was essentially zero. As can be seen from this figure, the dissolution at location $\mathrm{Y}$ is significant, and equal to 0.044 inches.

A closeup of the region $\mathrm{X}$ in Figure 17 is presented in Figure 18. At this point, as noted above, no macroscopic dissolution of the vessel wall was measured. The inside vessel surface is just above location 4 in this figure, and the outside vessel surface is well below location 2 . This figure also shows the Energy Dispersive X-Ray Spectroscopy (EDS) measurements at locations 1, 2, and 4. The fact that significantly large fraction of mass below the vessel surface is observed to consist of aluminum, shows that even though no dissolution was observed at this location, molten aluminum did indeed "attack" the stainless steel at this location. The labels on the right hand corners of the EDS measurements (e.g., 40-1, 40-2) correspond to the format: SEM photograph number - Location number. An enlarged view of the SEM image presented in Figure 18 is shown in Figure 19. The corresponding EDS measurements are shown in this and Figure 20. The evidence of stainless steel-

\footnotetext{
${ }^{15}$ Analysis performed by: R. L. Sabatini, Dept. of Applied Science, Brookhaven National Laboratory.
} 
aluminum intermetallic layers adjacent to the steel surface is clearly observable from the SEM image and the EDS measurements. While the composition at location 6 is the base metal (stainless steel), the fraction of aluminum mass keeps increasing as one moves from location 7 towards the free surface. Based upon the SEM image in Figure 19, the thickness of the intermetallic layer at this location is observed to vary from 30 to $50 \mu$. An enlargement of the region $Y$ in Figure 17, and the corresponding EDS measurements, are presented in Figure 21. This figure shows that at this location of significant dissolution, there is essentially no intermetallic layer adjacent to the steel surface. This result, and the results from Figure 19 should, however, not be used to draw the general conclusion that, at locations of large dissolution there is no intermetallic layer, and that at locations of negligible dissolution the intermetallic layer is thick. For example, the SEM and EDS analysis at another location ( $\mathrm{s}=11^{\prime \prime}, \theta=270^{\circ}$ ) of negligible dissolution showed virtually nonexistent intermetallic layer.

An SEM image of the cross-section of the vessel wall at the center of the test vessel is shown in Figure 22. Recall from Section 4.1.3 and Figure 14, that at this location no dissolution of the vessel wall was measured. In addition, the concentration measurements presented in Section 4.1.4 indicate that at the end of the experiment, molten aluminum at this location was saturated with dissolved stainless steel. The SEM image and the EDS measurements at locations 1 through 4 in this figure clearly show the presence of a relatively thick intermetallic layer. The thickness of this intermetallic layer is observed to vary from 60 to $85 \mu$. It is noted that these observed thicknesses of the intermetallic layers are much larger than those measured by Dybkov [2] at $700^{\circ} \mathrm{C}$.

Finally, an SEM image and the EDS measurements at a location of large dissolution are shown in Figure 23. The dissolution depth at this location was measured to be equal to 0.12 inches from an SEM image at this point. As can be seen from this figure, the intermetallic layer at this location is very thin, about $3.4 \mu$ deep.

Since the free stream concentration of stainless steel in the melt and the mass transfer coefficient on the vessel surface are expected to vary with the coordinate s, one would expect a variation in the dissolution rate with the coordinate $s$, as one travels from the vessel center towards the edge of the molten pool. However, no macroscopic phenomena are apparent that would explain the rather large variation in the dissolution rate with respect to the azimuthal coordinate, $\theta$, as seen from Figures 10 and 15. Clearly, the origin for this severe aximuthal non-uniformity in the dissolution process must be microscopic in nature. It is, however, quite likely that once the dissolution process has started, the dissolution induced convective motion within the melt may enhance the non-uniformity of dissolution. The rather limited SEM and EDS analysis performed and presented here is not sufficient to solve this problem. It is apparent that more experiments, possibly at higher temperatures, and a more detailed post-test microscopic metallurgical examinations of the test vessels are needed to resolve this puzzle. 

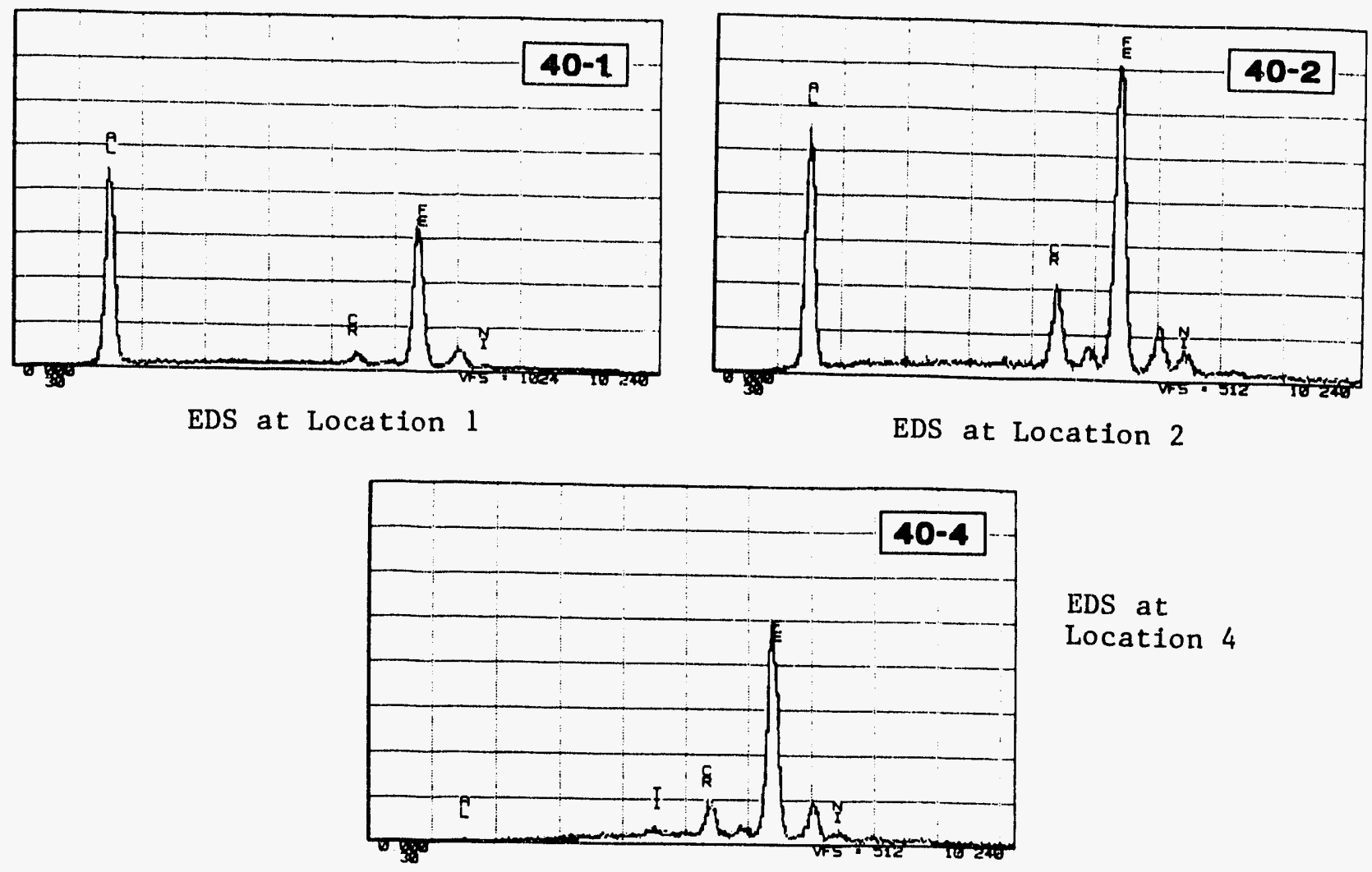

EDS at

Location 4

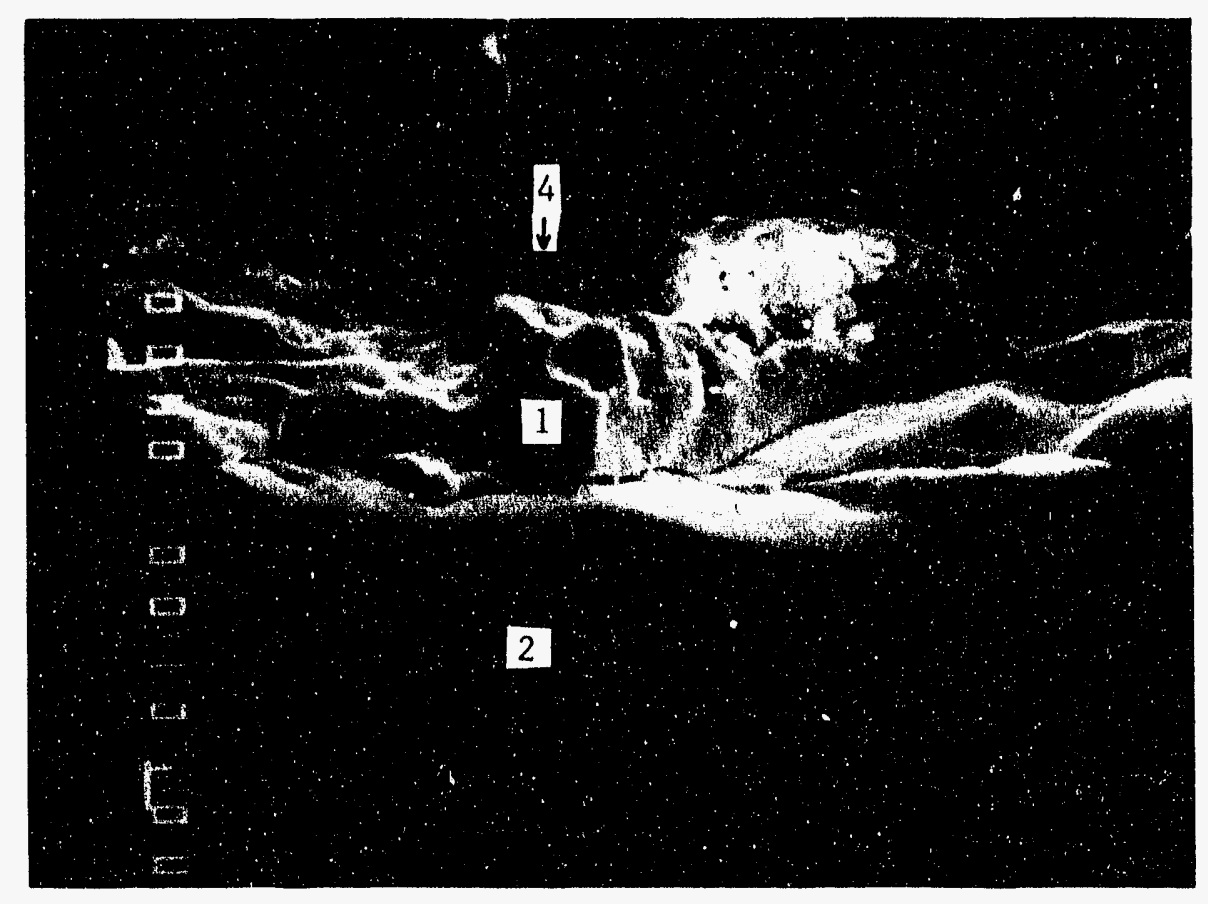

Figure 18. The SEM Image of the Cross-Section of the Test Vessel and Some EDS Measurements in the Neighborhood of $s=11^{\prime \prime}$ and $\theta=67.5^{\circ}$. A Magnified View of the Location $X$ in Figure 17. No Macroscopic Decrease in the Thickness of the Vessel Wall was Measured at This Point. 


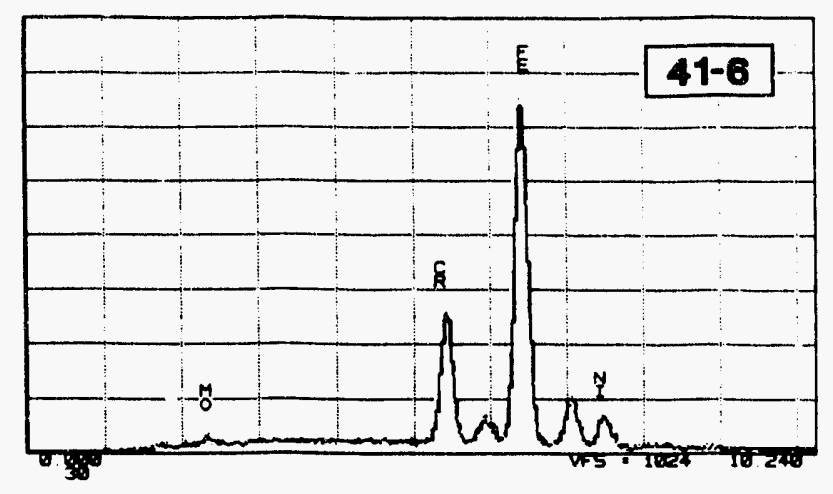

EDS at Location 6

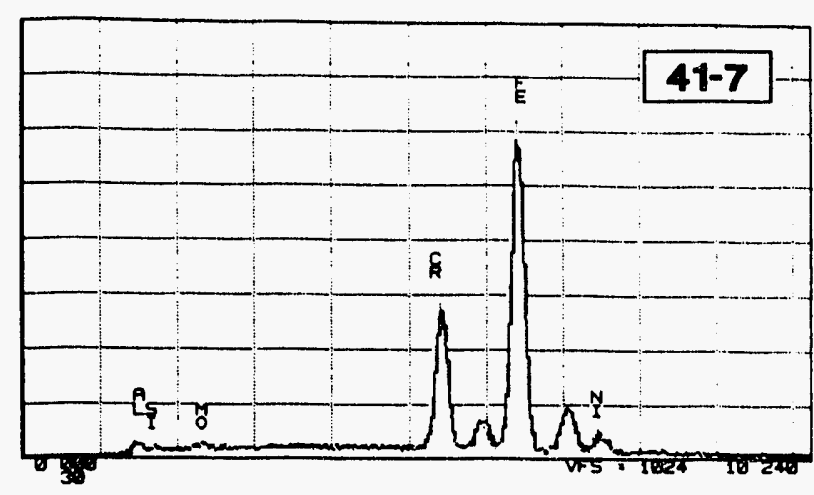

EDS at Location 7

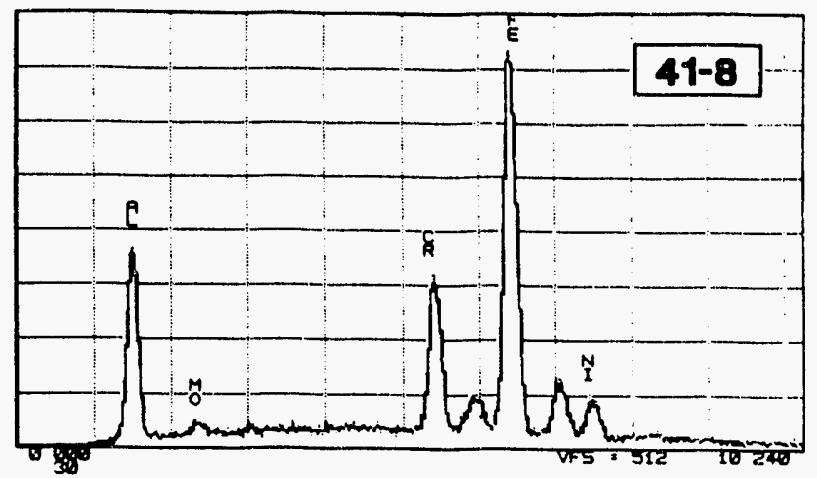

EDS at

Location 8

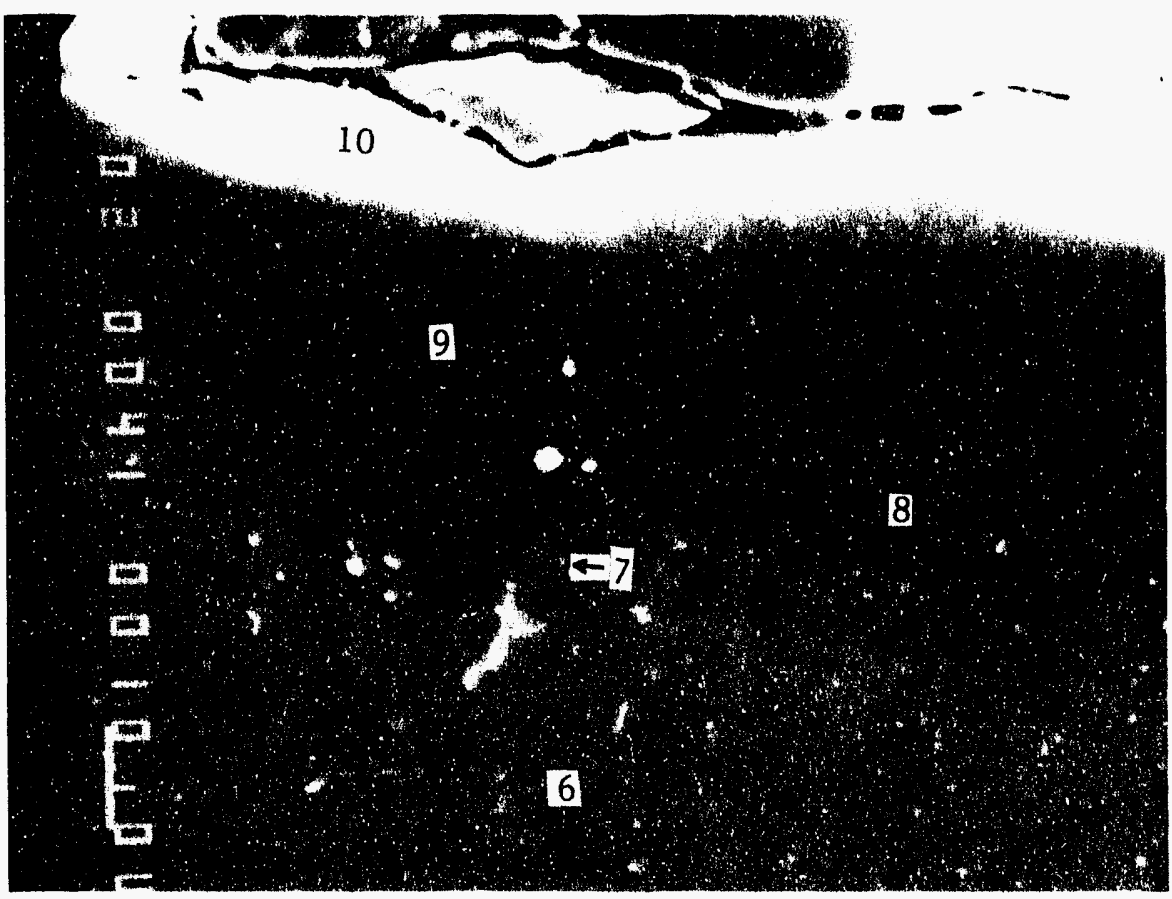

Figure 19. The SEM Image of the Cross-Section of the Test Vessel and Some EDS Measurements in the Neighborhood of $s=11^{\prime \prime}$ and $\theta=67.5^{\circ}$. An Enlargement of the View in Figure 18. 


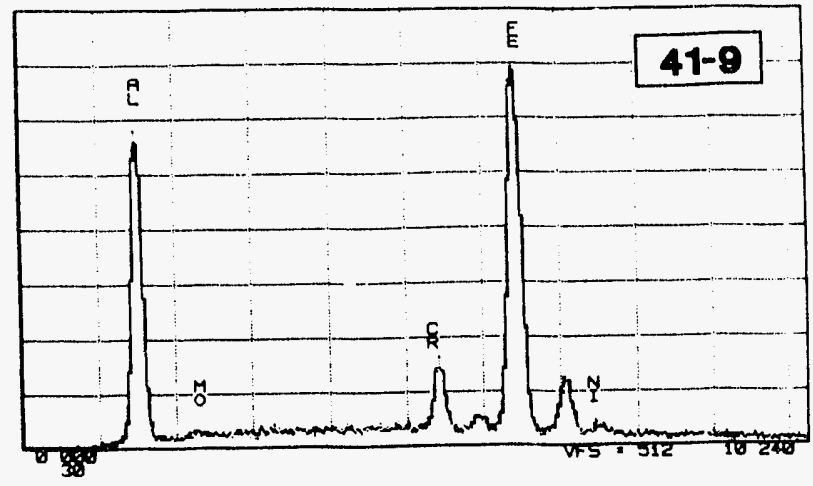

EDS at Location 9

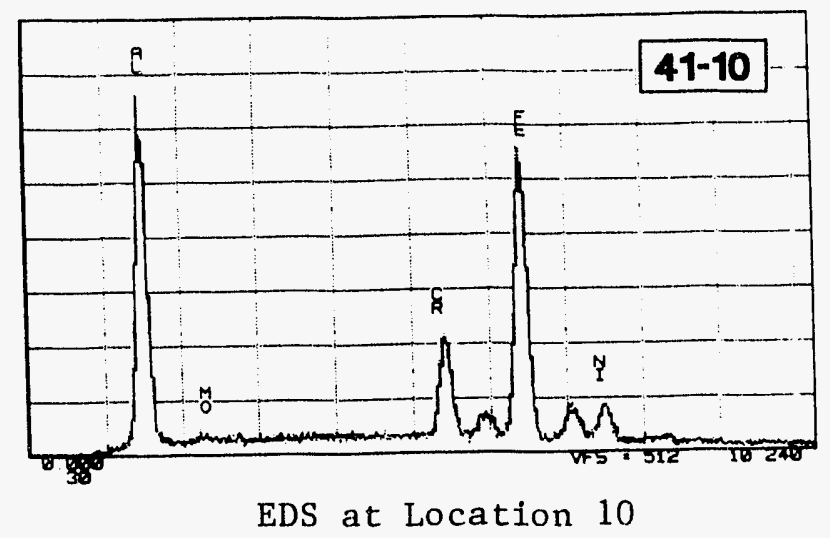

Figure 20. EDS Measurements at Locations 9 and 10 in Figure 19. 


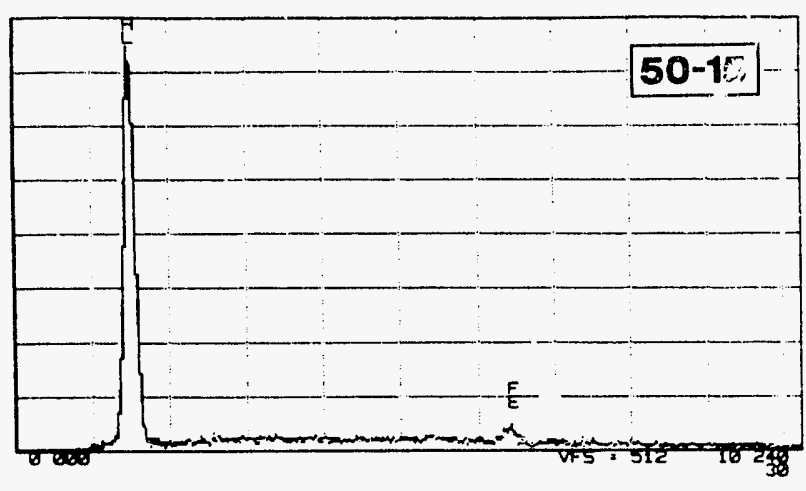

EDS at Location 15

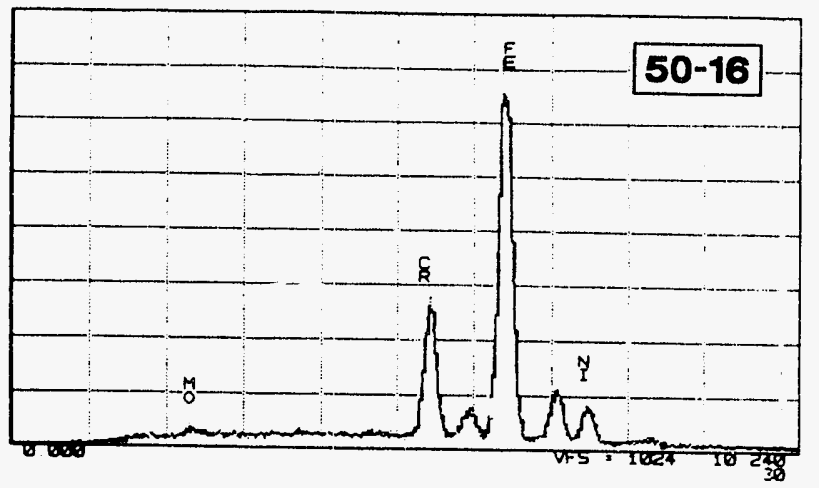

EDS at Location 16

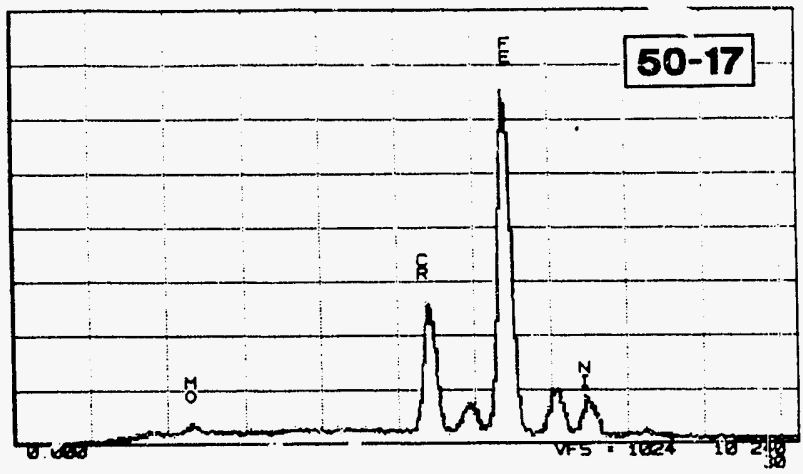

EDS at

Location 17

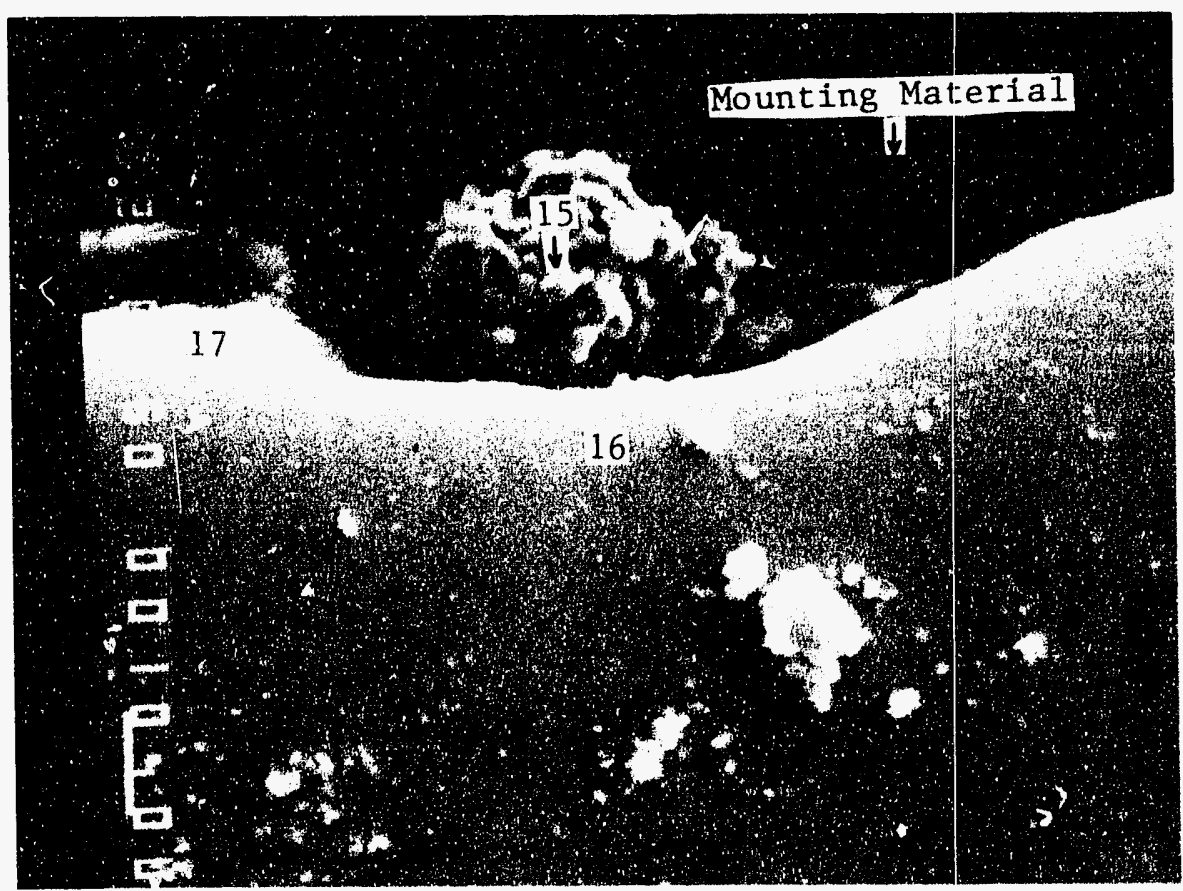

Figure 21. The SEM Image of the Cross-Section of the Test Vessel and Some EDS Measurements in the Neighborhood of $s=11^{\prime \prime}$ and $\theta=67.5^{\circ}$. A Magnified View of the Location $Y$ in Figure 17. The Dissolution Depth at This Point Was Measured to Be Equal to 0.044". 

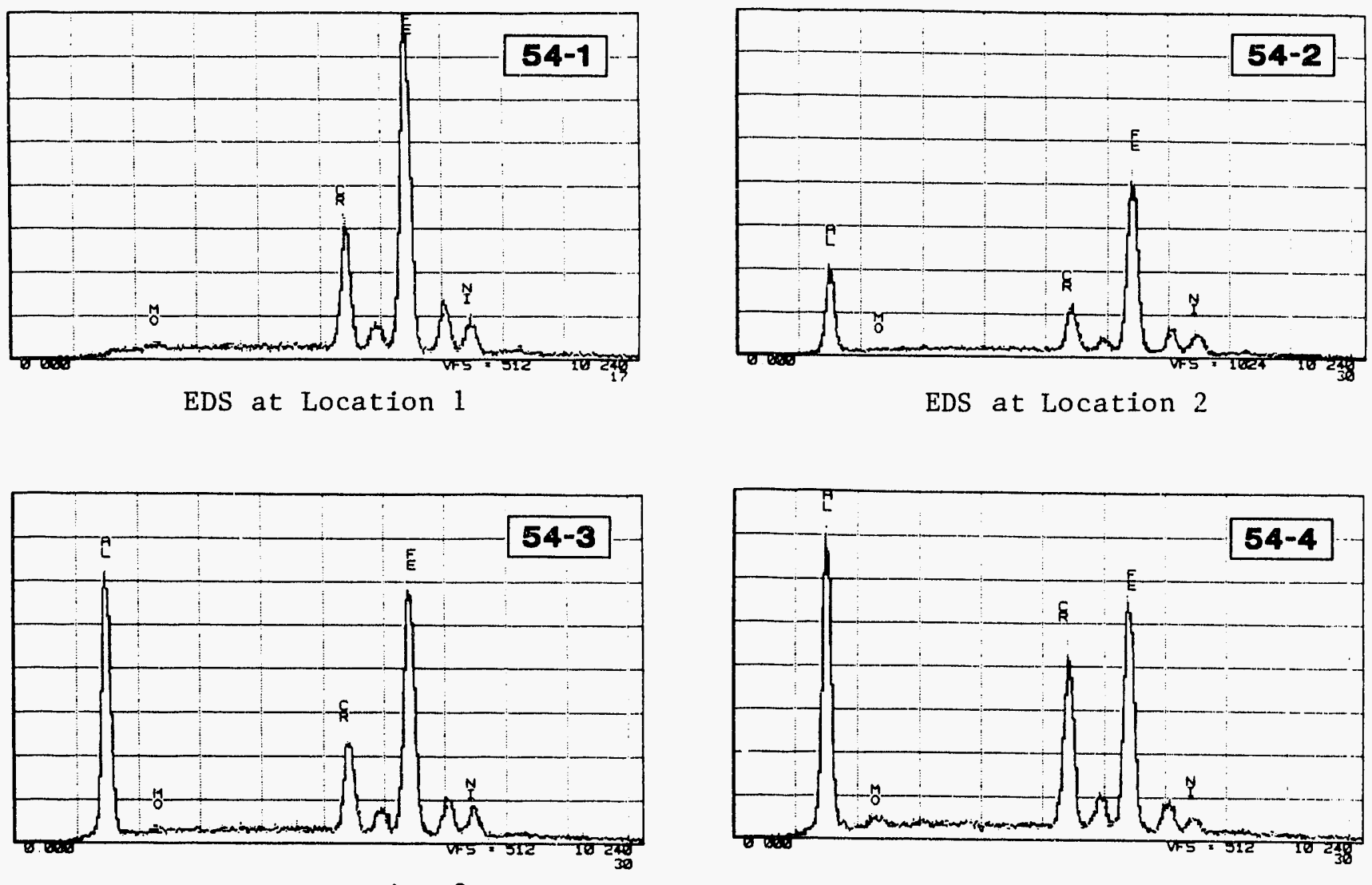

EDS at Location 3

EDS at Location 4

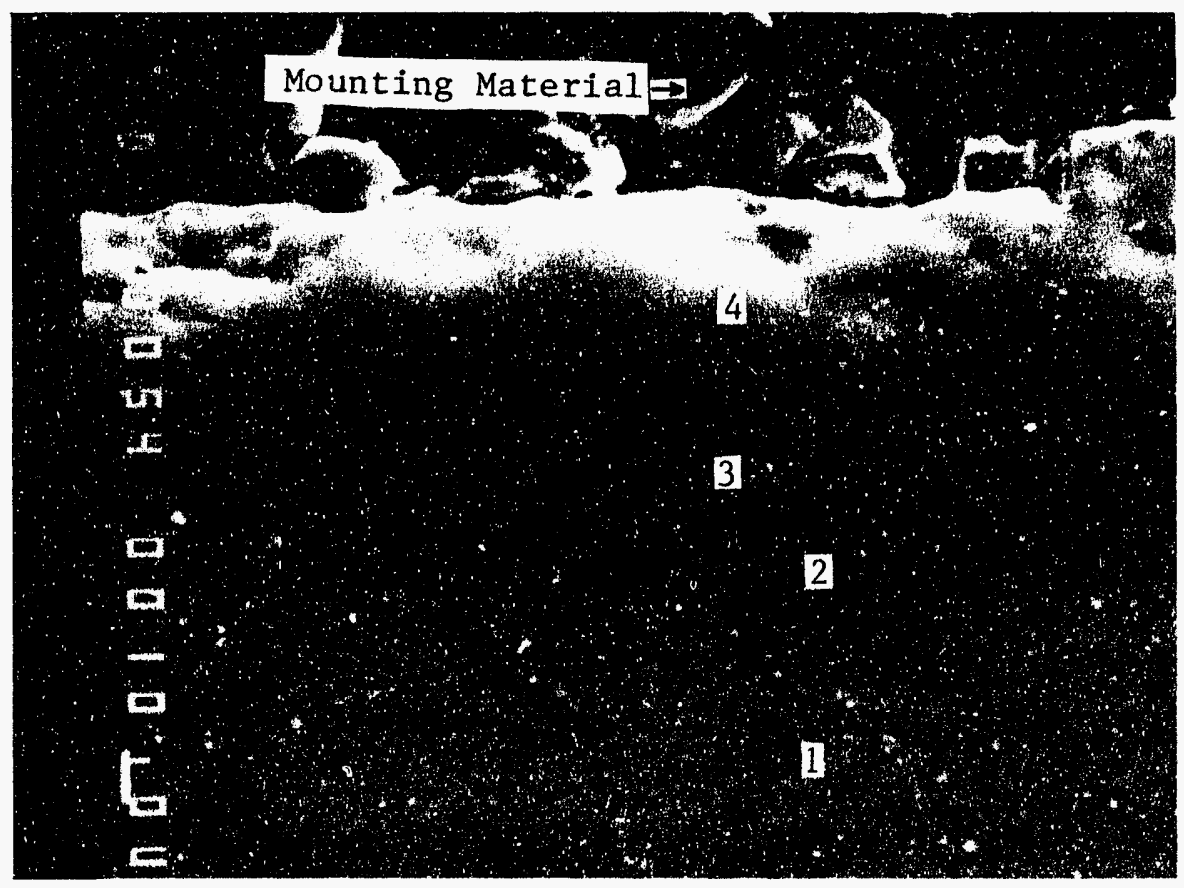

Figure 22. The SEM Image of the Cross-Section of the Test Vessel and Some EDS Measurements at the Center of the Test Vessel. 


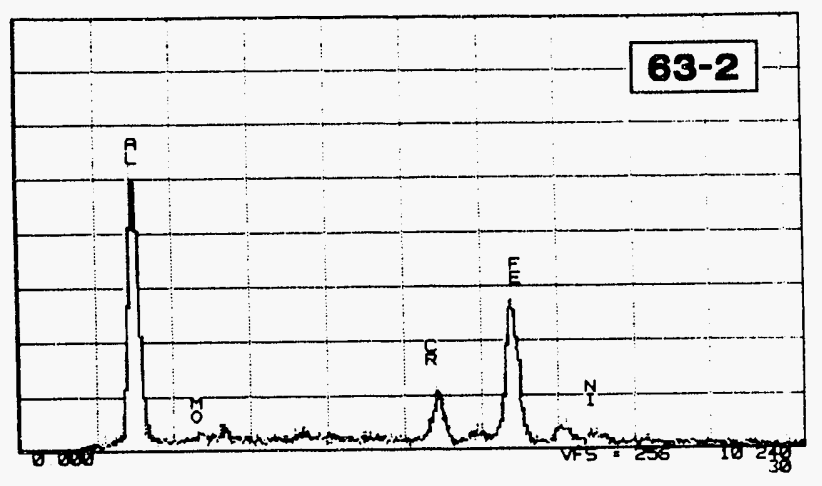

EDS at Location 2

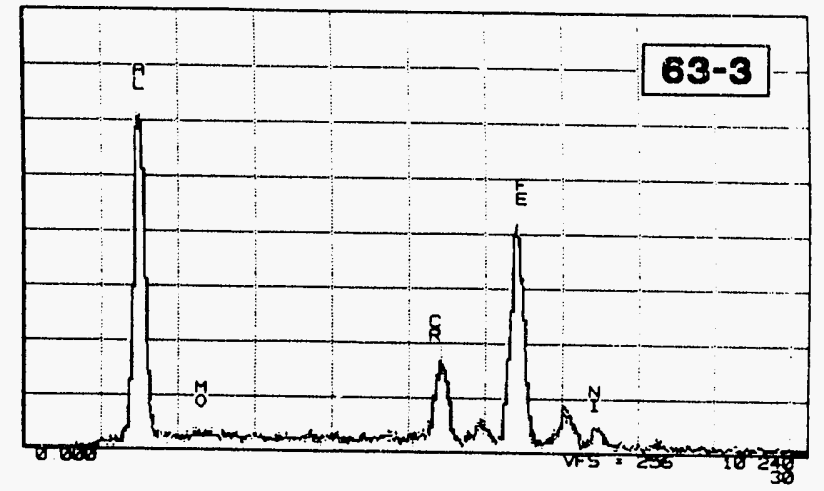

EDS at Location 3

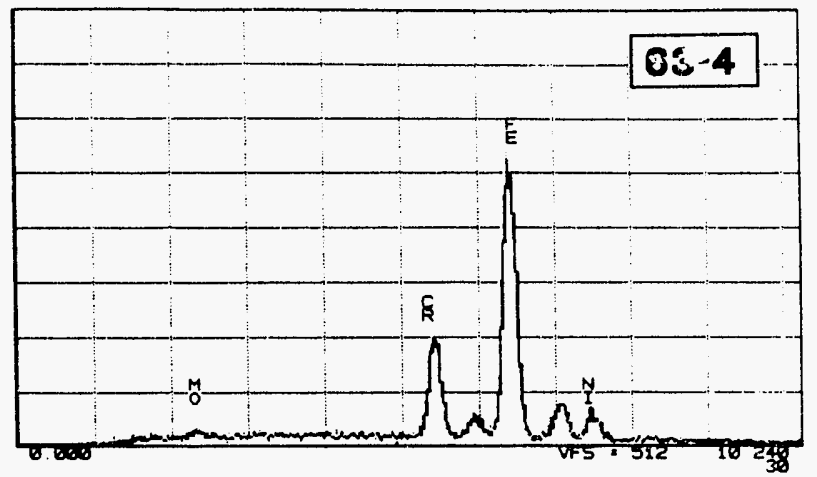

EDS at

Location 4

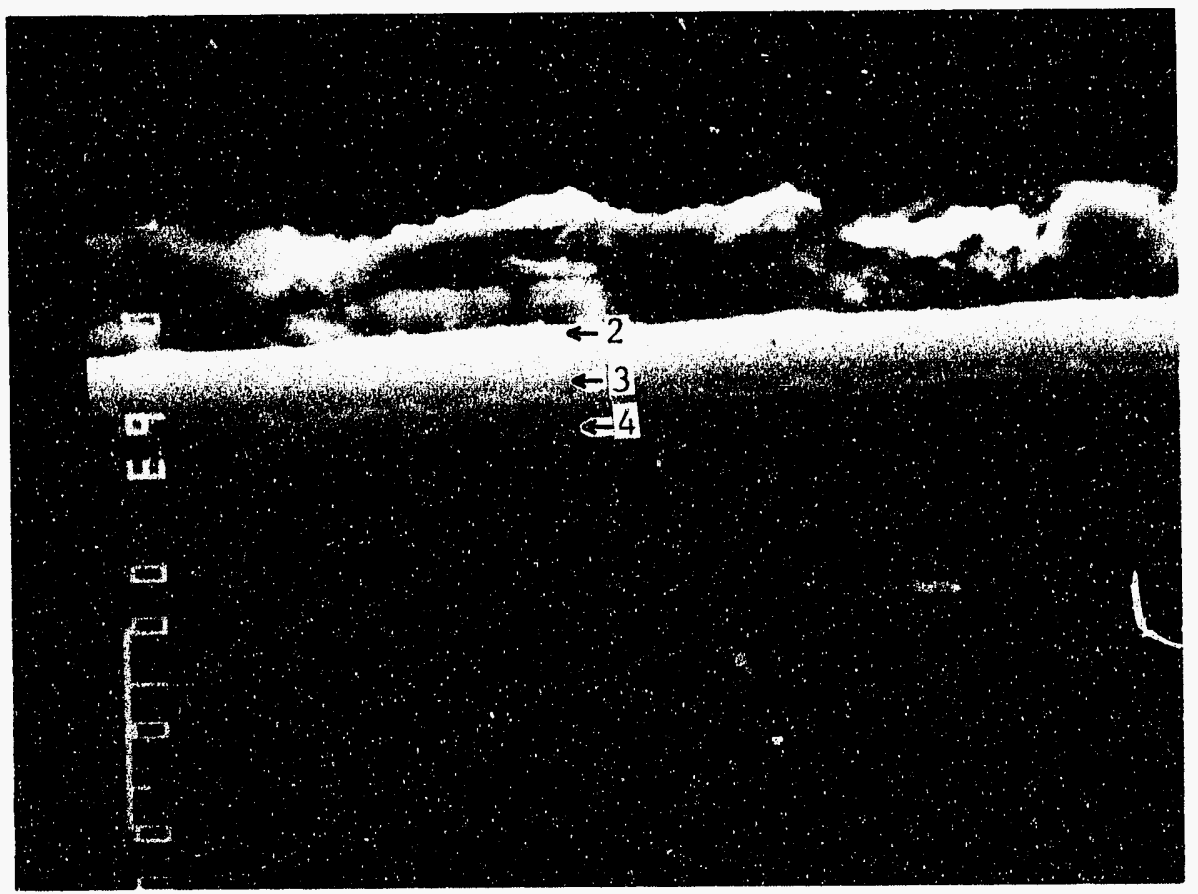

Figure 23. The SEM Image of the Cross-Section of the Test Vessel and Some EDS Measurements in the Neighborhood of $s=11^{\prime \prime}$ and $\theta=85^{\circ}$. The Dissolution Depth at This Location Was Large and Equal to 0.120". 


\subsection{Results From the Second Molten Pool Dissolution Experiment, Run No. MPD-02}

\subsubsection{The Melt and Test Vessel Temperature History}

Figure 24 shows a plot of the temperature traces from two melt thermocouples (VM1, VM3) and two vessel wall thermocouples (VS2, VS4) during the second molten pool dissolution experiment. The locations of these thermocouples are shown in Figure 8. The average melt temperature for this test was $1007^{\circ} \mathrm{C}$, and the melt remained in the test vessel for 2479 seconds. Since it took 21 seconds to deliver the melt into the vessel, and it required 10 seconds to drain the melt from the vessel at the end of the experiment, the uncertainty in the time interval of the test was \pm 15 seconds.

\subsubsection{Visual Post-Test Examination of the test Vessel}

An examination of the test vessel and the test vessel supporting structure at the end of this experiment revealed that significant oxidation of the test vessel had taken place during the experiment. By comparison, the test vessel used for the first experiment had shown negligible evidence of oxidation during the experiment. This oxidation of the test vessel during the secc:ad molten pool dissolution experiment is attributed to unexpected air infiltration into the "test vessel oven" during the experiment. A post-test photograph of the test vessel, taken prior to removal of the adhering aluminum and subsequent cleaning of the test vessel, is shown in Figure 25 . The heayily blackened appearance of the test vessel surface clearly shows that the vessel was oxidized significantly. The extent of oxidation clearly indicates that during this experiment, the inside surface of the test vessel was heavily pre-oxidized at the instant that molten aluminum was poured into the vessel. Thus, the initial condition of the surface of the test vessel for this test was different from that of the first test. Therefore, the results of this test will shcw the effect of a pre-existing oxide film on the dissolution of stainless steel by molten aluminum at a temperature of $1007^{\circ} \mathrm{C}$.

As discussed in Section 4.1.2, the post-test removal of the adhering aluminum on the inside surface of the test vessel was accomplished in two steps. These consisted of mechanical means under localized heating, followed by etching with an aqueous solution of $\mathrm{NaOH}$. A photograph of the test vessel following the $\mathrm{NaOH}$ treatment is presented in Figure 26. The closeups of the regions 2 and 3 in this figure are shown in Figures 27 and 28. A comparison of these figures with the post-test photographs for Run No. MPD-01, presented in Figures 10 and 11, shows a striking dissimilarity between the two results. The dissolution of the vessel wall during the second test is much smaller, and in comparison to that during the first test, it is almost negligible . In addition, no regions of very large dissolution rates near the edge of the molten pool are present in the second test. It is evident that the pre-existing oxide layer on the vessel surface has resulted in a large reduction in the dissolution rate. This is consistent with Greene's [3] observations. We also note from Figures 26 through 28 , that similar to the first test, the dissolution is observed to be spatially highly nonuniform. 


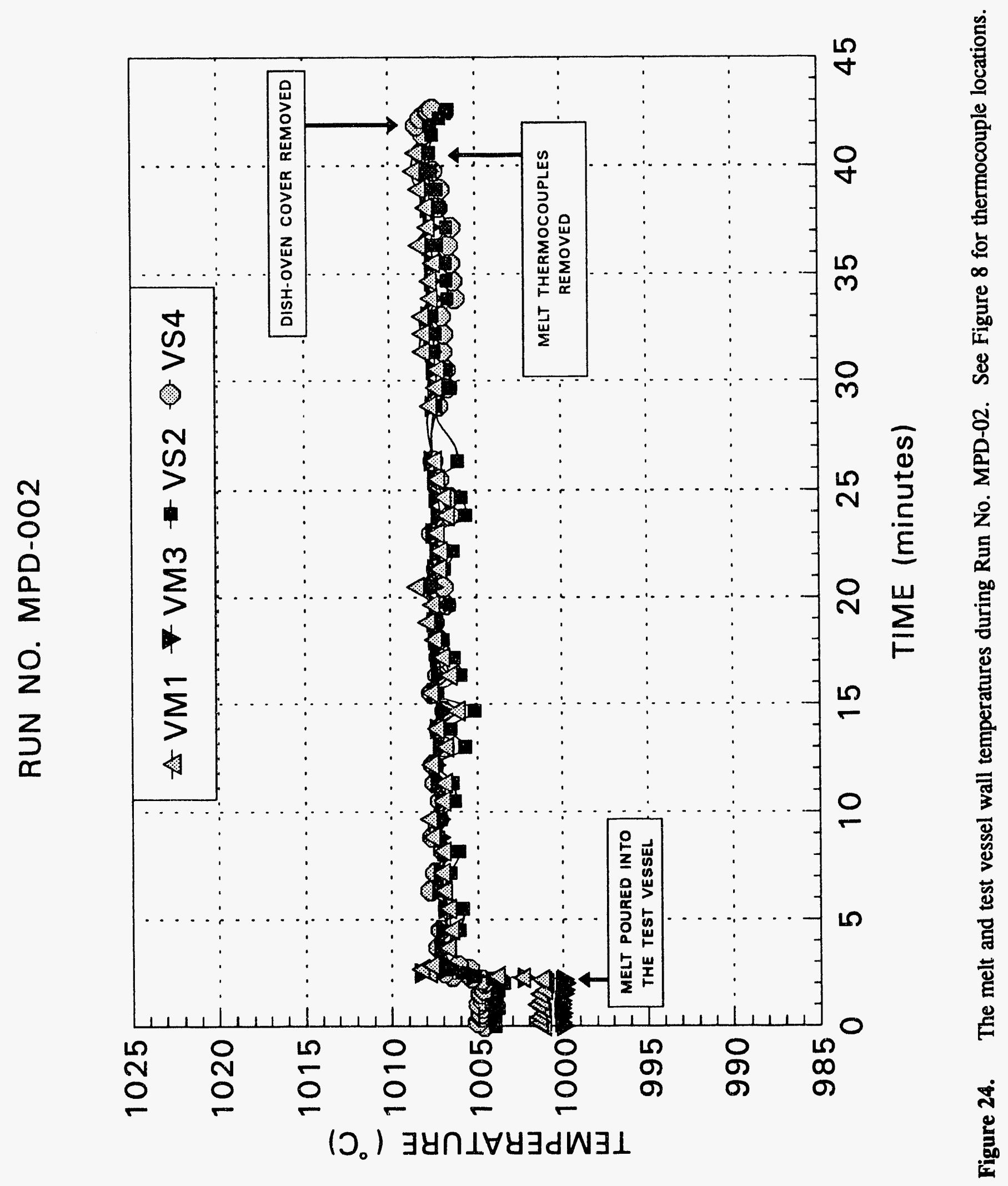




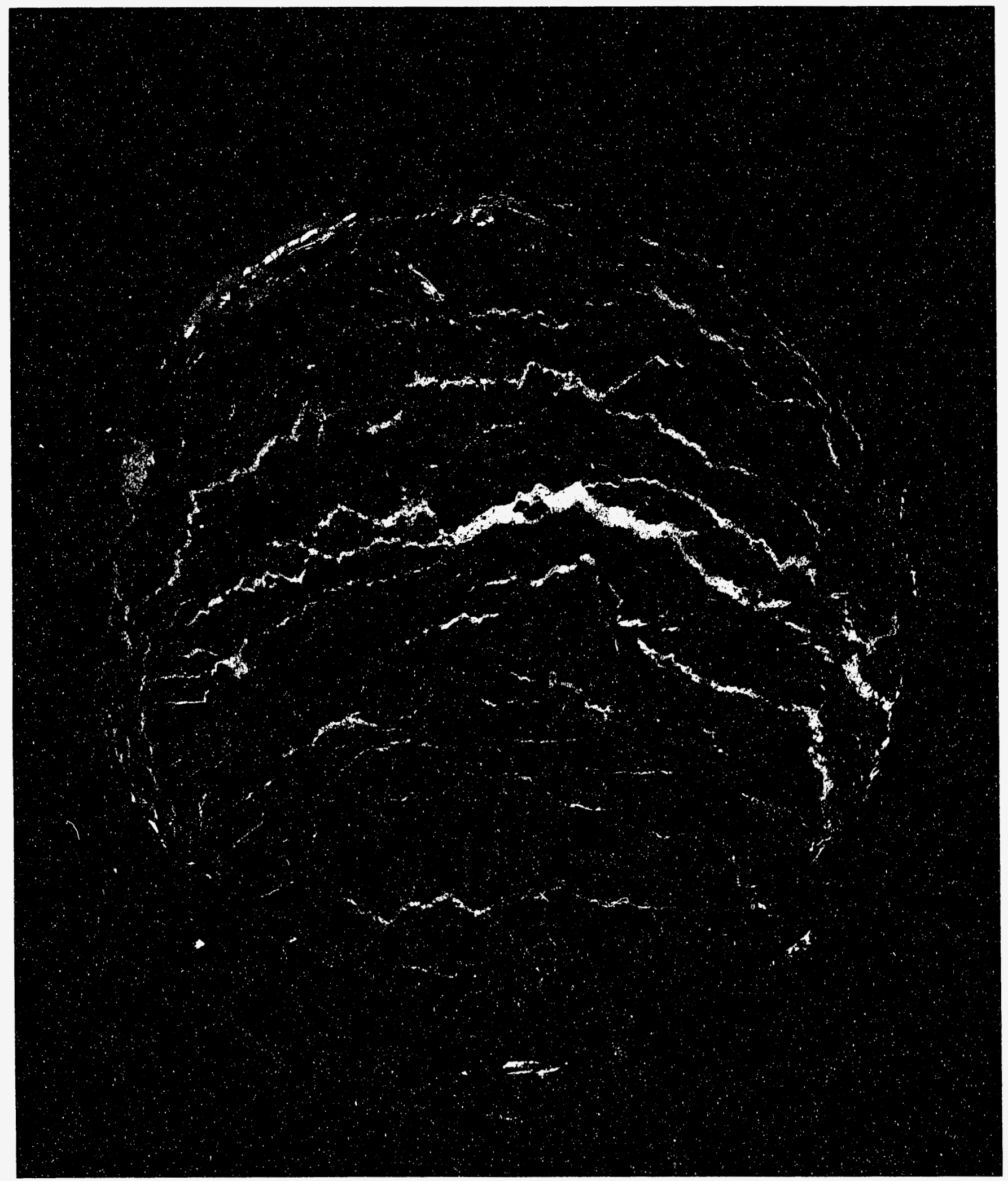

Figure 25. A Post-test photograph of the test vessel prior to cleaning of the test vessel. Run No. MPD-02. 


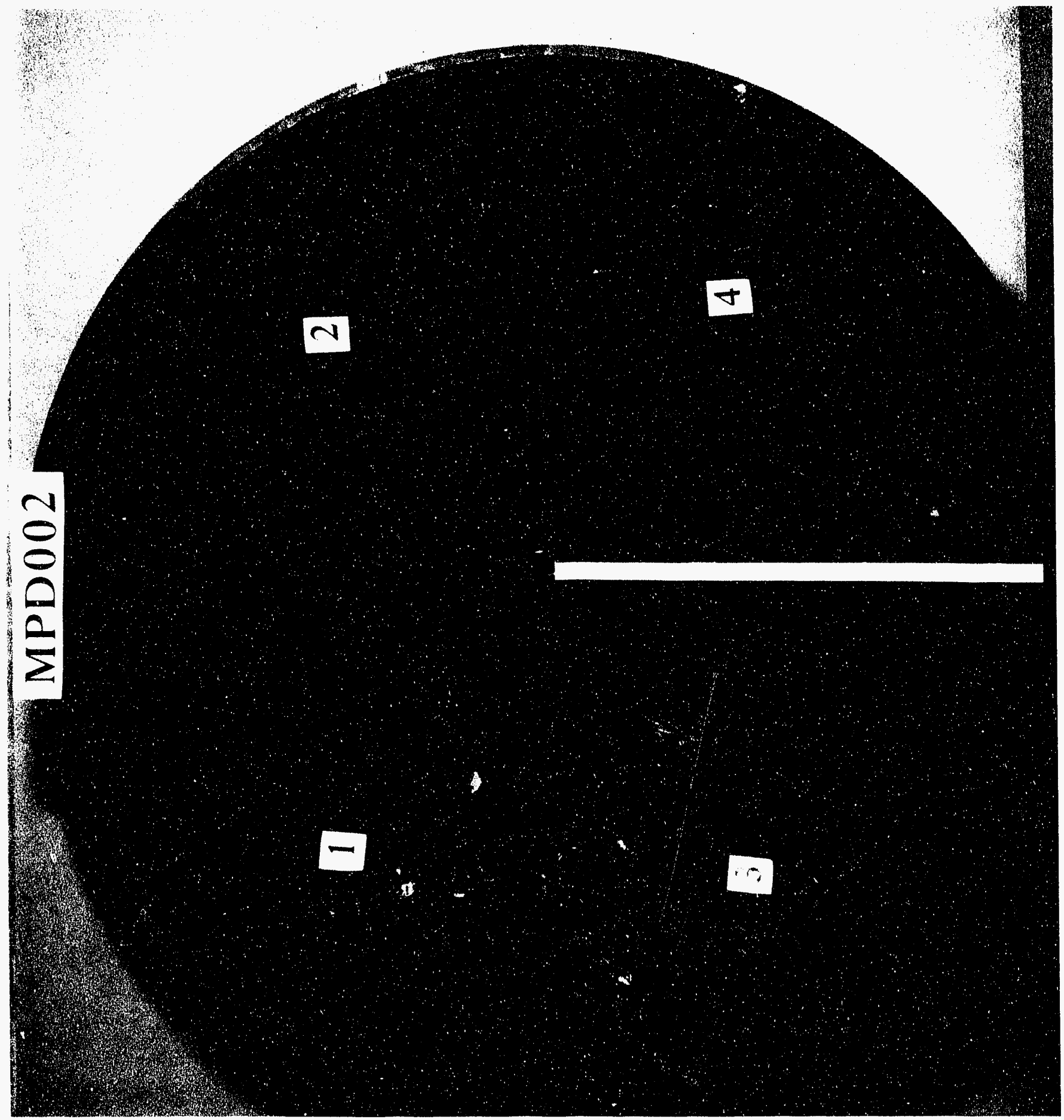

Figure 26. Post-test photograph of the test vessei following the $\mathrm{NaOH}$ treatment. Run No. MPD-02. 


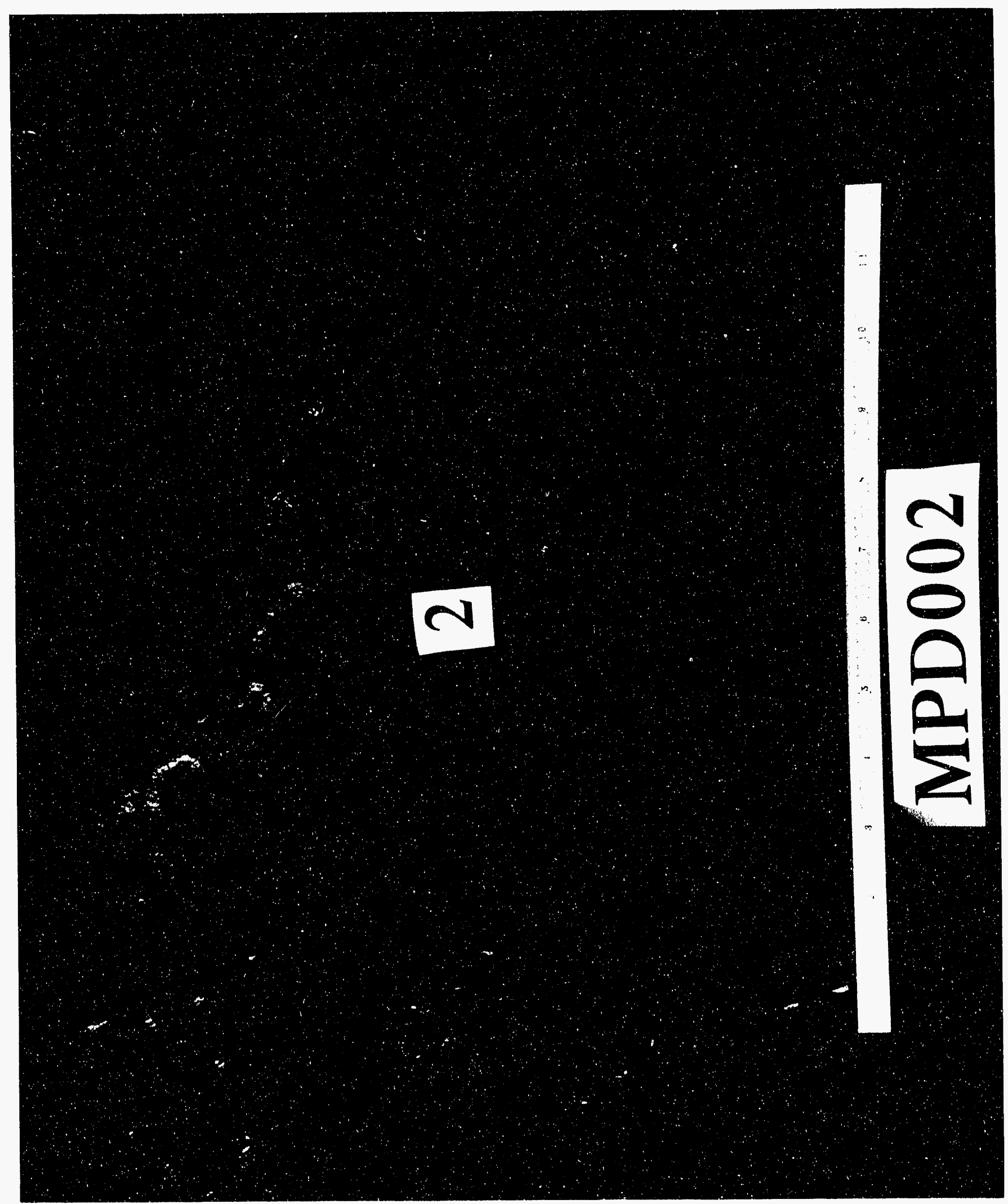

Figure 27. Post-test photograph of the test vessel for Run No. MPD-02. A close-up of the Region 2 in Figure 26. 


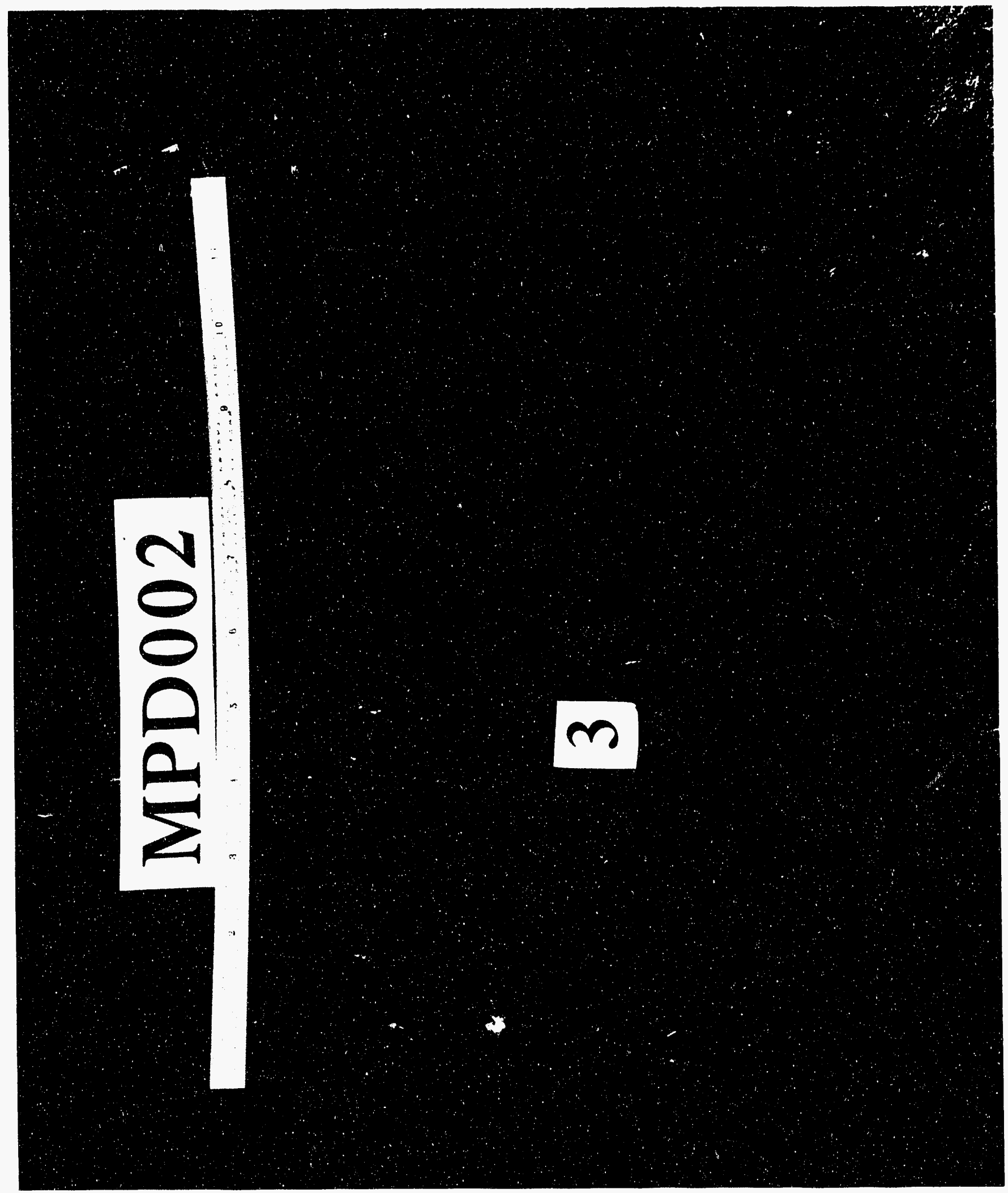

Figure 28. Post-test photograph of the test vessel for Run No. MPD-02. A close-up of the Region 3 in Figure 26. 


\subsubsection{The Linear Dissolution Depth Measurements}

Before performing the experiment, the initial wall thickness of the test vessel was measured at 137 locations. These measurements are presented in Figure 29. As discussed in Section 4.1.3, multiple data points corresponding to a single value of the coordinate s, correspond to different $\theta$ locations on the test vessel surface. The measured wall thickness was in the range $0.25^{\prime \prime} \leq \mathrm{t} \leq$ $0.266^{\prime \prime}$, with an average value of 0.2606 inches and a standard deviation of 0.00279 inches. After the experiment, the test vessel wall thickness was measured again at these and 123 other locations. For the latter 123 locations, the initial vessel wall thickness was estimated by interpolating from the data of Figure 29. For this purpose, the data in Figure 29 was re-plotted as a function of $s$ with $\theta$ as a parameter.

The measurements for the local dissolution depth, $d$, as a function of the coordinate $s$ are presented in Figure 30. The left ordinate shows the data for $d$ in inches, and the right ordinate shows the data in units of a time averaged linear dissolution rate. As can be seen from this figure, the maximum measured value of the dissolution rate for this test was $1.18 \mathrm{~mm} / \mathrm{hr}$. In contrast, as indicated in Section 4.1.3, the measured value of the peak dissolution rate for the first test was 5.05 $\mathrm{mm} / \mathrm{hr}$. In addition, a comparison of these results with those for the first experiment presented in Figure 14, shows another important dissimilarity. While during the first experiment (Figure 14) the dissolution depth appears to increase with increasing s, as one travels from the center of the vessel $(s=0)$ to the edge of the molten pool, for the second test (Figure 30) no such trend is observed. There are two apparent reasons for this. Since the average dissolution rate for this test was very low (presumably due to the pre-existing oxide film on the test vessel surface), no appreciable convective motion due to concentration induced density gradients would have been established in this test. Thus, there probably was no appreciable spatial variation in the mass transfer coefficient with $\mathrm{s}$. Secondly, because of the rather small overall dissolution during the second test, there probably was not any significant spatial variation in the concentration of stainless steel in the melt either.

As can be seen from Figure 30, small negative values of the dissolution depth were measured at many locations (indicating a post-test thickness greater than the pre-test thickness at these locations). This is attributed to the oxidation of the test vessel during the experiment. To further illustrate the extreme non-uniformity of the dissolution process observed during this experiment, a dissolution depth map, analogous to that for the first experiment, is presented in Figure 31. Please refer to the last paragraph of Section 4.1 .3 for the description of the $x$ and $y$ coordinates and the interpretation of the figure. The highly non-uniform nature of the observed dissolution process is clear from this figure.

Due to programmatic constraints, no concentration measurements using the ICP-AES or the scanning electron microscopy measurements were performed for this second experiment. However, since the test vessel suffered negligible dissolution during this experiment, it is unlikely that these measurements for the second test would yield any additional insights. 


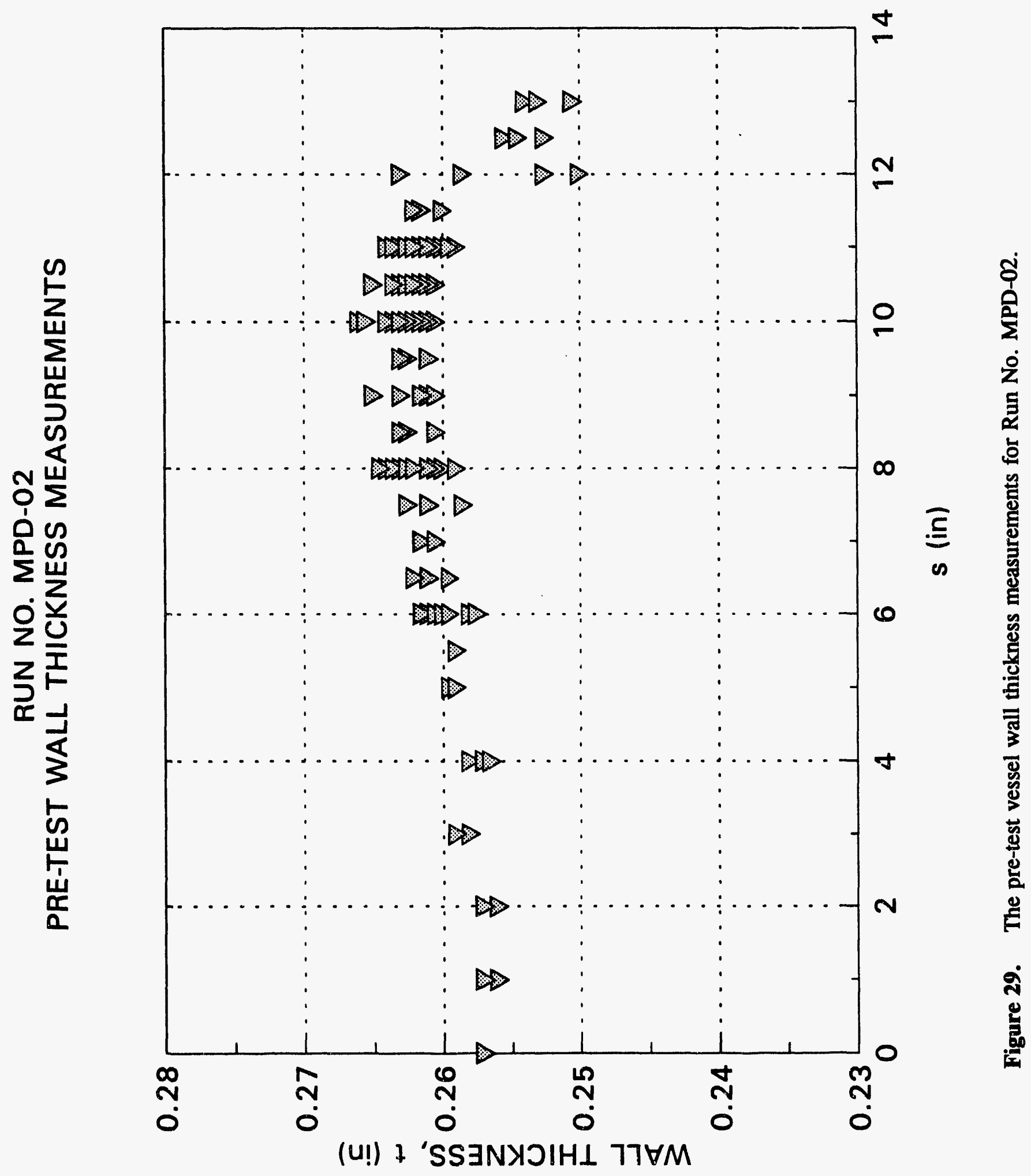




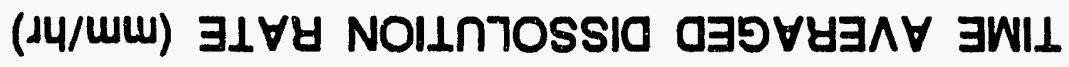

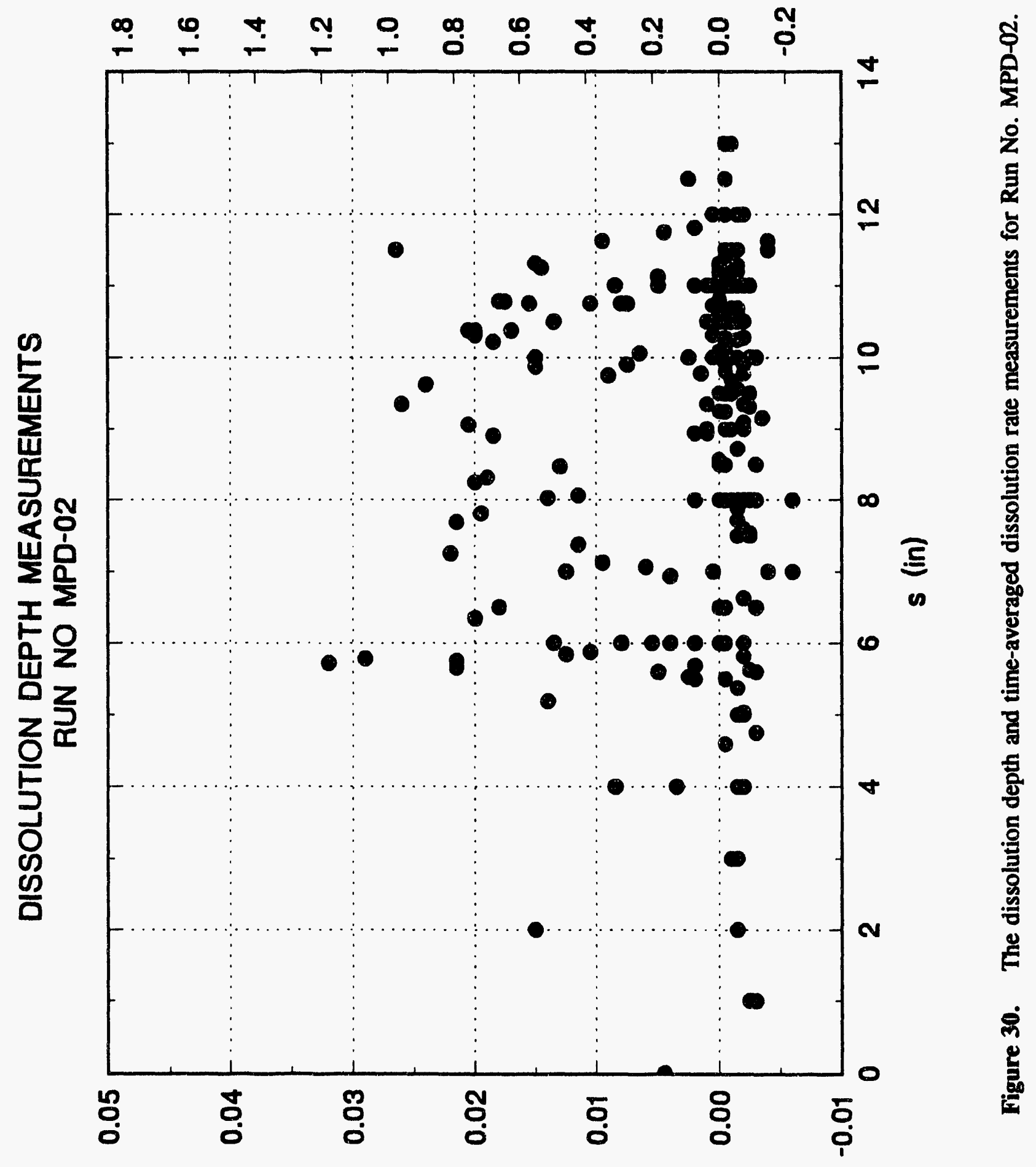

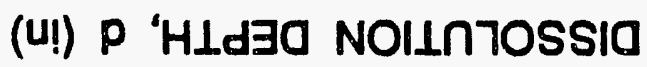


DISSOLUTION DEPTH MAP FOR RUN NO. MPD-02

$\cdot d<0.005 ", \quad \Delta 0.005 "<d<0.018 ", \quad-d>0.018 "$

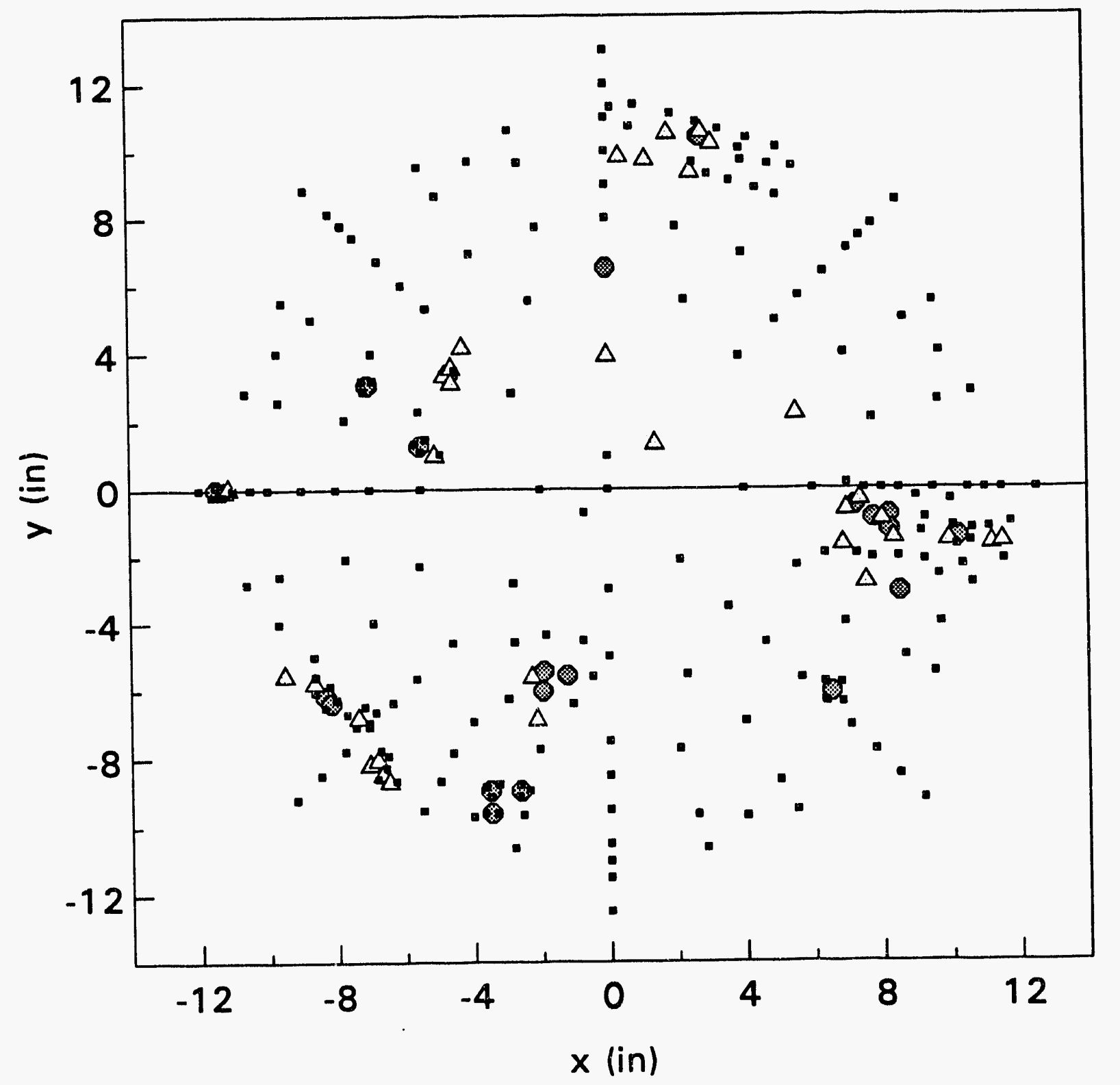

Figure 31. The dissolution depth map for Run No. MPD-02. $x=s \cdot \cos (\theta), y=s . \sin (\theta)$ 


\section{CONCLUDING REMARKS}

To study the chemical dissolution of a stainless steel vessel by a poo! of molten aluminum, two experiments were performed. In these molten aluminum pool dissolution experiments, 24 inch diameter 316L stainless steel "ASME Flanged and Dished Heads" were used as the test vessels. For these experiments, no forced convective motion was established in the molten aluminum pool. The nominal value of the average melt temperature for the first test was $977^{\circ} \mathrm{C}$, and for the second test it was $1007^{\circ} \mathrm{C}$. However, the major difference in initial conditions between the two experiments was the state of the test vessel surface just prior to the instant that molten aluminum was poured into the test vessel. While the inside surface of the test vessel for the first experiment was virtually unoxidized, it was heavily oxidized for the second test.

For the first experiment, the post-test visual inspection, and the measurements of the dissolution depth at various locations on the test vessel, show the dissolution process to be highly non-uniform spatially. There is almost insignificant dissolution in the bottom central portion of the vessel. This seems to be due to the fact that the concentration of stainless steel in the melt in this region is very high and close to saturation concentration of stainless steel in molten aluminum. On the other hand, the dissolution is observed to be very high in the outer regions of the vessel (near the molten pool edge). However, it is noted that even in these outer regions, there are zones which show very little dissolution. Qualitatively, the azimuthally-averaged dissolution depth was found to increase as one traversed frcm the vessel center towards the edge of the molten pool. The maximum local value of the measured time averaged dissolution rate for this test was found to be $5.05 \mathrm{~mm} / \mathrm{hr}$, and this occurred near the edge of the molten pool. This is about 3.5 times larger than the average dissolution rate predicted from Greene's [3] correlation for the dissolution of stainless steel by stagnant molten aluminum. It is interesting to note that Greene [3] reported the peak dissolution rate to be as much as a factor of four larger than the average dissolution rate.

The concentration measurements performed on samples of melt from the first experiment show the molten pool to be highly stratified with respect to the concentration of stainless steel in the melt (molten aluminum-stainless steel solution). The scanning electron microscopy analysis of the cross-section of the test vessel wall at various locations showed the presence of intermetallic (stainless steel components-aluminum) layers adjacent to the stainless steel surface. The observed thickness of these layers ranged from a few microns to $85 \mu$. Furthermore, the presence of these layers in regions where no macroscopic dissolution was measured indicated evidence of "attack" by molten aluminum on the test vessel surface at many of these regioris.

For the second experiment, wherein the inside surface of the test vessel was heavily oxidized prior to injection of molten aluminum, a large reduction in the dissolution rate was observed. The maximum value of the measured dissolution rate for this test was $1.18 \mathrm{~mm} / \mathrm{hr}$, which is much smaller than the peak dissolution rate of $5.05 \mathrm{~mm} / \mathrm{hr}$ in the first test. Thus this experiment shows that, at least up to a temperature of $1007^{\circ} \mathrm{C}$, a pre-existing oxide layer on the surface of stainless steel is protective in nature. However, it is noted that at higher temperatures, this may not be the case due to the expected thermite reaction between the iron oxide and molten aluminum.

Because the free stream concentration of stainless steel in the melt and the mass transfer coefficient on the vessel surface are expected to vary with the coordinate s, a variation in the dissolution rate with the coordinate $s$, as one travels from the vessel center towards the edge of the 
molten pool, is expected. However, no macroscopic phenomena are apparent that would explain the rather large variation in the dissolution rate with respect to the azimuthal coordinate, $\theta$, as indicated by the experimental data. Clearly, the origin for this severe aximuthal non-uniformity in the dissolution process must be microscopic in nature. It is, however, quite likely that once the dissolution process has started, the dissolution induced convective motion within the melt may enhance the non-uniformity of dissolution. The rather limited SEM and EDS analysis performed and presented here is not sufficient to reveal the reasons for the origin of the severe non-uniformity of dissolution. It is apparent that more experiments, possibly at higher temperatures, and a more detailed post-test microscopic metallurgical examinations of the test vessels would be needed to solve this problem. Neverthele $s, \mathrm{~s}$, this observed non-uniformity of dissolution clearly points out the limitations of the idealized models for the dissolution of stainless steel by molten aluminum. 


\section{REFERENCES}

1. Webb, J. D., "Reliability and Durability Study of a Thermal Receiver Utilizing ASI Type 316 Stainless Steel in Contact With Molten Aluminum," Solar Energy Research Institute, Golden, Colorado, SERI/TP-641-653, March 1980, also presented at: AS/ISES 1980 Annual Meeting, Phoenix, Arizona, June 2-6, 1980.

2. Dybkov, V. I., "Interaction of $18 \mathrm{Cr}-10 \mathrm{Ni}$ Stainless Steel With Liquid Aluminum," Journal of Materials Science, 25, 1990, pp. 3615-3633.

3. Greene, G. A., "Erosion/Corrosion of 316L Stainless Steel by Molten Aluminum, " Presented at the "Sixth Severe Accident Technical Coordination Meeting, Albuquerque, NM, June 16$17,1992$.

4. Marra, J. C., "Degradation of Stainless Steel by Molten Aluminum," Presented at the First Severe Accident Technical Coordination Meeting, New York, NY, October 16, 1991.

5. Marra, J. C., "Dissolution of Stainless Steel by Molten Aluminum and Aluminum Alloys Project Update Report," Presented at the Sixth Severe Accident Technical Coordination Meeting, Albuquerque, NM, June 16-17, 1992. See also: Marra, J. C., "Dissolution of Stainless Steel by Molten Aluminum and Aluminum Alloys - Final Report (U)," WSRC-TR92-543 (U), Westinghouse Savannah River Company, Aiken, SC 29808, November 1992.

6. Niinomi, M., Y. Ueda, and M. Sano, "Dissolution of Ferrous Alloys into Molten Aluminum," Transactions of the Japan Institute of Metals, Vol.23, No. 12, 1982, pp. 780787.

7. Aluminum: Properties and Physical Metallurgy, Edited by John E. Hatch, American Society of Metals, 1984.

8. Aluminum, Vol.I. Properties. Physical Metallurgy and Phase Diagrams, Edited by Kent R. Van Horn, American Society of Metals, 1967.

9. Niinomi, M., Y. Suzuki, and Y. Ueda, "Dissolution of Ferrous Alloys into Molten Pure Aluminum Under Forced Flow," Transactions of the Japan Institute of Metals, Vol. 25, No. 6, (1984), pp. 429-439.

10. Chawla, T. C., et al., "Thermophysical Properties of Mixed Oxide Fuel and Stainless Steel Type 316 For Use In Transition Phase Analysis," ANL/RAS 81-16, Argonne National Laboratory Report, Argonne, Illinois 60439.

11. Iida, T. and R. I. L. Guthrie, "The Physical Properties of Liquid Metals," Clarendon Press, Oxford, 1988.

12. Yeremenko, V. N., et al., "The Effect of Dissolution on the Growth of $\mathrm{Fe}_{2} \mathrm{Al}_{5}$ Interlayer in the Solid Iron-Liquid Aluminum System," Journal of Material Science, 16, (1981), pp 17481756. 
13. Kreith, F., "Principles of Heat Transfer," International Text Book Company, 1966.

14. Rohsenow, W. M. and H. Y. Choi, "Heat. Mass, and Momentum Transfer," Prentice-Hall, Inc., 1961.

15. Sienko, M. J. and R. A. Plane, "Chemistry: Principles and Properties," McGraw-Hill Book Company, 1966.

16. Bird, R. B., W. E. Stewart, and E. N. Lightfoot, "Transport Phenomena," John Wiley \& Sons, Inc., 1960.

17. Roy, A. K. and R. P. Chhabra, "Prediction of the Solute Diffusion Coefficients in Liquid Metals," Metallurgical Transactions A, Volume 19A, Feb. 1988, pp 273-279.

18. Uemura, K., "The Diffusion of Various Elements into Aluminum, " Tetsu To Hagane (J. Iron and Steel Inst., Japan), Volume 25, 1939, pp 24-29.

19. Edwards, J. B. et al., "Diffusion in Binary Liquid-Metal Systems, " Review 120, Part II, Metallurgical Reviews, 1968, pp 13-28.

20. Kato, M. and S. Minowa, "Diffusion of Iron in Some Non-Ferrous Metals," Tetsu Hagane (J. Iron and Steel Inst., Japan), 52 (1), 1966, pp 32-41. 

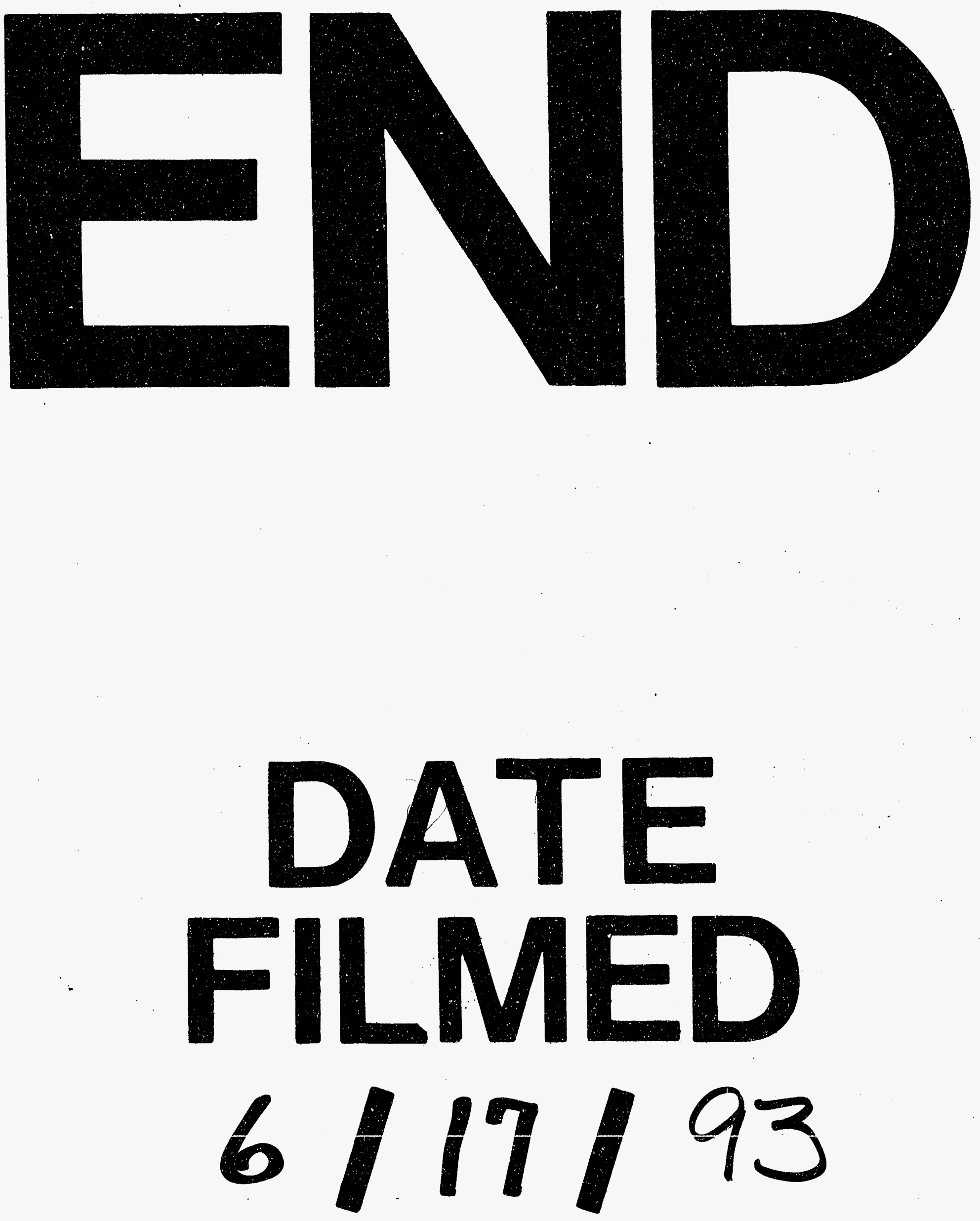
